\section{Autosomal dominant polycystic kidney disease unlinked to the PKD1 and $P K D 2$ loci presenting as familial cerebral aneurysm}

EDITOR-Autosomal dominant polycystic kidney disease (ADPKD) is a multisystem disease with intrafamilial phenotypic heterogeneity. Cerebral aneurysms develop in $10-20 \%$ of patients with ADPKD. ${ }^{12}$ Aneurysm rupture may precede the development of hypertension or renal manifestations of the disease. ${ }^{2}$ Two ADPKD loci (PKD1 and PKD2) map to chromosomes $16 \mathrm{p}$ and $4 \mathrm{q}$, respectively. Reports of unlinked pedigrees have suggested the existence of a third unmapped locus..$^{3-7}$ We report a three generation white family with an ADPKD like disease, unlinked to the PKD1 or PKD2 loci (fig 1, table 1). Other genetic causes of renal cysts, such as tuberous sclerosis and von HippelLindau disease, have been excluded clinically and linkage to the known loci for these diseases is unlikely. This family supports the case for a third locus for ADPKD, but differs from the previously described unlinked pedigrees by its presentation with cerebral aneurysm rupture.

Ethical approval for this study was granted by the local research ethics committee. The family was identified because three members had sustained a subarachnoid haemorrhage. All family members who were older than 18 were invited for examination and screening for intracranial aneurysms by magnetic resonance angiography (MRA). There was no clinical evidence of tuberous sclerosis, von Hippel-Lindau disease, or autosomal recessive polycystic kidney disease (diseases associated with cerebral aneurysm formation). MRA scans that were suspicious for cerebral aneurysm were followed up by conventional cerebral angiography. In view of advanced age, MRA screening was not offered to I.2, but it was noted that she had previously suffered a CVA of undetermined aetiology. II.2 and II.4 had both sustained a subarachnoid haemorrhage as a result of rupture of an anterior communicating artery aneurysm (ACoA), and II.6 had a ruptured posterior communicating artery aneurysm (PCoA). All three were normotensive with normal serum urea and creatinine concentrations when they presented with subarachnoid haemorrhage. There was no past history of ADPKD within the family. Subjects III.8, III.9, III.10, and III.12 declined examination.

Subjects meeting recognised criteria for diagnosis of polycystic kidney disease were classed as affected. ${ }^{8}{ }^{9}$ II.1, although designated normal, declined MRA and ultrasound investigation but was happy to provide blood. II.2 and II. 6 did not meet these criteria. II. 2 at the age of 57 had no renal cysts but was hypertensive, had a ruptured cerebral aneurysm, and had a son with renal cysts. II. 6 had marked hepatic cystic disease, was also hypertensive, and had a ruptured cerebral aneurysm. In addition, her son, III.7, had renal cysts and was mildly hypertensive at the age

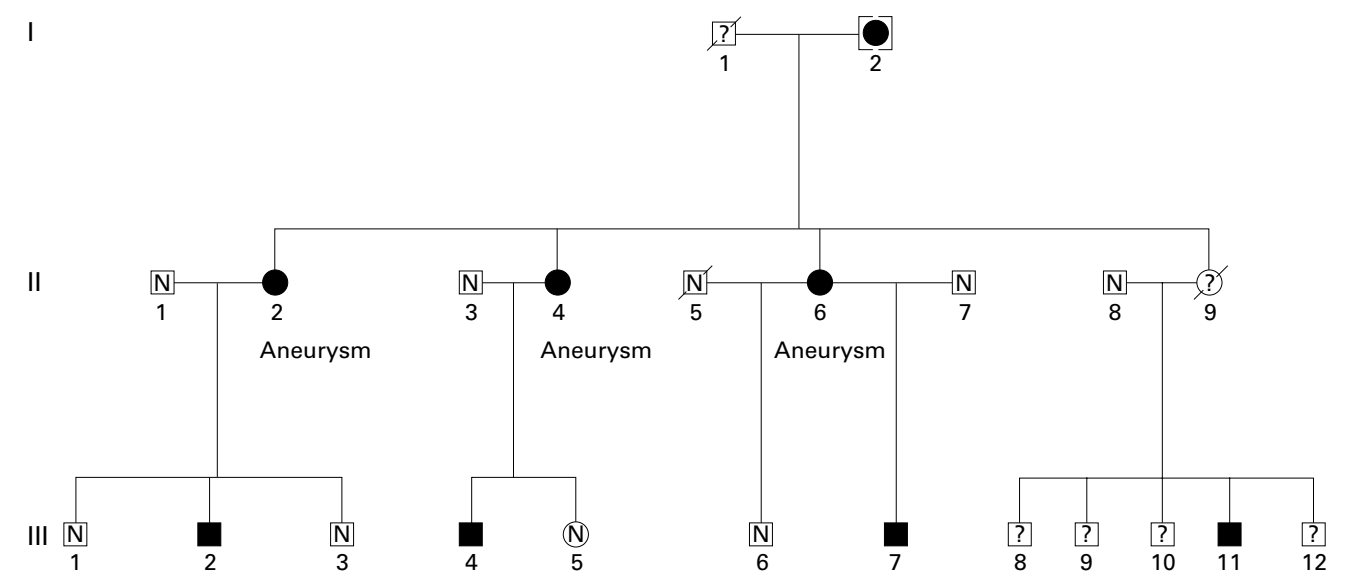

Figure 1 Pedigree with autosomal dominant polycystic kidney disease.

Table 1 Clinical details of family members

\begin{tabular}{|c|c|c|c|c|c|}
\hline & Age & Aneurysm & $\begin{array}{l}B P \\
(m m H g)\end{array}$ & $\begin{array}{l}\text { Creatinine } \\
\text { ( } \mu m o l / l)\end{array}$ & Ultrasound \\
\hline I. 2 & 88 & Unknown & $130 / 80$ & 117 & Multiple cysts in R kidney, single cyst in L kidney \\
\hline II. 2 & 57 & ACoA & HT & 99 & No cysts \\
\hline II. 4 & 65 & ACoA & HT & 87 & Multiple cysts \\
\hline II.6 & 54 & PCoA & HT & 64 & Several liver cysts, no renal cysts \\
\hline III. 1 & 36 & Normal & $130 / 80$ & 89 & No cysts \\
\hline III. 2 & 25 & Normal & $120 / 80$ & 98 & 2 cysts $L$ kidney, 1 cyst $R$ kidney \\
\hline III. 3 & 32 & Normal & $120 / 84$ & 85 & No cysts \\
\hline III.4 & 43 & Normal & $170 / 120$ & 92 & Multiple cysts in both kidneys \\
\hline III.5 & 37 & Normal & $120 / 80$ & 85 & 1 cyst in right kidney \\
\hline III.6 & 27 & Normal & $120 / 84$ & 69 & Normal \\
\hline III.7 & 19 & Normal & $140 / 100$ & 90 & 1 cyst in each kidney \\
\hline III.11 & 35 & Normal & $130 / 90$ & 90 & 2 cysts in each kidney, renal calculi \\
\hline
\end{tabular}

$\mathrm{ACoA}=$ anterior communicating artery aneurysm, $\mathrm{PCoA}=$ posterior communicating artery aneurysm, $\mathrm{HT}=$ hypertension diagnosed and treated. 
of 19 years. Both II. 2 and II. 6 were designated affected because they both had many phenotypic characteristics of the disease, had an affected parent, and also had affected offspring. Absence of renal cysts in a subject with ADPKD proven by linkage has been described previously. ${ }^{8}$

Linkage analysis was carried out. Microcrosatellite markers flanking the known loci of PKD1/TSC2, PKD2, and TSC1 were chosen. ${ }^{10-13}$ CI-46 was used as a marker for the VHL locus. ${ }^{14}$ Results were analysed in two separate fashions using the LINKAGE (v 5.04) program. ${ }^{15}$ First, we tested the hypothesis that this family had classical ADPKD linked to either the PKD1 or PKD2 loci using recognised liability classes for ADPKD. ${ }^{9}$ At risk but unaffected family members were assigned to three liability classes, less than 10 years, $20-25$ years, and greater than 25 years, with penetrances of $0.22,0.66$, and 0.85 , respectively. ${ }^{9}$ Linkage to the PKD1 and PKD2 loci was also assessed using an affecteds only analysis. Multipoint lod scores were consistently less than -2.0 across the PKD1/TSC2 and PKD2 loci using both methods. The disease is therefore not linked to these loci. Further linkage analysis was restricted to affected subjects only, as there are no data on the penetrance of ADPKD unlinked to PKD1 and PKD2.

We considered linkage to other loci associated with renal cystic disease or intracranial aneurysm formation. Multipoint lod scores plotted at TSC1/HHT1 (<-1.5) and ELA1/HHT2 (<-2.5) suggested non-linkage. Two point lod scores for the $V H L$ locus $(<-2.0$ within $0.08 \mathrm{cM}$ from CI-46) also showed non-linkage.

Since subjects I.1 and II.9 were non-smokers who died at an early age from emphysema, we considered the diagnosis of $\alpha 1$-antitrypsin deficiency. Serum $\alpha 1$ antitrypsin levels and phenotypes were recorded in I.2, II.2, II.4, II.6, and III.11. Results lay within the normal range and all subjects typed had the MM phenotype.

There are previous reports of unlinked pedigrees. ${ }^{3-7}$ Daoust et $a l^{\beta}$ reported a two generation family with six affected subjects. Although only one member in this pedigree showed evidence of renal insufficiency, affected subjects had renal, hepatic, splenic, and ovarian cysts and were hypertensive. Cerebral aneurysms were not reported in this pedigree. ${ }^{3}$ These authors reported negative lod scores at TSC1 and VHL. In the pedigree reported by de Almeida $e t ~ a l,{ }^{4}$ there were 25 subjects available for linkage analysis with 12 affected subjects in four generations. The phenotypic characteristics of all pedigree members were not presented. Affected subjects were noted to meet recognised ultrasonographic diagnostic criteria, to be variously hypertensive, and to show slow progression to renal replacement therapy. The authors specifically noted the absence of cerebral aneurysms or cerebral haemorrhage in the pedigree. ${ }^{4}$ TSC1 and VHL were not excluded by linkage analysis.

In conclusion, this family has an inherited condition similar to classical autosomal dominant polycystic kidney disease, with vertical transmission of disease. This is characterised by renal cysts, hepatic cysts, hypertension, and cerebral aneurysms. Within the pedigree there are no affected males of sufficient age to have allowed male to male transmission to be shown, so the possibility of $\mathrm{X}$ linked inheritance cannot be excluded. The family is not linked to the PKD1/TSC2 or PKD2 loci and supports the case for a third locus for ADPK-like conditions. This depends on us assuming that affected members of this pedigree are suffering from the consequences of the same monogenic disease mutation; it is possible (but unlikely) that the pedigree is a rare coincidental clustering of ADPKD-like phenotypes and that the condition is behaving as an autosomal dominant trait. The maximum and mean simulated lod scores for this pedigree at $\theta=0$ were 2.9 and 1.6, respectively, Thus, the available samples will not be able to show linkage at a lod score $>3$.

R S McConnell was supported by grants from the Department of Health and Social Services, Research Management Division, Northern Ireland, the Royal College of Surgeons of Edinburgh, and the Sanofi Winthrop Foundation. D C Rubinsztein is a Glaxo Wellcome Research Fellow.

R S MCCONNELL $\star \ddagger \ddagger$ D C RUBINSZTEINS T F FANNIN* C S MCKINSTRY* $\mathrm{B} \mathrm{KELLY}^{\star}$ I C BAILEY* A E HUGHES +

${ }^{\star}$ Department of Neurosurgery, Royal Victoria Hospital, Belfast, Northern Ireland

†Department of Medical Genetics, Belfast City Hospital, Lisburn Road, Belfast, Northern Ireland

$\ddagger$ Department of Neurosurgery, Addenbrooke’s Hospital, Hills Road, Cambridge CB2 2OO, UK

$\$$ Department of Medical Genetics, Wellcome Trust Centre for the Study of Molecular Mechanisms in Disease, Cambridge Institute for Medical

Research Wellcome /MRC Building Addenbrooke's Hospital, Hills Road, Cambridge CB2 2QQ, UK

Correspondence to: Dr Rubinsztein,dcr1000@cus.cam.ac.uk

1 Chapman AB, Rubinstein D, Hughes R, Stears JC, Earnest MP, Johnson $\mathrm{AM}$, Gabow PA, Kaehny WD. Intracranial aneurysms in autosomal dominant polycystic kidney disease. $N$ Engl F Med 1996;327:916-20.

2 Chauveau D, Pirson Y, Verellen Dumoulin C, Macnicol A, Gonzalo A, Grunfeld JP. Intracranial aneurysms in autosomal dominant polycystic kidney disease. Kidney Int 1994:45:1140-6.

3 Daoust MC, Reynolds DM, Bichet DG, Somlo S. Evidence for a third genetic locus for autosomal dominant polycystic kidney disease. Genomics 1995;25:733-6.

4 de Almeida S, de Almeida E, Peters D, Pinto JR, Tavora I, Lavinha J, Breuning $M$, Prata MM. Autosomal dominant polycystic kidney disease: ing $M$, Prata MM. Autosomal dominant polycystic kidney disease:
evidence for the existence of a third locus in a Portuguese family. Hum

5 Ariza M, Alvarez V, Marin R, Aguado S, Lopez-Larrea C, Alvarez J, Menendez MJ, Coto E. A family with a milder form of adult dominant polycystic kidney disease not linked to the PKD1 (16p) or PKD2 (4q) genes. F Med Genet 1997;34:587-9.

6 Turco AE, Clementi M, Rossetti S, Tenconi R, Pignatti PF. An Italian family with autosomal dominant polycystic kidney disease unlinked to either the PKD1 or PKD2 gene. Am F Kidney Dis 1996;28:759-61.

7 Bogdanova N, Dworniczak B, Dragova D, Todorov V, Dimitrakov D, Kalinov K, Hallmayer J, Horst J, Kalaydjieva L. Genetic heterogeneity of polycystic kidney disease in Bulgaria. Hum Genet 1995;95:645-50.

8 Ravine D, Walker GR, Gibson RN, Forrest SM, Richards RI, Friend K, Sheffield LJ, Kincald-Smith P, Danks DM. Phenotype and genotype heterogeneity in autosomal dominant polycystic kidney disease. Lancet 1996;340:1330-3.

9 Bear JC, McManamon P, Morgan J, Payne RH, Lewis H, Gault MH, Churchill DN. Age at clinical onset and at ultrasonographic detection of adult polycystic kidney disease: data for genetic counselling. Am $\mathcal{F}$ Med adult polycystic kidney
Genet 1984;18:45-53.

10 Kandt RS, Haines JL, Smith M, Northrup H, Gardner RJ, Short MP, Dumars K, Roach ES, Steingold S, Wall S. Linkage of an important gene locus for tuberous sclerosis to a chromosome 16 marker for polycystic kidney disease. Nat Genet 1992;2:37-41

11 Wright GD, Hughes AE, Larkin KA, Doherty CC, Nevin NC. Linkage disequilibrium between the CA microsatellite D16S283 and PKD1. I Am Soc Nephrol 1994;15:1159-61.

12 Mochizuki T, Wu G, Hayashi T, Xenophontos SL, Veldhuisen B, Saris JJ, Reynolds DM, Cai Y, Gabow PA, Pierides A. PKD2, a gene for polycystic kidney disease that encodes an integral membrane protein. Science 1996;272:1339-42.

13 San Millan JL, Viribay M, Peral B, Martinez I, Weissenbach J, Moreno F. Refining the localization of the PKD2 locus on chromosome 4q by linkage analysis in Spanish families with autosomal dominant polycystic kidney disease type 2. Am f Hum Genet 1995;56:248-53.

14 Latif F, Tory K, Gnarra J, Yao M, Duh F, Orcutt ML, Stackhouse T, Kuzmin I, Modi W, Geil L. Identification of the von Hippel-Lindau disease min I, Modi W, Geil L. Identification of the von

15 Lathrop GM, Lalouel J. Easy calculations of lod scores and genetic risks on small computers. Am $\dot{f}$ Hum Genet 1984;36:460-5. 


\section{Detection of heterozygous SMN1 deletions in SMA families using a simple fluorescent multiplex PCR method}

EDITOR - With a prevalence of 1/6000 live births, spinal muscular atrophy (SMA) represents the second most common fatal autosomal recessive disorder after cystic fibrosis. ${ }^{12}$ SMA is characterised by the degeneration of anterior horn cells of the spinal cord, resulting in progressive, symmetrical limb and trunk paralysis associated with muscular atrophy. This condition is clinically heterogeneous and has been subdivided into three types according to age of onset and clinical course ${ }^{3}$ : type I (Werdnig-Hoffmann disease, MIM 253300), type II (intermediate form, MIM 253550), and type III SMA (Kugelberg-Welander disease, MIM 253400). The SMA locus has been mapped to chromosome $5 \mathrm{q} 11.2-\mathrm{q} 13.3$ within a region characterised by the large inverted duplication of a $500 \mathrm{~kb}$ element. ${ }^{4-6}$ The survival motor neurone (SMN) gene, which lies within this element, is duplicated and both copies are expressed. The telomeric gene (SMN1) has been shown to be deleted or mutated in all three types of SMA. ${ }^{4}$ SMN1 encodes almost the full length transcript whereas the centromeric copy

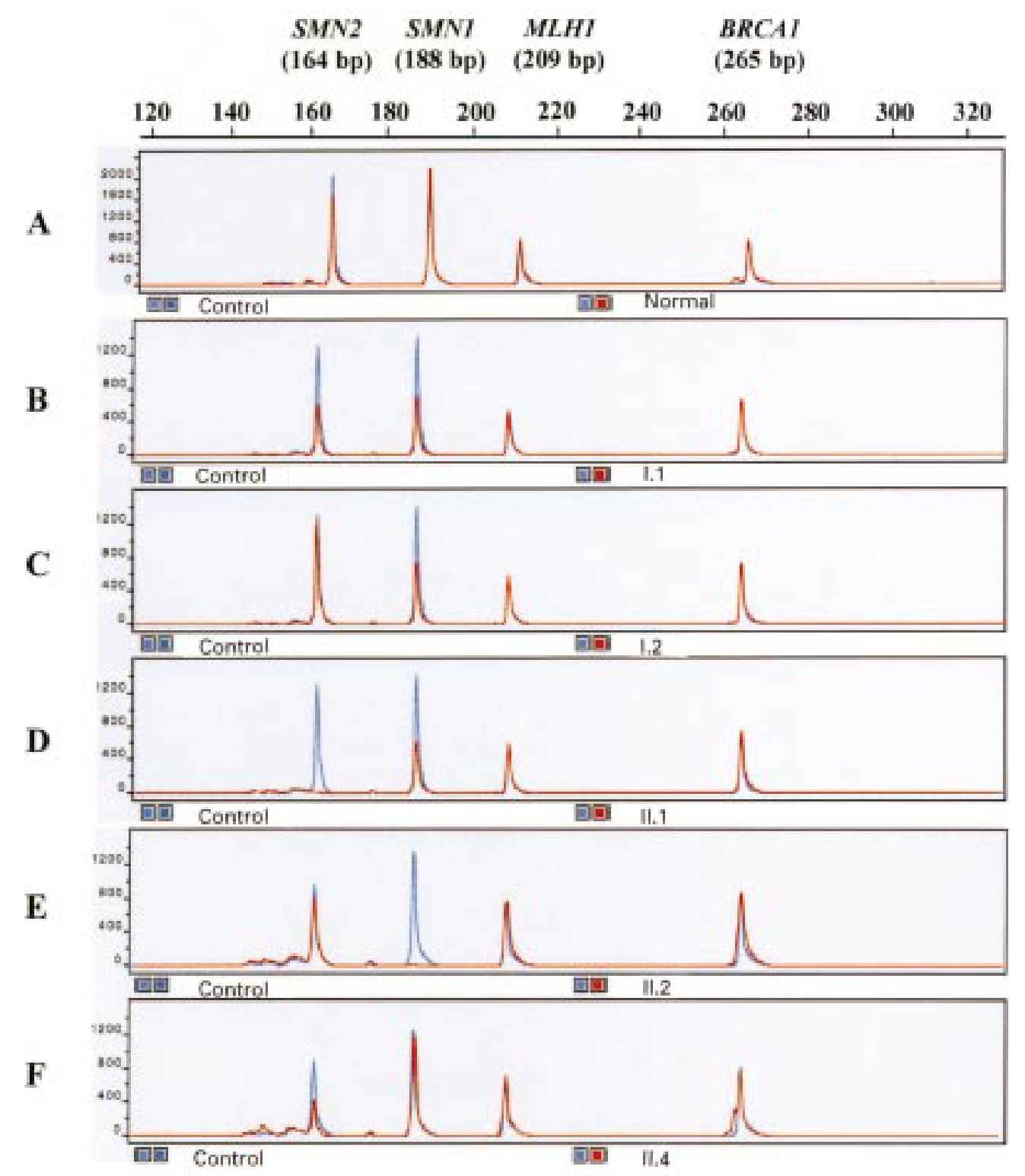

Figure 1 Quantification of SMN1 and SMN2 copies using a non-competitive fluorescent multiplex PCR assay. Genomic fragments were PCR amplified using dye labelled primers (table 1). After DraI digestion, fragments were separated by electrophoresis on an ABI 377 DNA automated sequencer and electropherograms from two subjects were superimposed. In each electropherogram, the y axis displays fluorescence intensity in arbitrary units and the $x$ axis indicates the size (in bp) of the fragments. The expected sizes are indicated. The superimposition of two distinct samples, a control sample with two copies of SMN1 and two of SMN2 (blue) and the analysed sample (red), indicates the number of SMN1 and SMN2 copies. The result of this quantification for one normal subject and five relatives of a SMA family (fig 2) are presented. (A) Normal subject with two copies of SMN1 and two copies of SMN2. (B) Index case's father (I.1) with one copy of SMN1 and one copy of SMN2. (C) Mother (I.2) with one copy of SMN1 and two copies of SMN2. (D) Unaffected sib (II.1) with one copy of SMN1 and no copy of SMN2. (E) Affected sib (II.2) with no copy of SMN1 and two copies of SMN2. (F), Unaffected sib (II.4) with two copies of SMN1 and one copy of SMN2. 
Table 1 Primers used for the multiplex PCR assay of SMN

\begin{tabular}{|c|c|c|c|}
\hline Gene & Sense primer & Antisense primer & $\begin{array}{l}\text { Size of the amplicon } \\
(b p)\end{array}$ \\
\hline$S M N$ & 5' AGACTATCAACTTAATTTCTGATCA $3^{\prime \star} \dagger$ & 5' CCTTCCTTCTTTTTGATTTTGTTT 3'‡ & 188 \\
\hline$M L H 1$ & 5' GTAGTCTGTGATCTCCGTTT 3' & 5' ATGTATGAGGTCCTGTCCTA $3^{\prime \star}$ & 244 \\
\hline$B R C A 1$ & 5' TGATTTGAACACCACTGAGA 3'^ & 5' CCGCCTATCATTACATGTTT 3' & 265 \\
\hline
\end{tabular}

$\star^{\prime}$ (6-FAM) labelled.

tR111 primer. ${ }^{5}$

$\ddagger \mathrm{X} 7$-Dra primer. ${ }^{17}$

(SMN2) generates alternatively spliced variants lacking the C-terminal sequence. ${ }^{57}$ The $S M N$ region contains low copy repeats triggering homologous recombination events. Indeed, approximately $95 \%$ of SMA patients lack both SMN1 genes owing to either deletion or gene conversion. ${ }^{4}$ In SMA patients who lack only one SMN1 gene, allelic intragenic mutations have been identified, confirming the involvement of SMN1 in the pathogenesis of SMA. ${ }^{5-10}$

The heterozygote frequency has been estimated to be $1 / 40$. However, the duplication of the SMA locus makes the detection of SMA carriers in the general population difficult, and this has hampered genetic counselling in affected families. Initial attempts to estimate the SMN copy number were based on the measurement of the SMN1/SMN2 ratios, ${ }^{11-13}$ but the broad variability of SMN2 copy number hinders reliable quantification. For this reason, subsequent studies have included two internal standards in the PCR reaction, corresponding to the modified SMN1 and CFTR sequences, respectively. ${ }^{1014} 15 \mathrm{In}$ these methods, the quantification of SMN copies is based on the ratio between the PCR amplification of the specific genomic DNA and that of an internal standard for each subject tested. The results are normalised to the mean of control samples. Although these methods can efficiently detect heterozygous SMN1 deletions, ${ }^{10} 1415$ overlaps between carriers and non-carriers have been observed. ${ }^{10}$

In the present study, we describe a novel method which allows easy detection of heterozygous SMN1 deletions in SMA carriers and SMA patients without homozygous SMN1 deletions. We devised a multiplex PCR assay of fluorescent fragments based on the approach that we initially developed for the detection of mismatch repair gene rearrangements in hereditary non-polyposis colorectal cancer. ${ }^{16}$ We simultaneously amplified exon 7 of the SMN1 and SMN2 genes using a mismatch primer X7-Dra, which introduced a DraI restriction site into amplified SMN1 exon $7,{ }^{17}$ BRCA1 exon 11 , and $M L H 1$ exon 18, which contains a natural internal DraI restriction site (table 1). The PCR reaction was performed in a final volume of $50 \mu \mathrm{l}$, using $0.75 \mu \mathrm{mol} / 1 S M N$ primers, $0.5 \mu \mathrm{mol} / 1$ BRCA1 primers, $0.35 \mu \mathrm{mol} / 1 \mathrm{MLH} 1$ primers, $0.2 \mathrm{mmol} / 1 \mathrm{dNTP}$, $1.5 \mathrm{mmol} / 1 \mathrm{MgCl}_{2}, 1$ unit of Taq polymerase (Eurobio, Les Ulis, France), and $100 \mathrm{ng}$ of genomic DNA. The PCR consisted of 20 cycles of $94^{\circ} \mathrm{C}$ for 15 seconds, $55^{\circ} \mathrm{C}$ for 15 seconds, and $72^{\circ} \mathrm{C}$ for 15 seconds, preceded by an initial denaturation step of five minutes at $94^{\circ} \mathrm{C}$ and followed by a final extension of five minutes at $72^{\circ} \mathrm{C}$. The entire PCR reaction was then digested using 4 units of DraI (New England Biolabs) in a total volume of $150 \mu \mathrm{l}$ for at least four hours. After purification using the Qiagen Gel Extraction Kit, PCR products were resuspended in a mix containing $2.5 \mu \mathrm{l}$ of deionised formamide, $0.5 \mu \mathrm{l}$ of GeneScan-500 Rox (PE Applied Biosystems, Perkin Elmer), and $1 \mu \mathrm{l}$ of loading buffer. After denaturation for two minutes at $90^{\circ} \mathrm{C}$, $2 \mu \mathrm{l}$ of each sample was loaded onto a $4.25 \%$ denaturing polyacrylamide gel (Sequagel). Electrophoresis was performed for three hours on an Applied Biosystems model 377 automated sequencer (PE Applied Biosystems, Perkin Elmer). Data were analysed using the Gene Scanner Model
672 Fluorescent Fragment Analyser (PE Applied Biosystems, Perkin Elmer) and electropherograms generated from different samples were superimposed.

Each multiplex PCR yielded a pattern composed of four fluorescent peaks corresponding to exonic fragments of $B R C A 1, M L H 1, S M N 1$, and SMN2 respectively and the patterns generated from two control samples could be easily superimposed (fig 1A). For validation, we studied the SMN1 and SMN2 copy numbers (fig 1) in a SMA family in which linkage analysis, using the C212 and C272 microsatellite markers, ${ }^{18}$ and analysis of the SMN1 and SMN2 genes by PCR digestion had previously shown a homozygous SMN1 gene deletion in the affected child and a homozygous $S M N 2$ gene deletion in an unaffected sib, which was suggestive of a large deletion encompassing both SMN1 and SMN2 on the paternal allele (fig 2). The relatives of this family were therefore predicted to harbour a variable number of SMN1 and SMN2 copies. Fig 1 shows that the multiplex PCR, using as a control a subject predicted to carry two copies of SMN1 and two of SMN2, easily detected no, one, or two copies of $S M N 1$ or $S M N 2$ within this family. This technique confirmed the large paternal deletion and showed a gene conversion event on the mutant maternal allele. We then tested 86 parents of SMA patients carrying a homozygous SMN1 deletion (50 parents of SMA type I, 28 parents of SMA type II, two parents of SMA type III, and six parents of SMA patients of undetermined type). An approximate 0.5 reduction of the SMN1 peak area, indicative of a heterozygous deletion, was clearly observed in 80 parents (93\%). Two SMN1 copies were detected in six putative carriers. In four out of these six families, linkage analysis with the C212 and C272 microsatellite markers and quantification of SMN1 in relatives allowed us to show the existence of two de novo deletions and two SMN1 duplications.

In contrast to the previously reported methods, ${ }^{1014} 15$ the estimation of SMN1 copy number in this assay is based on the comparison of the fluorescence levels between the SMN1 peak generated from different samples rather than between the different peaks generated from the same sample. In order to keep PCR amplification within an exponential range, we tested various numbers of cycles (18, 20,22 , and 24) and found that 20 cycles, with shorter times of annealing and extension than those previously described, were optimal. ${ }^{1014}$ The simultaneous amplification of two other fragments (BRCA1 and MLH1) allowed an accurate comparison of electropherograms generated from different samples. The absence of the $244 \mathrm{bp} M L H 1$ PCR product and the appearance of a 209 bp peak (fig 1), expected from $D r a I$ digestion, indicated that the enzymatic digestion was complete, a feature which is essential to distinguish between SMN1 and SMN2 amplified fragments.

The simplicity of this assay should facilitate its development in molecular diagnostic laboratories and hopefully aid in genetic counselling in SMA families. However, one must keep in mind the existence of (1) small intragenic mutations within the SMN1 gene, (2) SMN1 duplications in cis (on one chromosome) masking a heterozygous deletion on the other chromosome, (3) de novo deletions, and 


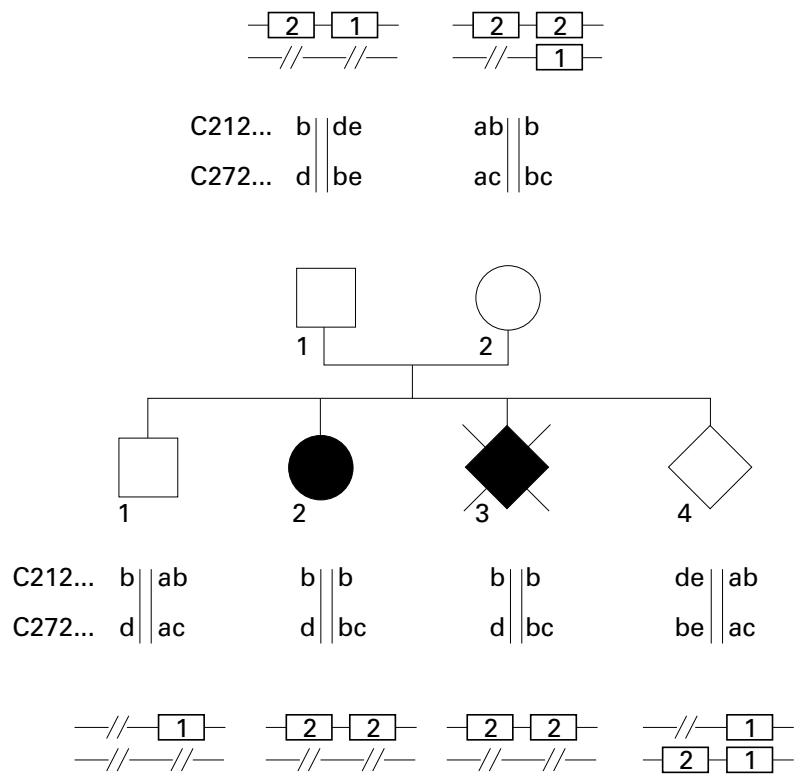

Figure 2 Pedigree of the SMA family used to validate the multiplex PCR. Filled symbols, affected subjects; open symbols, asymptomatic subjects. For each subject, the haplotype analysis using the C212 and C272 microsatellite markers ${ }^{18}$ and the schematic representation of the SMN locus (1: SMN1, 2: SMN2) are indicated.

(4) germline mosaicism. Small intragenic SMN1 mutations account for $1.3-3.4 \%$ of the mutant $S M N 1$ alleles and have been identified in SMA patients carrying heterozygous SMN1 deletions. ${ }^{5-10}$ On the other hand, de novo SMN1 deletions have been shown to be involved in approximately $2 \%$ of SMA cases. ${ }^{15}{ }^{19}$ In order to estimate the error risk resulting from duplication or de novo deletion, we counted SMN1 copies in 86 parents of SMA children carrying a homozygous SMN1 deletion and found that six out of 86 putative carriers $(7 \%)$ had more than one SMN1 copy. These data are in complete agreement with the results of Chen et al, ${ }^{15}$ who detected 5/60 putative SMA carriers with two copies of SMN1 $(8.3 \%$ including one carrier with a small intragenic SMN1 mutation, two putative carriers with a de novo deletion, and two carriers with a SMN1 duplication). Finally, germline mosaicism has to be considered..$^{20}$ Despite this error risk (less than 10\%), the determination of SMN1 copy number in relatives of SMA patients, harbouring homozygous SMN1 deletions, will make genetic counselling easier and hopefully limit prenatal screening. For example, for a couple with an a priori risk of $1 / 320$ of having an affected child (corresponding to the situation of the index case's uncle or aunt), detection of two SMN1 copies in both the relative and his/her spouse will reduce the probability of having an affected child to $1 / 32000([1 / 2 \times 1 / 10] \times[1 / 40 \times 1 / 10] \times 1 / 4)$, which is lower than the risk of the general population. Detection of one copy in the relative and two copies in his/her spouse will decrease the risk to $1 / 1600(1 \times[1 / 40 \times 1 / 10] \times 1 / 4)$. This assay will also facilitate the detection of heterozygous SMN1 deletion in SMA patients without a homozygous SMN1 deletion who must be screened for small SMN1 mutations on the other allele, as previously shown by Wirth et $a l^{10}$ Finally, this assay will allow the study of the influence of SMN2 copy numbers on the SMA phenotype for research purposes, a feature previously suggested by both the observation of an increased number of SMN2 copies in patients with a milder phenotype $e^{51214152122}$ and by the effect of the expression of human SMN2 in $S m n^{-1-}$ mice. $^{2324}$

This work was supported by Association Française contre les Myopathies (AFM).
PASCALE SAUGIER-VEBER * NATHALIE DROUOT* SUZIE LEFEBVRE†

FRANÇOISE CHARBONNIER* ELODIE VIAL† ARNOLD MUNNICH $†$ THIERRY FRÉBOURG*

*INSERM EMI 9906, Faculté de Médecine et de Pharmacie, 76183 Rouen, IFRMP, 76821 Mont-Saint-Aignan and Service de Génétique, CHU de Rouen, 76031 Rouen, France

†INSERM U393 and Département de Génétique, Hôpital Necker Enfants-Malades, 75743 Paris, France

Correspondence to: Dr Saugier-Veber, Pascale.Saugier-Veber@chu-rouen.fr.

1 Pearn J. The gene frequency of acute Wernig-Hoffmann disease (SMA type I). A total population survey in north-east England. 7 Med Genet 1973;10:260-5.

2 Pearn J. Incidence, prevalence and gene frequency studies of chronic childhood spinal muscular atrophy. F Med Genet 1978;15:409-13.

3 Munsat TL. Workshop report: international SMA collaboration. Neuromusc Disord 1991;1:81.

4 Lefebvre S, Bürglen L, Frézal J, Munnich A, Melki J. The role of the $S M N$ gene in proximal spinal muscular atrophy. Hum Mol Genet 1998; 7:1531-6.

5 Lefebvre S, Bürglen L, Reboullet S, Clermont O, Burlet P, Viollet L, Benichou B, Cruaud C, Millasseau P, Zeviani M, Le Paslier D, Frézal J, Cohen D, Weissenbach J, Munnich A, Melki J. Identification and Cohen D, Weissenbach J, Munnich A, Melki J. Identification and
characterization of a spinal muscular atrophy-determining gene. Cell 1995;

6 Roy N, Mahadevan MS, McLean M, Shutler G, Yaraghi Z, Farahani R, Baird S, Besner-Johnston A, Lefebvre C, Kang X, Salih M, Aubry H, Tamai $\mathrm{K}$, Guan X, Ioannou P, Crawford TO, de Jong PJ, Surh L, Ikeda JE, Korneluk RG, MacKenzie A. The gene for neuronal apoptosis inhibitory protein is partially deleted in individuals with spinal muscular atrophy. Cell 1995;80:167-78.

7 Gennarelli M, Lucarelli M, Capon F, Pizzuti A, Merlini L, Angelini C, Novelli G, Dallapiccola B. Survival motor neuron gene transcript analysis in muscles from spinal muscular atrophy patients. Biochem Biophys Res Commun 1995;213:342-8

8 Bussaglia E, Clermont O, Tizzano E, Lefebvre S, Bürglen L, Cruaud C, Urtizberea JA, Colomer J, Munnich A, Baiget M, Melki J. A frame-shift deletion in the survival motor neuron gene in Spanish spinal muscular deletion in the survival motor neuron gene

9 Parsons DW, McAndrew PE, Iannaccone ST, Mendell JR, Burghes AH, Parsons DW, McAndrew PE, Iannaccone ST, Mendell JR, Burghes AH,
Prior TW. Intragenic telSMN mutations: frequency, distribution, evidence Prior TW. Intragenic telSMN mutations: frequency, distribution, evidence type by cenSMN copy number. Am f Hum Genet 1998;63:1712-23.

10 Wirth B, Herz M, Wetter A, Moskau S, Hahnen E, Rudnik-Schoneborn S, Wienker T, Zerres K. Quantitative analysis of survival motor neuron copies: identification of subtle SMN1 mutations in patients with spinal muscular atrophy, genotype-phenotype correlation, and implications for genetic counseling. Am F Hum Genet 1999;64:1340-56

11 Matthijs G, Schollen E, Legius E, Devriendt K, Goemans N, Kayserili H, Apak MY, Cassiman JJ. Unusual molecular findings in autosomal recessive spinal muscular atrophy. F Med Genet 1996;33:469-74.

12 Velasco E, Valero C, Valero A, Moreno F, Hernandez-Chico C. Molecular analysis of the SMN and NAIP genes in Spanish spinal muscular atrophy (SMA) families and correlation between number of copies of $\mathrm{BCD} 54$ and SMA phenotype. Hum Mol Genet 1996;5:257-63.

13 Schwartz M, Sorensen N, Hansen FJ, Hertz JM, Norby S, Tranebjaerg L, Skovby F. Quantification, by solid-phase minisequencing, of the telomeric Skovby F. Quantification, by solid-phase minisequencing, of the telomeric
and centromeric copies of the survival motor neuron gene in families with and centromeric copies of the survival motor neuron gene
spinal muscular atrophy. Hum Mol Genet 1997;6:99-104.

14 McAndrew PE, Parsons DW, Simard LR, Rochette C, Ray PN, Mendell JR, Prior TW, Burghes AH. Identification of proximal spinal muscular atrophy carriers and patients by analysis of SMNT and SMNC gene copy number. Am F Hum Genet 1997;60:1411-22.

15 Chen KL, Wang YL, Rennert H, Joshi I, Mills JK, Leonard DG, Wilson RB. Duplications and de novo deletions of the $S M N t$ gene demonstrated by fluorescence-based carrier testing for spinal muscular atrophy. Am f Med Genet 1999;85:463-9.

16 Charbonnier F, Raux G, Wang Q, Drouot N, Cordier F, Limacher J, Saurin JC, Puisieux A, Olschwang S, Frebourg T. Detection of large deletions and duplications of the mismatch repair genes in HNPCC families using multiplex PCR of short fluorescent fragments. Cancer Res 2000;60:2760-3.

17 Van der Steege G, Grootscholten PM, Van der Vlies P, Draaijers TG, Osinga J, Cobben JM, Scheffer H, Buys CH. PCR-based DNA test to confirm clinical diagnosis of autosomal recessive spinal muscular atrophy. Lancet 1995;345:985-6.

18 Melki J, Lefebvre S, Bürglen L, Burlet P, Clermont O, Millasseau P, Reboullet $S$, Benichou B, Zeviani M, Le Paslier D, Cohen D, Weissenbach J, Mun-
nich A. De novo and inherited deletions of the 5 q13 region in spinal musnich A. De novo and inherited deletions of
cular atrophies. Science 1994;264:1474-7.

19 Wirth B, Schmidt T, Hahnen E, Rudnik-Schoneborn S, Krawczak M, Muller-Myhsok B, Schonling J, Zerres K. De novo rearrangements found in $2 \%$ of index patients with spinal muscular atrophy: mutational mechanisms, parental origin, mutation rate, and implications for genetic counseling. Am f Hum Genet 1997;61:1102-11.

20 Campbell L, Daniels RJ, Dubowitz V, Davies KE. Maternal mosaicism for a second mutational event in a type I spinal muscular atrophy family. $A m \mathcal{F}$ Hum Genet 1998;63:37-44.

21 Wirth B, Hahnen E, Morgan K, DiDonato CJ, Dadze A, RudnikSchoneborn S, Simard LR, Zerres K, Burghes AH. Allelic association and deletions in autosomal recessive proximal spinal muscular atrophy: association of marker genotype with disease severity and candidate cDNAs. Hum Mol Genet 1995;4:1273-84

22 Taylor JE, Thomas NH, Lewis CM, Abbs SJ, Rodrigues NR, Davies KE, Mathew CG. Correlation of SMNt and SMNc gene copy number with age
of onset and survival in spinal muscular atrophy. Eur 7 Hum Genet 1998;6: of onset and 
23 Hsieh-Li HM, Chang JG, Jong YJ, Wu MH, Wang NM, Tsai CH, Li H. A mouse model for spinal muscular atrophy. Nat Genet 2000;24:66-70.

4 Monarsons DW, Andreassi C,

Le TT, Jablonka S, Schrank B, Rossol W, Prior TW, Morris GE,
Burghes AH. The human centromeric survival motor neuron gene $(\mathrm{SMN} 2)$ rescues embryonic lethality in $\operatorname{Smn}(-/-)$ mice and results in a mouse with spinal muscular atrophy. Hum Mol Genet 2000;9: 333-9.

\section{Low prevalence of SPINK1 gene mutations in adult patients with chronic idiopathic pancreatitis}

EDITOR-Chronic idiopathic pancreatitis is a genetically heterogeneous disease. ${ }^{1-3}$ Mutations of the cationic trypsinogen $(C T)$ gene underlie some cases of juvenile pancreatitis, ${ }^{3-5}$ and mutations of the cystic fibrosis transmembrane conductance regulator $(C F T R)$ gene have been associated with chronic pancreatitis in adults. ${ }^{6-8}$ However, these genes account for only a relatively small proportion of cases. More recently, the serine proteinase inhibitor Kazal type 1 (SPINK1) gene, also called PSTI, has attracted attention as a possible cause for chronic pancreatitis. $^{910}$ One study by Chen $e t$ al ${ }^{9}$ did not find disease causing mutations of SPINK1 among 14 families with hereditary and 30 patients with sporadic pancreatitis, apart from two rare amino acid substitutions which were observed at a comparable frequency to the general population. By contrast, another study by Witt et al ${ }^{10}$ reported 23 out of 68 children and adolescents with chronic pancreatitis whose disease was associated with the occurrence of SPINK1 mutations in the heterozygous or homozygous state. In particular, one founder mutation, N34S, was identified in $18 / 68$ German patients but only in $1 / 279$ controls. ${ }^{10}$ In the work presented here, we have addressed the role of SPINK1 mutations in a series of 20 adult German pancreatitis patients, a cohort that we had previously analysed for mutations in the $C T$ and CFTR genes. ${ }^{8}$

The mean age of patients in our series was 32 years (range 19-46 years). All of them presented with either recurrent pancreatitis characterised by at least three episodes of pancreatitis at least 12 months apart or with chronic idiopathic pancreatitis. ${ }^{8}$ Genomic DNA was extracted from white blood cells and the four exons of the SPINK1 gene were amplified by PCR using published primers ${ }^{9} 10$ and scanned for mutations by single strand conformation polymorphism (SSCP) analysis and direct sequencing.

Only two patients were found to carry sequence alterations of the SPINK1 gene (table 1). One 26 year old patient was homozygous for the previously reported missense mutation N34S. ${ }^{9}{ }^{10}$ His parents were both heterozygotes and did not show any signs of pancreatitis, consistent with an autosomal recessive mode of inheritance. This

Table 1 Summary of genotypes of 20 German adults with chronic idiopathic pancreatitis analysed for mutations of the SPINK1, CFTR, and CT genes (this study). ${ }^{8}$ CFTR and SPINK1 gene alterations were identified in six patients as listed in columns 1 and 2, respectively. Mutations of unknown significance are shown in italics. No mutations have been found in the CT gene

\begin{tabular}{llllll}
\hline \multirow{2}{*}{ Patient } & \multicolumn{2}{l}{ CFTR mutations } & & \multicolumn{2}{l}{ SPINK1 mutations } \\
\cline { 2 - 3 } \cline { 5 - 6 } & Allele 1 & Allele 2 & & Allele 1 & Allele 2 \\
\hline 1 & R75Q & - & & - & - \\
5 & I336K & R75Q & & - & - \\
8 & - & - & & N34S & N34S \\
11 & IVS8-5T & - & & - & - \\
12 & Y1092X & - & & R65Q & - \\
20 & $\Delta$ F508 & - & & - \\
\hline
\end{tabular}

patient had not been found to carry a CFTR gene alteration in our previous study ${ }^{8}$ (table 1). The second patient, a 35 year old male, was heterozygous for a new SPINK1 mutation, a $\mathrm{G} \rightarrow \mathrm{A}$ transition at nucleotide 194 , that is, the last nucleotide of exon 3 (fig 1A). The $194 \mathrm{G} \rightarrow \mathrm{A}$ transition could be confirmed by restriction enzyme analysis as it abolishes a recognition site for $H p h \mathrm{I}$ and creates a new site for $T s p$ RI (fig 1B). This substitution does not seem to affect splicing of SPINK1 mRNA, as assessed by nested RT-PCR from a rectal biopsy of the patient (not shown). However, it leads to a missense mutation R65Q at an amino acid position that is conserved in rat and mouse, although some variability exists in cattle. ${ }^{11}$ Interestingly, the same patient had also been found to be heterozygous for a nonsense mutation of the CFTR gene, Y1092X in exon $17 b^{8}$ (table 1). To elucidate the role of this double heterozygosity further, we performed a segregation analysis among the healthy family members of the patient. Both the SPINK1 and CFTR mutations were also found in the patient's

A

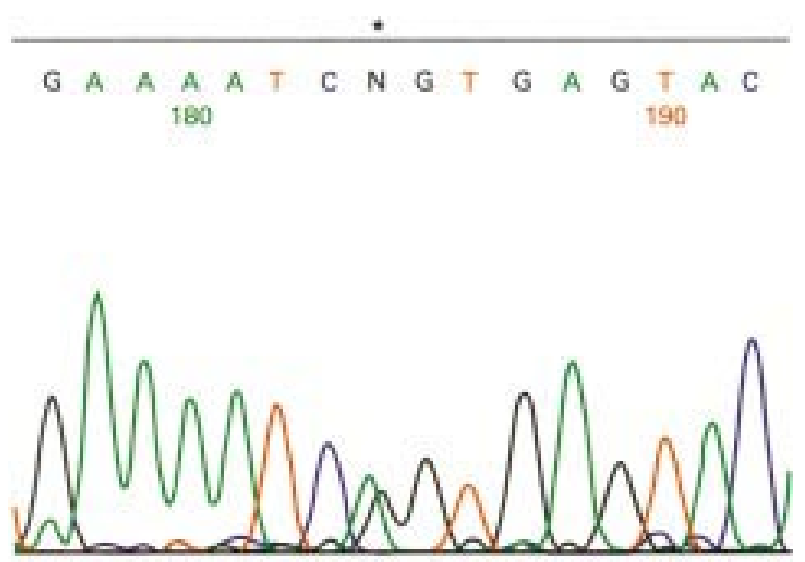

B

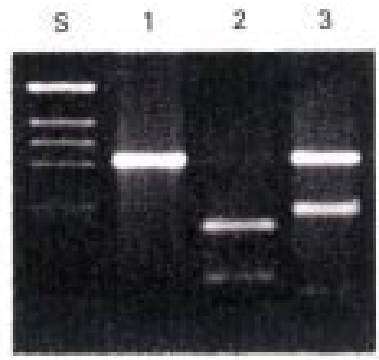

Figure 1 (A) Direct sequencing of exon 3 of the SPINK1 gene showing heterozygosity for the $R 650$ substitution (asterisk). (B) Screening for missense mutations $N 34 S$ and $R 65 Q$ by restriction enzyme analysis. Exon 3 PCR products were amplified using primers from Witt et al ${ }^{10}$ and were digested with TspRI and separated on a $2 \%$ agarose gel. Lane 1: size marker ( $k b$ ladder, BRL), lane 2: wild type control, lane 3: homozygous N34S, lane 4: heterozygous R65Q. Note the distinct patterns for mutations $N 34 S$ and $R 65 Q$ in this assay. 
mother and sister who did not show any signs of pancreatitis. These observations indicate that double heterozygosity for the SPINK1 R65Q and the CFTR Y1092X mutations is not sufficient to cause chronic pancreatitis or at least not fully penetrant.

In summary, the frequency of SPINK 1 mutations is low in our cohort of adult patients with chronic idiopathic pancreatitis. This is in agreement with the previous report from Brittany, ${ }^{9}$ but seems to contrast with the study of German patients by Witt et al. ${ }^{10}$ One possible reason for the discrepancy may lie in a sampling bias. Similar to CT mutations, SPINK1 gene mutations might be predominantly responsible for juvenile early onset pancreatitis, a condition not preferentially selected for in our study. In total, mutations of the CT, CFTR, and SPINK1 genes constituted less than one third of our cases with adult pancreatitis suggesting that additional genes may be involved in the aetiology of this disorder. A pathogenic role of double heterozygosity for SPINK1 and CFTR gene variations could not be confirmed in the single family identified here, but such a possibility may deserve further investigation in larger cohorts.

JOHANN OCKENGA THILO DÖRK† MANFRED STUHRMANN ${ }^{\star}$ Department of Gastroenterology, Medical School Hannover, D-30625 Hannover, Germany †Department of Biochemistry and Tumour Biology. Clinics of Gynaecology and Obstetrics, Medical School Hannover, D-30569 Hannover, Germany $\ddagger$ Institute of Human Genetics, Medical School Hannover, D-30625

Hannover, Germany

Correspondence to: Dr Dörk, doerk.thilo@mh-hannover.de

1 Perrault J. Hereditary pancreatitis. Pediatr Gastroenterol 1994;23:743-52.

2 Dasouki MJ, Cogan J, Summar ML, Neblitt W III, Foroud T, Koller D, Phillips JA III. Heterogeneity in hereditary pancreatitis. Am $\mathcal{f}$ Med Genet 1998;77:47-53.

3 Férec C, Raguénès O, Salomon C, Roche C, Bernard JP, Guillot M, Quéré I, Faure C, Mercier M, Audrézet MP, Guillausseau PJ, Dupont C, Munnich A, Bignon JD, Le Bodic L. Mutations in the cationic trypsinogen gene and evidence for genetic heterogeneity in hereditary pancreatitis. $\mathcal{F}$ Med Genet 1999;36:228-32.

4 Whitcomb DC, Gorry MC, Preston RA, Furey W, Sossenheimer MJ, Ulrich CD, Martin SP, Gates LK Jr, Amann ST, Toskes PP, Liddle R, McGrath K, Uomo G, Post JC, Ehrlich GD. Hereditary pancreatitis is caused by a mutation in the cationic trypsinogen gene. Nat Genet 1996;14:141-5.

5 Teich N, Ockenga J, Hoffmeister A, Manns M, Mössner J, Keim V. Chronic pancreatitis associated with an activation peptide mutation that facilitates trypsin activation. Gastroenterology 1999;119:461-5.

6 Sharer N, Schwarz M, Malone G, Howarth A, Painter J, Super M, Braganza $\mathrm{J}$. Mutations of the cystic fibrosis gene in patients with chronic pancreatitis. N Engl F Med 1998;39:645-52.

7 Cohn JA, Friedman KJ, Noone PG, Knowles MR, Silverman LM, Jowell PS. Relation between mutations of the cystic fibrosis gene and idiopathic pancreatitis. N Engl f Med 1998;39:653-8.

8 Ockenga J, Stuhrmann M, Ballmann M, Teich N, Keim V, Dörk T, Manns MP. Mutations of the cystic fibrosis gene but not cationic trypsinogen gene are associated with recurrent or chronic idiopathic pancreatitis. Am f Gastroenterol 2000;95:2061-7.

9 Chen JM, Mercier B, Audrezet MP, Ferec C. Mutational analysis of the human pancreatic secretory trypsin inhibitor (PSTI) gene in hereditary and sporadic pancreatitis. 7 Med Genet 2000;37:67-9.

10 Witt H, Luck W, Hennies HC, Classen M, Kage A, Lass U, Landt O, Becker M. Mutations in the gene encoding the serine protease inhibitor, Kazal type 1 are associated with chronic pancreatitis. Nat Genet 2000;25:213-16.

11 Marchbank T, Freeman TC, Playford RJ. Human pancreatic secretory trypsin inhibitor. Digestion 1998;59:167-74. [AQ:1]

\section{Interaction of coding region mutations and the Gilbert-type promoter abnormality of the $U G T 1 A 1$ gene causes moderate degrees of unconjugated hyperbilirubinaemia and may lead to neonatal kernicterus}

EDITOR-Crigler-Najjar syndrome types 1 and 2 (CN1 and $\mathrm{CN} 2$ ) are inherited as autosomal recessive conditions and are characterised by severe non-haemolytic unconjugated hyperbilirubinaemia. $\mathrm{CN1}$ is the most severe form, in which a virtual absence of hepatic bilirubinuridinediphosphoglucuronate glucuronosyltransferase (UGT1A1) (PIR Accession A31340) activity results in serum bilirubin levels of 340-685 $\mu \mathrm{mol} / 1$ or higher (normal 1.7-17.1 $\mu \mathrm{mol} / \mathrm{l}) .{ }^{1} \mathrm{~A}$ milder variant of this disorder, termed $\mathrm{CN} 2$, is associated with intermediate levels of hyperbilirubinaemia (120-340 $\mu \mathrm{mol} / \mathrm{l})$ as a result of an incomplete deficiency of hepatic UGT1A1 activity. Usually, the residual UGT1A1 activity can be induced by phenobarbital administration, resulting in partial amelioration of jaundice. ${ }^{2}$ A third type of inherited unconjugated hyperbilirubinaemia, termed Gilbert's syndrome, is associated with mild, fluctuating hyperbilirubinaemia, ranging from normal levels to up to $85 \mu \mathrm{mol} / 1{ }^{3}{ }^{3}$ Hepatic UGT1A1 activity is reduced to approximately $30 \%$ of normal in Gilbert's syndrome. In all three forms of inherited hyperbilirubinaemia, other hepatic functions are unaffected and the liver is morphologically normal. ${ }^{4}$ Before the institution of routine phototherapy, CN1 used to be uniformly lethal because of bilirubin encephalopathy (kernicterus). ${ }^{5}$ Although phototherapy has prolonged survival, it becomes progressively ineffective around puberty. ${ }^{6}$ Hepatocyte transplantation has resulted in partial amelioration of jaundice, ${ }^{89}$ but at present liver transplantation remains the only definitive therapy. ${ }^{10}{ }^{11}$ Kernicterus is much less common in CN2, and does not occur in Gilbert's syndrome.

UGT1A1 is one of the several UGT isoforms that are expressed from the $U G T 1 A$ gene locus, ${ }^{12}$ located in human chromosome $2 \mathrm{q} 37 .{ }^{13}$ The locus contains four exons at the 3 ' end (exons 2, 3, 4, and 5), which are used in several UGT1A isoform mRNAs and encode the identical carboxy-terminal half of these enzymes. Upstream to these common region exons are a series of unique exons (exon $1 \mathrm{~A} 1$ to $1 \mathrm{~A} 12$ ), only one of which is used in a given UGT1A isoform mRNA. Each unique exon encodes the variable $\mathrm{N}$-terminal region of one UGT1A isoform, which imparts its substrate specificity. The individual isoforms of the UGT1A subfamily are named according to the unique exon used. For example, UGT1A1 is encoded by exons $1 \mathrm{~A} 1,2,3,4$, and 5, and the gene is termed UGT1A1 (GenBank accession No AF 180372, OMIM 191740). Following the initial report in $1992,{ }^{14}$ studies from several laboratories have shown that $\mathrm{CN} 1$ and $\mathrm{CN} 2$ are caused by genetic lesions of any of the five exons of the UGT1A1 gene, or their flanking splice junctions. These mutations have been reviewed recently. ${ }^{15} 16$ The severity of the functional deficiency of UGT1A1 is determined by the nature of the genetic lesion. ${ }^{17} \mathrm{CN} 1$ results from genetic lesions that cause premature truncation of UGT1A1 or substitution of critical amino acid residues, whereas CN2 is caused by substitution of single amino acid residues that markedly reduce, but do not abolish the catalytic activity of the enzyme. Although the incidence of Crigler-Najjar syndromes is not known precisely, these disorders probably occur in less than one in a million live births in the western 
hemisphere. ${ }^{11}$ Thus, the gene frequency can be estimated to be $1: 1000$ or less. Because the expression of one structurally normal allele is sufficient to keep serum bilirubin levels within normal limits, heterozygous carriers are not expected to have hyperbilirubinaemia.

In contrast to CN1 and CN2, Gilbert's syndrome is one of the most common inherited disorders in humans. In western populations, this condition is associated with a TA insertion within a dinucleotide repeat in the TATAA element, upstream of the first exon of UGT1A1. The normal TATAA element sequence is A(TA) ${ }_{6}$ TAA, whereas in Gilbert syndrome the sequence is A(TA) ${ }_{7}$ TAA. ${ }^{18}$ The variant TATAA element reduces the expression of the structurally normal enzyme. ${ }^{18}$ Two additional polymorphisms of the TATAA element, a shorter (A(TA) ${ }_{5}$ TAA) and a longer (A(TA) ${ }_{8}$ TAA) variant, have been described in people of African origin. ${ }^{19}$ An inverse relationship between the length of the TATAA element and UGT1A1 expression has been reported. The common Gilbert-type TATAA element ( $\left.\mathrm{A}(\mathrm{TA})_{7} \mathrm{TAA}\right)$ is present in homozygous state in approximately $9 \%$ of the European and North American population, the gene frequency being $30 \% .{ }^{18}{ }^{20-22}$ Homozygosity for the variant TATAA element is required, but not sufficient for the manifestation of the Gilbert phenotype, which is found in $4-7 \%$ of the general population. ${ }^{18}$ Other factors contribute to the serum bilirubin levels. For example, the Gilbert phenotype is seen less commonly in women, probably because of lower daily bilirubin production. ${ }^{23}$ In addition to the promoter abnormality, Japanese investigators have reported that some structural mutations of UGT1A1 can result in mild hyperbilirubinaemia, compatible with the diagnosis of Gilbert's syndrome. ${ }^{24-26}$ These mutations have not been reported in white, black, south Asian, or Middle Eastern populations.

Interestingly, intermediate levels of hyperbilirubinaemia are observed commonly in families of patients with $\mathrm{CN} 1$ or $\mathrm{CN} 2$, which had given rise to conflicting opinions regarding the mode of inheritance of CN2 in the past. ${ }^{2727}$ Because the gene frequency of the Gilbert-type promoter is $30 \%$ in the western population, a significant percentage of heterozygous carriers of CN-type mutations of the structural region of $U G T 1 A 1$ would be expected also to carry a Gilbert-type promoter on one or both alleles. Sporadic cases of coexistence of a Gilbert-type promoter and a structural mutation of UGT1A1 have been reported. ${ }^{28-30}$ We postulated that such compound heterozygosity should be a more common cause of intermediate levels of jaundice than homozygosity for a structural mutation. We have examined this postulate in a systematic study over the course of the last three years by performing routine genetic analysis of a large number of referred patients with various levels of unconjugated hyperbilirubinaemia and their families. Here we report eight patients from four families, who had intermediate levels of unconjugated hyperbilirubinaemia because of compound heterozygosity of a Gilbert-type promoter and a structural region mutation of UGT1A1. Three of the structural mutations are being reported here for the first time. In one of these families, a pair of dizygotic twins, who also had ABO incompatibility with the mother, developed severe neonatal hyperbilirubinaemia, leading to chronic encephalopathy.

Four families, designated families A to D, were studied. The probands in all the families showed clinical jaundice with predominantly unconjugated hyperbilirubinaemia. In families A, B, and D the children were the probands, while in family $\mathrm{C}$ the mother was the primary subject of the study. In all probands and their family members, the serum aspartate aminotransferase (AST), alanine aminotransferase (ALT), and alkaline phosphatase levels were within normal limits and there was no evidence of any other liver disease or chronic haemolysis. Therefore, an inherited disorder of bilirubin glucuronidation was suspected.

Blood samples were obtained from all the subjects studied with appropriate informed consent. Genomic DNA was extracted from whole anticoagulated blood using the Qiagen kit (Qiagen, Valenica, CA), according to the manufacturer's instructions, and was used as template for amplification by polymerase chain reaction (PCR). A segment of the UGT1A1 upstream untranslated region, the five exons, and the flanking intronic sequences were amplified in three pieces using specific amplimers. A $104 \mathrm{bp}$ segment upstream of the translation initiation codon (ATG), exon 1, and a short segment of intron 1 were amplified as a single amplicon. Exons 2, 3, and 4 and introns 2, 3, and a short segment of intron 4 were amplified as a second amplicon. Exon 5 and its flanking intronic sequences were amplified as the third amplicon. The amplicons generated by the first PCR were isolated by electrophoresis on low melting agarose gels and reamplified. The sequences and the locations of the primers used for the PCR reactions are as follows. Exon 1 (including $29 \mathrm{bp}$ untranslated region $+85 \mathrm{bp}$ upstream genomic sequence: sense: 5' GTCACGTGACACAGT CAAAC 3' (85 nt upstream of 5' end of exon 1), antisense: 5' GCTTGCTCAGCATATATCTGG 3' (74 bp downstream of the 3 ' end of exon 1 ); exons 2 , 3, and 4 , intron 2 and 3 and flanking DNA sequences: sense: 5 ' CTCTATCT CAAACACGCATGCC 3' (105 nt upstream of 5' end of exon 2), antisense: 5' TTATCATGAATGCCATGACC 3' (29 nt downstream of 3 ' end of exon 4); exon 5 and flanking DNA sequences: sense: 5' GAGGATTGTTCATAC CACAGG 3' (35 nt upstream of 5' end of exon 5), antisense: 5' TGAATTTAACACTGATTCTGTT 3' (nt 1666 to nt 1687). The DNA template for PCR was first denatured for five minutes at $94^{\circ} \mathrm{C}$ and then cycled 35 times using the following cycling parameters: $94^{\circ} \mathrm{C}$ for 30 seconds, $56^{\circ} \mathrm{C}$ for 30 seconds, $72^{\circ} \mathrm{C}$ for 60 seconds. Finally, a five minute extension cycle at $72^{\circ} \mathrm{C}$ was performed. After the second amplification, the PCR products were purified using Qiagen PCR purification kit (Qiagen). The nucleotide sequence of the purified amplicons was determined using the sequitherm excel DNA sequencing kit, (Epicenter Technologies, Madison, WI 53713). Nesting primers end labelled with radioactive ${ }^{32} \mathrm{P}$ (Amersham Pharmacia Biotech Inc, NJ) were used for sequence analysis. The primers used for sequence determination were as follows. TATAA element of the promoter region: antisense, 5' GGACACCACT GGGCCCAGCACA 3' (+59 to +81); exon 1: sense, 5' AGGAGCAAAGGCGCCATGGCT $3^{\prime}(-15$ to +6$)$, sense, 5' GCGTGTCATCAAAACATACAA 3' (+321 to +341), antisense, 5' GCTTGCTCAGCATATATCTGG 3' (intronic primer, $74 \mathrm{nt}$ downstream of $3^{\prime}$ end of exon 1); exon 2: sense, 5' GTATGTAGTCATCAAAGAATATG 3' (intronic primer $63 \mathrm{nt}$ upstream of $5^{\prime}$ end of exon 2); exon 3: sense, 5' TAGTTAGTATAGCAGA 3' (intronic primer 59 nt upstream of $5^{\prime}$ end of exon 3); exon 4: sense, 5' GTCCAGCTGTGAAACTCAGA 3' (intronic primer, 39 nt upstream of $5^{\prime}$ end of exon 4); exon 5: sense, 5' GAGGATTGTTCATACCACAGG 3' (intronic primer 36 nt upstream of $5^{\prime}$ end of exon 5); antisense, 5' TGAATT TAACACTGATTCTGTT 3' (+1666 to +1687). Nucleotide sequences were determined by the dideoxy chain termination method ${ }^{31}$ using a cycle sequencing procedure as follows: denaturation, $94^{\circ} \mathrm{C}$ for 60 seconds, followed by 20 cycles of $94^{\circ} \mathrm{C}$ for 30 seconds, $56^{\circ} \mathrm{C}$ for 30 seconds, $72^{\circ} \mathrm{C}$ for 60 seconds, and 10 cycles of $94^{\circ} \mathrm{C}$ for 30 seconds, and $72^{\circ} \mathrm{C}$ for 60 seconds. Sequence abnormality in each sample was confirmed by repeat analysis of an amplicon generated by a second independent PCR.

To determine the consequence of the two newly observed point mutations that predicted single amino acid 
substitutions (the $1490 \mathrm{~T}>\mathrm{A}$ and $1452 \mathrm{G}>\mathrm{A}$ mutations, found in families B and C, respectively) on the catalytic activity of UGT1A1, site directed mutagenesis was performed on a plasmid, pSVK3, which contains the entire UGT1A1 coding region. ${ }^{17}$ The mutagenised UGT1A1 cDNA was excised by partial digestion with EcoRI and complete digestion with $X h o I$ and subcloned into the pcDNA3.1/Zeo(+) (Invitrogen) expression vector and the nucleotide sequence was determined to confirm the introduction of the point mutation. COS-7 cells, grown in 100 $\mathrm{mm}$ dishes and at 50-60\% confluency, were transfected with the pcDNA3.1/Zeo(+) containing normal or mutagenised UGT1A1 sequences, using DEAE dextran (Amersham Pharmacia Biotech) as previously described. ${ }^{17}$ Total protein in the cell lysates was quantitated ${ }^{32}$ and an equal amount of protein from lysates of cells transfected with the different plasmids was subjected to western blot analysis using a monoclonal antibody against UGT1A1 (mab WP1). The immunoreactive bands were detected using a chemiluminescent substrate (Pierce, Rockford, IL).

Expressed UGT1A1 in each cell lysate was quantitated by a sandwich ELISA as previously described. ${ }^{17}$ Briefly, ELISA plates were coated overnight with WP1 (a monoclonal antibody against UGT1A isoforms), blocked with a solution containing 3\% bovine serum albumin and $5 \%$ fetal calf serum, and then overlaid with lysates of the transfected cells. A rabbit antibody raised against a synthetic peptide corresponding to a unique region of UGT1A1 (Pab136) was applied. The detection system consisted of a goat anti-rabbit IgG, conjugated with horseradish peroxidase. Based on ELISA quantitation, equal amounts of UGT1A1 from the various cell lysates were assayed for bilirubin-UGT activity in the presence of 80 $\mu \mathrm{mol} / 1$ bilirubin and $4.4 \mathrm{mmol} / \mathrm{l} \mathrm{UDP}$-glucuronic acid as previously described. ${ }^{17}$ At the end of incubation for 60 to 120 minutes, the reaction was stopped by adding $0.4 \mathrm{~mol} / 1$ $\mathrm{HCl}$-glycine buffer ( $\mathrm{pH} 1.8)$ and pigments were extracted in chloroform/ethanol $(1: 1 \mathrm{v} / \mathrm{v}) .{ }^{17}$ The solvents were evaporated under a stream of nitrogen, the pigments were dissolved in dimethyl sulphoxide and methanol, and analysed by reverse phase high pressure liquid chromatography using a Waters $\mathrm{C}_{18} \mu$ Bondapak column (Waters, Milford, MA) as previously described..$^{33}$ Formation of bilirubin glucuronides was calculated from the electronically integrated areas under the bilirubin glucuronide peaks.

Brief clinical histories of the four families follow. The genotypes of the TATAA element and coding region of UGT1A1 are listed in table 1.

Family $A$. Eighteen month old twin girls were brought to the paediatrician for evaluation of jaundice. Both girls had severe neonatal hyperbilirubinaemia, with peak serum bilirubin levels of $456.5 \mu \mathrm{mol} / 1$ and $410.4 \mu \mathrm{mol} / 1$ ( $>90 \%$ "indirect" by van den Bergh reaction) on the fifth postnatal day. Initially the babies were Coomb's test positive and the exaggerated neonatal hyperbilirubinaemia had been attributed to $\mathrm{ABO}$ incompatibility. However, the jaundice persisted after their blood samples became Coomb's nonreactive, and a diagnosis of Crigler-Najiar syndrome was suspected after excluding other causes of hyperbilirubinaemia. The twins were placed on phenobarbital and phototherapy. This resulted in a reduction of serum bilirubin concentrations to the current level of 136-171 $\mu \mathrm{mol} / 1$. Unfortunately, the infants had already sustained brain damage, presumably from the high neonatal bilirubin levels. At the age of 18 months, neurological examination of the twins showed spastic cerebral palsy, chorioathetoid movements, and signs of retarded mental development. The affected infants were compound heterozygotes for the Gilbert-type TATAA element and the deletion of the "A" at nt 1223. The frameshift caused by this deletion introduces a premature stop codon at codon 497, predicting the truncation of the protein by 122 amino acids and complete catalytic inactivation of UGT1A1. The father was heterozygous for the structural region mutation but had a normal TATAA sequence. The mother carried a Gilbert-type TATAA element on one allele, but the entire coding region had normal nucleic acid sequence.

Family B. The proband, a male, had persistent scleral icterus, first brought to the attention of the physician at the age of 10 years. The peak serum bilirubin level was 205 $\mu \mathrm{mol} / 1$ ( $>90 \%$ "indirect" reacting). An 18 year old sister of the proband was also noted to have milder hyperbilirubinaemia ( $85.5 \mu \mathrm{mol} / 1,>85 \%$ "indirect" reacting). The proband and his sister were compound heterozygotes for the Gilbert-type TATAA element and a point mutation $1490 \mathrm{~T}>\mathrm{A}$ in exon 5 . The father had a normal TATAA sequence but was heterozygous for the point mutation $1490 \mathrm{~T}>\mathrm{A}$ in exon 5 . The mother was heterozygous for the Gilbert-type TATAA element and had normal coding region sequence. The premature termination codon introduced by this mutation is predicted to truncate the carboxy-terminal end of the protein by 37 amino acids. This was confirmed by immunoblot analysis of lysates of COS cells transfected with the mutagenised expression plasmid, pcDNA3.1/zeo(+)- hUGT1A1 (fig 1). The expressed truncated UGT1A1 was catalytically inactive.

Family $C$. The proband was a female infant with persistent hyperbilirubinaemia since birth with a peak level of 376.2 $\mu \mathrm{mol} / 1$ (predominantly "indirect" reacting). Phenobarbital treatment was not effective in reducing the serum bilirubin

Table 1 Promoter and structural mutations in the four families

\begin{tabular}{|c|c|c|c|c|}
\hline Subjects (gender) & TATAA element & Structural mutation & Effect on protein sequence & Serum bilirubin \\
\hline \multicolumn{5}{|l|}{ Family $A$} \\
\hline Infant $\mathrm{A} 1(\mathrm{~F})$ & $(\mathrm{TA})_{6} \mathrm{TAA} /(\mathrm{TA})_{7} \mathrm{TAA}$ & $1223 \mathrm{delA} /$ normal & Truncated/normal & $456 \mu \mathrm{mol} / 1^{\star}$ \\
\hline Infant A2 (F) & (TA) ${ }_{6} \mathrm{TAA} /(\mathrm{TA})_{7} \mathrm{TAA}$ & $1223 \mathrm{delA} /$ normal & Truncated/normal & $410 \mu \mathrm{mol} / 1^{\star}$ \\
\hline Mother & $\mathrm{TA})_{6} \mathrm{TAA} /(\mathrm{TA})_{7} \mathrm{TAA}$ & Normal/normal & Normal/normal & $10 \mu \mathrm{mol} / 1$ \\
\hline Father & $(\mathrm{TA})_{6} \mathrm{TAA} /(\mathrm{TA})_{6} \mathrm{TAA}$ & $1223 \mathrm{delA} /$ normal & Truncated/normal & $15 \mu \mathrm{mol} / 1$ \\
\hline \multicolumn{5}{|l|}{ Family B } \\
\hline Proband $(\mathrm{M})$ & $(\mathrm{TA})_{6} \mathrm{TAA} /(\mathrm{TA})_{7} \mathrm{TAA}$ & $1490 \mathrm{~T}>\mathrm{A} /$ normal & L497X/normal & $205 \mu \mathrm{mol} / 1$ \\
\hline $\mathrm{Sib}(\mathrm{F})$ & (TA) ${ }_{6} \mathrm{TAA} /(\mathrm{TA}){ }_{7} \mathrm{TAA}$ & $1490 \mathrm{~T}>\mathrm{A} /$ normal & L497X/normal & $85 \mu \mathrm{mol} / 1$ \\
\hline Mother & $(\mathrm{TA})_{6} \mathrm{TAA} /(\mathrm{TA})_{7} \mathrm{TAA}$ & Normal/normal & Normal/normal & $7 \mu \mathrm{mol} / 1$ \\
\hline Father & (TA) TAA/(TA) TAA & $1490 \mathrm{~T}>\mathrm{A} /$ normal & L497X/normal & 9 umol/1 \\
\hline \multicolumn{5}{|l|}{ Family $C$} \\
\hline Child C (F) & $(\mathrm{TA})_{6} \mathrm{TAA} /(\mathrm{TA})_{6} \mathrm{TAA}$ & $1452 \mathrm{G}>\mathrm{A} / 1452 \mathrm{G}>\mathrm{A}$ & W484X/W484X & $359 \mu \mathrm{mol} / 1^{\star}$ \\
\hline Mother & (TA) ${ }_{6} \mathrm{TAA} /(\mathrm{TA})_{7} \mathrm{TAA}$ & $1452 \mathrm{G}>\mathrm{A} /$ normal & W484X/normal & $51 \mu \mathrm{mol} / 1$ \\
\hline \multirow{2}{*}{\multicolumn{5}{|c|}{ Family D }} \\
\hline & & & & \\
\hline Case D1 (F) & $(\mathrm{TA})_{7} \mathrm{TAA} /(\mathrm{TA})_{7} \mathrm{TAA}$ & $524 \mathrm{~T}>\mathrm{A} / 524 \mathrm{~T}>\mathrm{A}$ & L175Q/L175Q & $282 \mu \mathrm{mol} / 1$ \\
\hline Case D2 (F) & $(\mathrm{TA})_{7} \mathrm{TAA} /(\mathrm{TA})_{7} \mathrm{TAA}$ & $524 \mathrm{~T}>\mathrm{A} / 524 \mathrm{~T}>\mathrm{A}$ & $\mathrm{L} 175 \mathrm{Q} / \mathrm{L} 175 \mathrm{Q}$ & $203 \mu \mathrm{mol} / 1$ \\
\hline Father & $(\mathrm{TA})_{7} \mathrm{TAA} /(\mathrm{TA})_{7} \mathrm{TAA}$ & $524 \mathrm{~T}>\mathrm{A} /$ normal & L175Q/normal & $60 \mu \mathrm{mol} / 1$ \\
\hline
\end{tabular}

${ }^{\star}$ Represents peak serum bilirubin levels. 


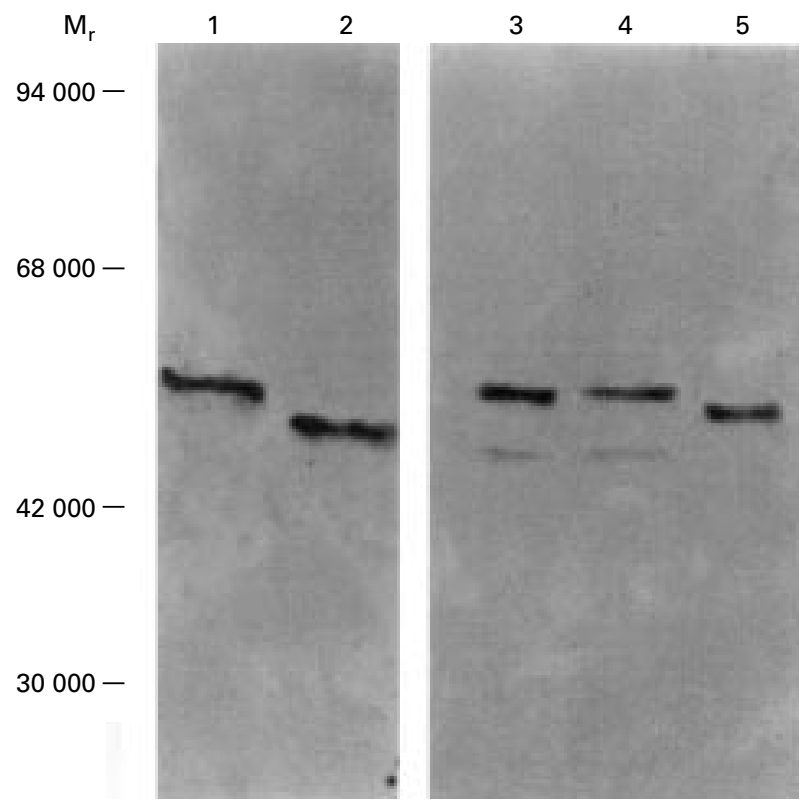

Figure 1 Western blot analysis. The mutations detected in two of the four families, $1490 T>A$ (family $B$ ) and $1452 G>A$ (family $C$ ), were introduced in the plasmid pSVK3-UGT1A1 (see text). The mutated and normal UGT1A1 cDNAs were subcloned into pcDNA3.1/Zeo(+) (see text) and transfected into COS cells. The lysate of the cells were checked for the synthesis of UGT1A1 by western blotting as described in the text. Lanes 1, 3, and 4 represent normal UGT1A1 $(53 \mathrm{kDa})$. Lanes 2 and 5 are the mutated forms of the protein synthesised from UGT1A1 cDNAs carrying the mutations $1452 G>A$ and $1490 T>A$, respectively. In both cases, $1452 G>A$ and $1490 T>A$, the protein is truncated at its $C$-terminal end by 52 and 37 amino acids respectively. These mutant forms of the protein migrated faster than their normal counterpart corresponding to their respective truncations.

levels and the patient is currently being treated with phototherapy. A diagnosis of $\mathrm{CN} 1$ was made. The parents of the infant are first cousins and the father has normal bilirubin levels. The mother had a history of prolonged neonatal hyperbilirubinaemia. Her recent serum bilirubin level was $51.3 \mu \mathrm{mol} / 1$. Several other relatives of the proband have noticed intermittent yellow discolouration of the sclera, but these samples were not available for genetic analysis. The proband was homozygous for a $1452 \mathrm{G}>\mathrm{A}$ mutation in exon 5, which predicts the truncation of UGT1A1 at Trp484. As for family $\mathrm{B}$, this was confirmed by Western blot analysis of the expressed mutagenised UGT1A1 (fig 1). The expressed truncated UGT1A1 was catalytically inactive. The father, who was heterozygous for the structural mutation, but had normal UGT1A1 TATAA elements, had normal serum bilirubin levels. In contrast, the mother, who was also heterozygous for the $1452 \mathrm{G}>\mathrm{A}$ mutation, but carried a Gilbert-type TATAA element on the structurally normal allele, was hyperbilirubinaemic $(51 \mu \mathrm{mol} / \mathrm{l})$.

Family D. Two sisters and their father were studied from this family. One of the sisters had been included in the original study in 1962 describing CN2 as an entity distinct from $\mathrm{CN} 1{ }^{2}$ This patient has had predominantly unconjugated hyperbilirubinaemia since birth, averaging $282 \mu \mathrm{mol} / \mathrm{l}$. Serum bilirubin concentrations were reduced by $80 \%$ after administration of phenobarbital. The sister of this case, who was also studied, had a serum unconjugated bilirubin level of $203.5 \mu \mathrm{mol} / 1$. The father was also hyperbilirubinaemic with serum bilirubin levels of $60 \mu \mathrm{mol} / 1$. Both sisters were homozygous for the Gilbert-type promoter and also for a 524T $>\mathrm{A}$ mutation that predicted the substitution of leucine by glutamine at amino acid residue 175 . The father was homozygous for the Gilbert-type promoter and heterozygous for the $524 \mathrm{~T}>\mathrm{A}$ mutation. We had previously determined the effect of the 524T >A mutation (L175Q, family D), which reduced the UGT1A1 activity towards bilirubin to approximately $38 \%$ of normal. ${ }^{17}$

The findings in the four families described here are examples of the effect of coexistence of a structural mutation of UGT1A1 with a Gilbert-type promoter abnormality. In families $\mathrm{A}$ and $\mathrm{B}$, the fathers of the probands had a normal TATAA element in the promoter on both alleles of UGT1A1 and were heterozygous for a structural mutation that predicted (in family A) or was shown (in family B) to truncate and completely inactivate UGT1A1. Consistent with the recessive inheritance of $\mathrm{CN} 1$, these heterozygous carriers did not have hyperbilirubinaemia. The mothers in both these families were heterozygous for the Gilbert-type promoter, but the $U G T 1 A 1$ coding regions were structurally normal. In these women also, serum bilirubin levels were normal, which is consistent with recessive inheritance of Gilbert's syndrome. In contrast, the twin infants in family A and the two children in family B who inherited the Gilbert-type promoter abnormality from their mothers and the structural lesions from their fathers were hyperbilirubinaemic. The presence of the Gilbert-type promoter on the structurally normal UGT1A1 allele resulted in hyperbilirubinaemia in the children. In family $\mathrm{C}$, the mother of the affected child with $\mathrm{CN} 1$ was heterozygous for the $1452 \mathrm{G}>\mathrm{A}$ mutation (which was shown to truncate and inactivate UGT1A1) and carried a Gilbert-type TATAA element on the structurally normal allele. Since heterozygosity for the variant promoter or the CN1 type mutation does not cause hyperbilirubinaemia by itself, the increased serum bilirubin levels in the mother again illustrates the effect of interaction of the Gilbert-type promoter and coding region lesions.

In family $\mathrm{D}$, the two sisters studied were homozygous for both the Gilbert-type TATAA element and the structural region abnormality (L175Q), which reduces the UGT1A1 catalytic activity to $38 \%{ }^{17}$ This level of residual UGT1A1 activity is similar to that seen in subjects with Gilbert syndrome and, therefore, does not explain the relatively high level of hyperbilirubinaemia seen in these sisters. Because the observed bilirubin levels cannot be accounted for by either the structural mutation or the Gilbert-type promoter alone, these cases show that the reduced expression of the mutated UGT1A1 owing to the presence of a Gilbert-type promoter results in a more severe phenotype, where the expressed enzyme has some residual catalytic activity. In the father, the Gilbert-type promoter on both alleles and a heterozygous 524T $>$ A mutation caused mild hyperbilirubinaemia (serum bilirubin $60 \mu \mathrm{mol} / \mathrm{l}$ ). Such mild hyperbilirubinaemia would be compatible with the promoter defect alone, but might have been accentuated by the coexistence of the structural mutation.

Promoter reporter studies indicate that the Gilbert-type promoter reduces the expression of UGT1A1 to $20-30 \%$ of normal. ${ }^{18}$ In cases where one allele produces nonfunctional UGT1A1 and the expression of the only structurally normal allele is reduced because of the presence of the variant promoter, the residual UGT1A1 activity can be calculated to be only $10-15 \%$ of normal. The resulting hyperbilirubinaemia is expected to be more severe than that found in Gilbert's syndrome, but less severe than that seen in Crigler-Najjar syndrome type 1 . These considerations and our observed results differ from the conclusion of Ciotti et $a l^{29}$ that the presence of a Gilbert-type promoter on one allele and a CN1 type mutation on the other allele leads to a CN1 phenotype.

Depending on the nature and location of a mutation, amino acid substitutions can lead to a wide range of serum bilirubin concentrations. At one end of the spectrum, there may be only a small reduction of the catalytic activity of UGT1A1, resulting in unconjugated hyperbilirubinaemia which is mild enough to be compatible with the diagnosis of 
Gilbert syndrome. At the other end are those that cause the most severe forms of $\mathrm{CN} 2$ and $\mathrm{CN} 1$. In any case, the coexistence of a Gilbert-type promoter, either on the allele bearing the CN-type mutation or on the structurally normal allele (in the case of a heterozygous mutation), can further aggravate the UGT1A1 deficiency. It should be noted, however, that serum bilirubin levels depend not only on the residual UGT1A1 activity, but also on other factors, such as the rate of bilirubin production. This may explain the strong sex difference in the phenotypic expression of Gilbert's syndrome. The majority of females who are homozygous for the Gilbert-type TATAA element do not have clinical hyperbilirubinaemia, probably because of a lower bilirubin load. ${ }^{23}$ Consistent with this, the mother in family $\mathrm{C}$ had a relatively mild hyperbilirubinaemia $(51.3 \mu \mathrm{mol} / \mathrm{l})$, despite the presence of an inactivating genetic lesion on one allele and a Gilberttype promoter on the other. The gender effect is also apparent from the data on family B. Although the proband and his sister had identical compound heterozygosity, the sister had lower serum bilirubin levels (table 1). In addition to gender, other known or unknown variables, superimposed on the UGT1A1 genotype, can affect serum bilirubin concentrations. For example, reduced UGT1A1 activity, in combination with a high bilirubin load, can result in higher levels of hyperbilirubinaemia. In the twins in family $\mathrm{A}$, the increased bilirubin load because of $\mathrm{ABO}$ incompatibility and the resulting haemolysis led to marked exaggeration of neonatal hyperbilirubinaemia $(\sim 428 \mu \mathrm{mol} / \mathrm{l})$. After cessation of haemolysis and initiation of phenobarbital therapy serum bilirubin levels stabilised at 136-171 $\mu \mathrm{mol} / 1$. Unfortunately, however, permanent brain damage had already occurred in the affected infants. This case exemplifies the importance of compounding of heterozygosity for a structural mutation with the Gilbert-type TATAA element in the promoter of the structurally normal allele. Because of the very high incidence of Gilbert's syndrome in the general population, the possibility of compound heterozygosity for a structural mutation and the Gilbert-type of TATAA element in the promoter should be considered even if only one of the parents has a family history of inherited jaundice.

Based on a gene frequency of 0.3 for the Gilbert-type promoter, as found in several studies in Europe and the USA, ${ }^{18}{ }^{20-22} 9 \%$ of the general population would be homozygous and $42 \%$ would be heterozygous for the variant promoter. Thus, approximately $51 \%$ of the general population carry a Gilbert-type promoter on at least one allele. Therefore, heterozygous carriers of a structural mutation of UGT1A1 (CN1 or CN2 type) have a relatively high probability of carrying a Gilbert-type promoter on the normal allele. This explains the long standing observation that members of families of patients with $\mathrm{CN}$ often exhibit intermediate grades of hyperbilirubinaemia. Although the exact incidence of $\mathrm{CN}$ is not known, it appears to be less than one in a million, indicating that the gene frequency is less than $1: 1000$. Based on the gene frequency for the Gilbert-type promoter and that of the structural mutations, compound heterozygosity for a Gilbert-type promoter and CN-type genetic lesion can be calculated to be over 300 times more common than is homozygosity for a structural region mutation. Consistent with this, in our analysis of over 100 cases of intermediate levels of unconjugated hyperbilirubinaemia (persistently between $51 \mu \mathrm{mol} / 1$ and $308 \mu \mathrm{mol} / \mathrm{l}$ ) in whom the clinical history was clearly known, we identified the eight cases reported here, in whom an interaction between the Gilbert-type promoter and the structural region mutation was thought to be the cause of jaundice. In only one other case (not included in this paper) was homozygosity for a structural mutation, in the absence of a promoter mutation, the basis of the intermediate level hyperbilirubinaemia. These findings are different from those reported in a
Japanese population by Yamamoto et $a l .^{30}$ In that report, homozygosity or compound heterozygosity for structural region mutations was the cause of jaundice in six cases and in only one case hyperbilirubinaemia was caused by the interaction of a Gilbert-type promoter and a structural region mutation. One possible explanation for the difference in results is that the incidence of the longer TATAA element (A(TA)7TAA) is much lower (gene frequency 0.11) in Japan than in the white or black populations (gene frequency 0.30).${ }^{24-26}$ Furthermore, structural mutations causing mild hyperbilirubinaemia appear to be much more common in Japan. $^{25} 34{ }^{35}$ In the American population, however, coexistence of a Gilbert-type promoter and a mutation in the structural region of the UGT1A1 gene appears to be a much more common cause of intermediate grades of hyperbilirubinaemia than homozygosity for a mutation in the coding sequences of the gene. The routine use of intense phototherapy has permitted an increasing number of patients with $\mathrm{CN} 1$ or $\mathrm{CN} 2$ to survive to ages where pregnancy becomes an option. These patients ask for genetic counselling regarding the probability of inherited jaundice in their offspring and the risk of kernicterus in the newborn period. Our results indicate that both the structural mutation and the promoter genotype of the parents should be taken into account in providing the genetic counselling.

Electronic database Information: GenBank-http://www.ncbi.nlm.nih.gov/ genbank, Online Mendelian Inheritance in man (OMIM)-http:// genbank, Online Mendelian Inheritance in man (OMIM)-http://
www.ncbi.nlm.nih.gov/omim, wbrf.georgetown.edu/

This work was supp

This work was supported in part by the following NIH grants: DK 39137 (to NRC), DK 46057 (to JRC), Liver Research Core Center (P30-DK 41296, PI, D A Shafritz), 1M01 RR12248-04 (to General Clinical Research Center, PI, D P Purpura). BALJIT S SAPPAL * SIDDHARTHA S GHOSH* MARK LOWENHEIM+ ABHIJIT CHOWDHURY SUJIT CHOWDHURY $\ddagger$ AMAL SANTRA IRWIN M ARIAS\$ JAYANTA ROY CHOWDHURY* NAMITA ROY CHOWDHURY*

${ }^{\star}$ Departments of Medicine and Molecular Genetics, and Marion Bessin Liver Research Center, Albert Einstein College of Medicine, Bronx, NY, USA

†Department of Pediatrics, Division of Pediatric Gastroenterology, Health Science Center, Children's Medical Center at Stony Brook, Stony Brook, NY, USA

$\ddagger$ Institute of Postgraduate Medical Education and Research, Calcutta, India

\Departments of Physiology and Medicine, Tufts University School of Medicine, Boston, MA, USA

Correspondence to Dr N Roy Chowdhury, chowdhur@aecom.yu.edu

1 Crigler JF, Najjar VA. Congenital familial non-hemolytic jaundice with kernicterus. Pediatrics 1952;10:169-80.

Arias IM. Chronic unconjugated hyperbilirubinemia without overt signs of hemolysis in adolescents and adults. F Clin Invest 1962;41:2233-45.

3 Gilbert A, Lereboullet P. La cholemae simple familiale. Semin Med 1901;21: 241.

4 Jansen PLM, Bosma PJ, Roy Chowdhury J. Molecular biology of bilirubin metabolism. In: Boyer JL, Ockner RK, eds Progress in liver diseases. Philadelphia: WB Saunders, 1995:125-50.

5 Childs B, Sidbury JB, Migeon CJ. Glucuronic acid conjugation by patients with familial non-hemolytic jaundice and their relatives. Pediatrics 1959;23: 903 .

6 Wolkoff AW, Roy Chowdhury J, Gartner LA, Rose AL, Biempica L, Giblin DR, Fink D, Arias IM. Crigler-Najjar syndrome (type I) in an adult male. Gastroenterology 1979;76:840-8.

7 Blaschke TF, Berk PD, Scharschmidt BF, Guyther JR, Vergalla J, Waggoner JG. Crigler-Najiar syndrome: an unusual course with development of neurologic damage at age eighteen. Pediatr Res 1974;8:573.

8 Fox IJ, Roy Chowdhury J, Kaufman SS, Goertzen TC, Roy Chowdhury N, Warkentin PI, Dorko K, Sauter BV, Strom SC. Treatment of Crigler-Najijar syndrome type I with hepatocyte transplantation. N Engl f Med 1998;338: 1422-6.

9 Roy Chowdhury J, Roy Chowdhury N, Strom SC, Kaufman SS, Horlsen S, Fox IJ. Human hepatocyte transplantation: gene therapy and more? Pediat rics 1998; 102:647-8.

10 Sokal EM, Silva ES, Hermans D, Redding R, De Ville de, Goyet J, Ruts JP, Otte JB. Orthotopic liver transplantation for Crigler-Najjar type I disease in six children. Transplantation 1995;60:1095-8.

11 Van der Veere CN, Sinaasappel M, McDonagh AF, Rosenthal P, Labrune P, Odievre M, Fevery J, Otte JB, McClean P, Heller K, Wilson JP, Shepherd $\mathrm{R}$, Jansen PL. Current therapy for Crigler-Najiar syndrome type 1: report of a world registry. Hepatology 1996;24:311-15. 
12 Ritter JK, Chen F, Sheen YY, Tran HM, Kimura S, Yeatman MT, Owens IS. A novel complex locus, UGT1, encodes human bilirubin, phenol and other ADP-glucuronosyltransferase isoenzymes with identical carboxytermini. $\mathcal{f}$ Biol Chem 1992;267:3257-61.

13 Van Es HHG, Bout A, Liu J, Anderson L, Duncan AMV, Bosma P, Oude Elferink RPJ, Jansen PLM, Roy Chowdhury J, Schurr E. Assignment of the human UDP-glucuronosyltransferase gene (UGT1A1) to the chromosome region 2q37. Cytogenet Cell Genet 1993;63:114-16.

14 Bosma PJ, Roy Chowdhury N, Goldhoorn BG, Hofker MH, Oude Elferink RPJ, Jansen PLM, Roy Chowdhury J. Sequence of exons and flanking regions of human bilirubin UDP-glucuronosyltransferase gene complex and identification of a genetic mutation in a patient with Crigler-Najiar syndrome, type I. Hepatology 1992;15:941-7.

15 Kadakol A, Ghosh SS, Sappal BS, Sharma G, Roy Chowdhury J, Roy Chowdhury N. Genetic lesions of bilirubin uridinediphosphoglucuronate glucuronosyltransferase causing Crigler-Naijar and Gilbert's syndromes: correlation of genotype to phenotype. Hum Mutat 2000;16:297-306.

16 Gantla S, Bakker CTM, Deocharan B, Thumala NR, Zweiner J, Sinaasappel M, Roy Chowdhury J, Roy Chowdhury N. Splice-site mutations: a pel M, Roy Chowdhury J, Roy Chowdhury N. Splice-site mutations: a Genet 1998;62:585-92.

17 Seppen J, Bosma PJ, Goldhoorn BG, Bakker CTM, Roy Chowdhury J, Roy Chowdhury N, Jansen PLM, Oude Elferink RPJ. Discrimination between Crigler-Najiar type I and II by expression of mutant bilirubin uridine diphosphate-glucuronosyltransferase. F Clin Invest 1994;94:2385-91.

8 Bosma PJ, Roy Chowdhury J, Bakker C, Gantla S, DeBoer A, Oostra BA, Lindhout D, Tytgat GNJ, Jansen PLM, Oude Elferink RPJ, Roy Chowdhury N. A sequence abnormality in the promoter region results in reduced expression of bilirubin-UDP-glucuronosyltransferase-1 in Gilbert's syndrome. N Engl f Med 1995;333:1171-5.

19 Beutler E, Gelbart T, Demina A. Racial variability in the UDPglucuronosyltransferase 1 (UGT1A1) promoter: a balanced polymorphism for regulation of bilirubin metabolism? Proc Natl Acad Sci USA 1998;95:8170-4

20 Monaghan G, Ryan M, Seddon R, Hume R, Burchell B. Genetic variation in bilirubin UDP-glucuronosyltransferase gene promoter and Gilbert's in bilirubin

21 Tsezou A, Tseti M, Kitsiou S. Genotype analysis and correlation phenotype in children. Pediatriki 2000;63:21-6.

22 Sampietro M, Lupica L, Perrero L, Romano R, Molteni V, Fiorelli G. TATA-box mutant in the promoter of the uridine diphosphate glucuronosyltransferase gene in Italian patients with Gilbert's syndrome. Ital $\mathcal{F}$ Gastroenterol Hepatol 1998;30:194-8.
23 Powell LW, Billing BH, Williams HS. The assessment of red cell survival in idiopathic unconjugated hyperbilirubinaemia (Gilbert's syndrome) by the use of radioactive diisopropylfluorophosphate and chromium. Aust Ann Med 1967;16:221-5.

24 Koiwai O, Nishizawa M, Hasada K, Aono S, Adachi Y, Mamiya N, Sato H. Gilbert's syndrome is caused by a heterozygous missense mutation in the gene for bilirubin UDP-glucuronosyltransferase. Hum Mol Genet 1995;4: 1183-6.

25 Aono S, Adachi, Y, Uyama, E, Yamada Y, Keino H, Nanno T, Koiwai O, Sato $\mathrm{H}$. Analysis of genes for bilirubin UDP-glucuronosyltransferase in Gilbert's syndrome. Lancet 1995;345:958.

26 Akaba K, Kimura T, Sasaki A, Tanabe S, Wakabayashi T, Hiroi M, Yasumura S, Maki K, Aikawa S, Hayasaka K. Neonatal hyperbilirubinemia and a common mutation of the bilirubin uridine diphosphateglucuronosyltransferase gene. Fpn f Hum Genet 1999;44:22-5.

27 Hunter JO, Thompson RPH, Dunn PM, Williams R. Inheritance of type II Crigler-Naijar hyperbilirubinemia. Gut 1973;14:46-9.

28 Chalasani N, Roy Chowdhury N, Roy Chowdhury J, Boyer TD. Kernicterus in an adult who is heterozygous for Crigler-Najjar syndrome and homozygous for Gilbert-type genetic defect. Gastroenterology 1997;112: homozygo $2099-103$.

29 Ciotti M, Chen F, Rubatelli FF, Owens IS. Coding and a TATA box mutation at the bilirubin UDP-glucuronosyl transferase gene cause CriglerNajjar syndrome type 1 disease. Biochim Biophys Acta 1998;1407:40-50.

30 Yamamoto K, Soeda Y, Kamisako T, Hosaka H, Fukano M, Sato H, Fujiyama Y, Adachi Y, Satoh Y, Bamba T. Analysis of bilirubin uridine 5'diphosphate (UDP)-glucuronosyltransferase gene mutations in seven patients with Crigler-Najiar syndrome type II. F Hum Genet 1998;43:111-14.

31 Sanger F, Nicklen S, Coulson AR. DNA sequencing with chain-terminating inhibitors. Proc Natl Acad Sci USA 1977;74:5463-7.

32 Bradford MM. A rapid and sensitive method for the quantification of microgram quantities of protein utilizing the principle of protein dye binding. Anal Biochem 1976;72:248-54.

33 Roy Chowdhury J, Roy Chowdhury N, Wu G, Shouval R, Arias IM. Bilirubin monoglucuronide and diglucuronide formation by human liver in vitro: Assay by high pressure liquid chromatography. Hepatology 1981;1: 622-7.

34 Maruo Y, Sato H, Yamano T, Doida Y, Shimada S. Gilbert's syndrome caused by homozygous missense mutation (Tyr486Asp) of bilirubin-UDP glucuronosyl transferase. F Pediatr 1998;132:1045-7.

35 Soeda Y, Yamamoto K, Adachi Y, Hori T, Aono S, Koiwai O, Sato H. Predicted homozygous missense mutation in Gilbert's syndrome. Lancet 1995; 346:1494.

\section{Identification of two novel mutations in the $C A C N A 1 A$ gene responsible for episodic ataxia type 2}

EDITOR-Episodic ataxia type 2 (EA-2) (OMIM 108500) is an autosomal dominant neurological disorder. Affected subjects experience discrete episodes of cerebellar ataxia usually associated with migraine symptoms, interictal nystagmus, as well as residual mild and, in some cases, a progressive cerebellar incoordination. These attacks usually begin in childhood or adolescence, last a few hours, may be precipitated by stress, exercise, or fatigue, and respond to acetazolamide. ${ }^{1-3}$

As with other acetazolamide responsive diseases, EA-2 is a channelopathy. ${ }^{4}$ It was first linked to chromosome $19 \mathrm{p} 13^{35-7}$ and subsequently shown to be allelic to familial hemiplegic migraine (FHM) when mutations for both disorders were identified in the P/Q type calcium channel $\alpha_{1 \mathrm{~A}}$ subunit gene, $C A C N A 1 A .{ }^{8}$ Shortly thereafter, an intragenic expansion of a CAG repeat within $C A C N A 1 A$ was shown to cause spinocerebellar ataxia type 6 (SCA6). ${ }^{9}$ To date, mutations causing EA-2 all appear to disrupt the translational reading frame of the $\alpha_{1 \mathrm{~A}}$ subunit gene, ${ }^{8}{ }^{10-12}$ while those causing FHM all seem to be missense mutations. ${ }^{813-15} \mathrm{~A}$ single missense mutation, however, in the $C A C N A 1 A$ gene has also been shown to cause severe progressive cerebellar ataxia. ${ }^{16}$

The $\alpha_{1 \mathrm{~A}}$ subunit has been shown to be the pore forming unit of the $\mathrm{P} / \mathrm{Q}$ type calcium channel ${ }^{17}{ }^{18}$ which is involved in controlling neurotransmitter release ${ }^{19}$ and is expressed throughout the brain with abundant expression in the cerebellum..$^{20-22}$ This high voltage activated calcium channel consists of five subunits, $\alpha_{1 \mathrm{~A}}, \beta_{4}, \alpha_{2}, \delta$, and $\gamma$. The $\alpha_{1 \mathrm{~A}}$ subunit is subdivided into four homologous domains (DIDIV) that each contain six putative transmembrane regions (S1-S6) (fig 1). ${ }^{19}$ The fourth transmembrane domain functions as the voltage sensor while the four loops between transmembrane domains S5-S6 compose the pore forming unit. Thus, the $\alpha_{1 \mathrm{~A}}$ subunit of the P/Q type calcium channel is responsible for directing channel activity, while the other subunits appear to act as auxiliary regulators of the channel. ${ }^{19} 23$

Here, we describe two novel mutations in the $C A C N A 1 A$ gene that cause EA-2: a guanine insertion after nucleotide 3091 (insG3091) that is the first mutation identified to occur in an intracellular loop and a guanine deletion at nucleotide 5123 (delG5123) representing the most 3' mutation reported to date. Similar to previously reported EA-2 mutations, these nucleotide changes disrupt the $C A C N A 1 A$ translational reading frame and are predicted to result in proteins which prematurely truncate after domain I.

Blood samples were obtained with informed consent from 81 subjects: an apparently sporadic case of EA-2 and her sib, 29 members of a family segregating EA-2, and 50 unrelated, healthy controls. Genomic DNA was extracted from the blood samples using standard techniques. Probands were assessed to have EA-2 by a clinical neurologist and were referred for study.

Single stranded conformational polymorphism (SSCP) analysis was used to screen polymerase chain reaction (PCR) products of exons in the CACNA1A gene for molecular variants. ${ }^{24} 25$ Published primers $^{816}$ and redesigned primers (table 1 ) were used to amplify all 47 exons from the intronic sequences flanking each exon. PCR amplification conditions were optimised for each primer pair and the products were labelled by incorporation of $\left[\alpha-{ }^{32} \mathrm{P}\right] \mathrm{dCTP}$ into the amplification reaction. The labelled 


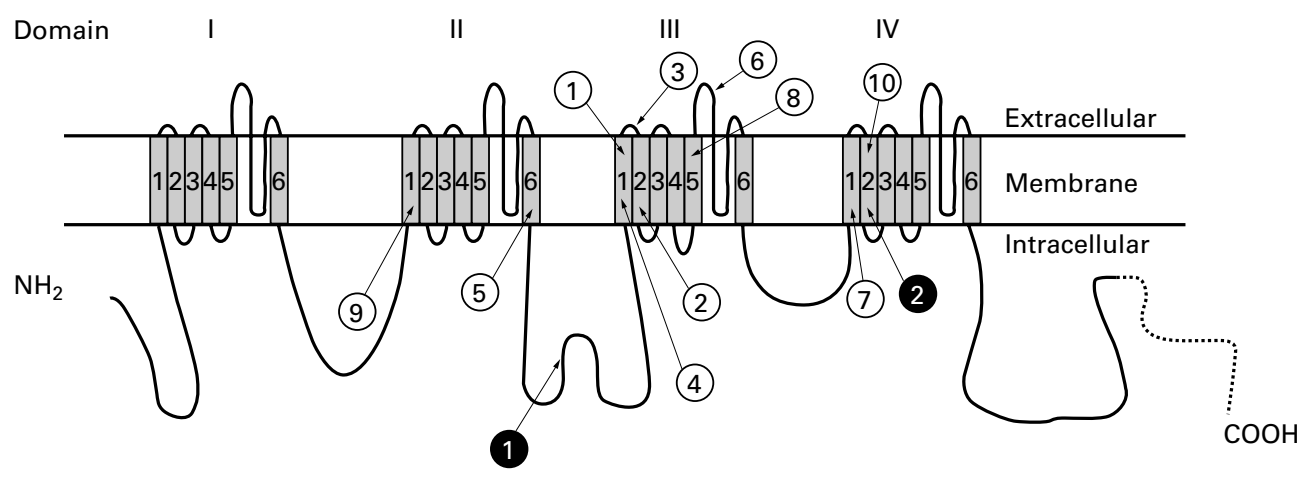
(1) C deletion
(6) Tyr 1443 stop
(1) G insertion
(2) Splice mutation
(7) Arg 1547 stop
(2) G deletion
(3) Arg 1279 stop
(8) Splice mutation
(4) C deletion
(9) Splice mutation
(5) AG deletion
(10) CTT deletion

Figure 1 Schematic diagram of the $P / Q$ type calcium channel $a_{1 A}$ subunit illustrating the location of EA-2 mutations. The two EA-2 causing mutations identified in this study are represented in black. The 10 previously reported EA-2 causing mutations ${ }^{810-12}$ are in white.

PCR product was diluted with $50 \mu$ loading dye (98\% formamide, $10 \mathrm{mmol} / 1$ EDTA, $0.1 \%$ bromophenol blue, $0.1 \%$ xylene cyanol $\mathrm{FF}$ ) and denatured at $95^{\circ} \mathrm{C}$ for five minutes. An aliquot of the denatured PCR product was then loaded immediately onto a non-denaturing gel $(55 \mathrm{~cm} \times 30 \mathrm{~cm})$ consisting of $7.5 \%$ acrylamide (49:1 acrylamide:bisacrylamide) and $0.5 \times$ TBE. Gel electrophoresis was performed at $4^{\circ} \mathrm{C}$ and $50 \mathrm{~W}$. Gels were transferred to filter paper and exposed to $x$ ray film (AGFA Curix Ortho HT-G Ecopac) at $-80^{\circ} \mathrm{C}$ overnight. Abnormally migrating conformers were detected by visual inspection.

PCR products were initially gel purified using GFX PCR DNA and Gel Band Purification Kit (Amersham Pharmacia Biotech). DNA sequence analysis of the purified PCR products was then performed manually using the Thermo Sequenase Cycle Sequencing Kit (Amersham Pharmacia Biotech) according to the manufacturer's recommended conditions. Denatured sequencing reactions were immediately loaded and electrophoresed through a $6 \%$ acrylamide gel (SequaGel-6, National Diagnostics). Sequencing gels were exposed to $x$ ray film (AGFA Curix Ortho HT-G Ecopac) for 18 hours at $-80^{\circ} \mathrm{C}$ and autoradiographs were examined for sequence changes. All nucleotide, codon, and exon numbering corresponds to GenBank accession number X99897 (http://www.ncbi.nlm.nih.gov/).

Allele specific oligonucleotide hybridisation (ASOH) was performed to look for segregation of mutations in a family and to rule out the possibility that these mutations are common polymorphisms. Exon 30 was amplified from $200 \mathrm{ng}$ of genomic DNA from case 1, her sib, and 50 normal controls. Exon 19b was amplified from $200 \mathrm{ng}$ of

Table 1 Redesigned primers for SSCP analysis of the CACNA1A gene

\begin{tabular}{lll}
\hline Exon & Forward primer & Reverse primer \\
\hline 14 & cag aaa gtt ggg aaa gtg agc & Same as ref 8 \\
19 a & atc cat cca agc tac agt gc & ctt gtt ggt gtt gtt gtt gc \\
22 & ctg aac ctg cgc tac ttt gag atg t & atc cca ccc tac cta tga gca ttt t \\
23 & Same as ref 8 & tgt gtt ctc act tat aat ctg c \\
24 & gag agg cta gag agt ggg tgg cag c & caa gag gaa acc ctt gcg aag aga c \\
28 & tct ccc tgc ccc att cct tg & agt ttt taa agg aca gat gg \\
29 & Same as ref 8 & ttt atc agg gta gag gca gg \\
30 & gac ccc tgc tac tcc tgc ttc & ttc caa gcc cat agc tgt agc \\
31 & cct ctg ttg gca tct ctg tc & ttc tcc ctc tct ggt cat gg \\
42 & ttc tgg aag ctg ccc aag cg & ttc ctt cca ccg caa cca cc \\
44 & tct gtg tgc acc atc cat g & Same as ref 8 \\
45 & ctt ggt gct agc tgc tga c & Same as ref 8 \\
\hline
\end{tabular}

genomic DNA from patient IV.7 (case 2), 28 of his family members, and 50 normal controls. PCR products were electrophoresed through $1.5 \%$ agarose gels and transferred onto Hybond-N membranes (Amersham Pharmacia Biotech) for three hours under denaturing conditions $(0.5 \mathrm{~N}$ $\mathrm{NaOH}, 1.5 \mathrm{~mol} / 1 \mathrm{NaCl})$. The blots were then neutralised ( $1 \mathrm{~mol} / \mathrm{l}$ Tris-Cl, $\mathrm{pH} 7.5,1.5 \mathrm{~mol} / \mathrm{l} \mathrm{NaCl}$ ) and the DNA was UV cross linked to the membranes. Membranes were prehybridised $(5 \times$ SSPE, $5 \times$ Denhardt's, and $1 \%$ SDS $)$ for 30 minutes and the respective blots were then probed for one hour with either wild type exon 30 ASO (5' TGGAATGTGTGCTGAAAG - 3') at $52^{\circ} \mathrm{C}$, mutant exon 30 ASO (5' - TGGAATGTGTGCTAAAG - 3') at $48^{\circ} \mathrm{C}$, wild type exon 19 ASO (5' - CGGCAGGGGGGCAG $\mathrm{CAG}-3^{\prime}$ ) at $62^{\circ} \mathrm{C}$, or mutant exon 19 ASO (5' CGGCAGGGGGGGCAGCAG - 3') at $66^{\circ} \mathrm{C}$. Oligonucleotides were end labelled using $\mathrm{T} 4$ polynucleotide kinase (New England Biolabs) and $\left[\gamma-{ }^{32} \mathrm{P}\right] \mathrm{ATP}$. Unincorporated phosphates were removed with a G-25 Sephadex spin column (Boehringer Mannheim) according to the manufacturer's instructions. The activity of the probes was determined by scintilation counting and $0.6-0.8 \times 10^{6} \mathrm{cpm}$ of denatured probe was added per $\mathrm{ml}$ of hybridisation solution. Membranes were washed twice with $2 \times$ SSPE $/ 0.1 \%$ SDS for 15 minutes at the hybridisation temperature and then exposed to $x$ ray film.

Case 1 is a 43 year old woman who has had episodes of loss of equilibrium and loss of coordination of the limbs, to the point where she may be unable to walk. These episodes were usually precipitated by physical activity or by sudden emotional excitement and lasted for four to five minutes to several hours. On examination she was noted to have horizontal and vertical nystagmus and she complained of diplopia on lateral gaze. She had some incoordination on finger to nose testing and tandem gait was possible. Deep tendon reflexes varied from brisk to sluggish on different examinations. Diamox proved effective in preventing attacks. She was seen originally at the age of 14 when she presented with a five month history of intermittent headaches, double vision, dizziness, and faintness. Family history was negative for episodic ataxia. Both parents are dead, but her sib gave a blood sample for mutation analysis. 
Case 1 was evaluated for a mutation in CACNA1A. SSCP analysis unveiled a unique conformer in exon 30 (fig 2A1, lane 8) which was further evaluated by PCR and direct sequencing. Sequence analysis showed a single guanine deletion at nucleotide position 5123 (codon 1616) in one allele, as illustrated by the start of a double banding pattern on the autoradiograph at this site (fig $2 \mathrm{~B} 1$ ). This deletion disrupts the translational reading frame and alters the subsequent amino acid sequence resulting in the formation of a stop codon at the junction of exons 30 and 31, codon 1624 (fig 2C1). ASOH was then performed using PCR amplified DNA from the patient, her sib, and 50 unrelated controls. The mutant oligonucleotide hybridised with only the patient sample (data not shown).

Case 2 is the proband of a 39 member white family spanning four generations (IV.7, fig 3A). The inheritance pattern is autosomal dominant and the disorder has been previously linked to the EA-2 locus on $19 \mathrm{p} 13 .{ }^{3}$ The proband, aged 29 years, began experiencing episodes at 18 months. Attacks were stereotyped and heralded by lightheadedness and a sense of leg weakness. This was quickly followed by progressive truncal ataxia with an inability to stand or sit unaided. There were striking head titubations and large amplitude dysmetric limb movements. Speech was scanning and markedly dysarthric. Ocular movements were impaired with notable difficulty in initiating volitional saccades, saccadic pursuit, ocular dysmetria, and coarse nystagmus. During an attack, the subject was slow to respond and appeared dazed.

A1
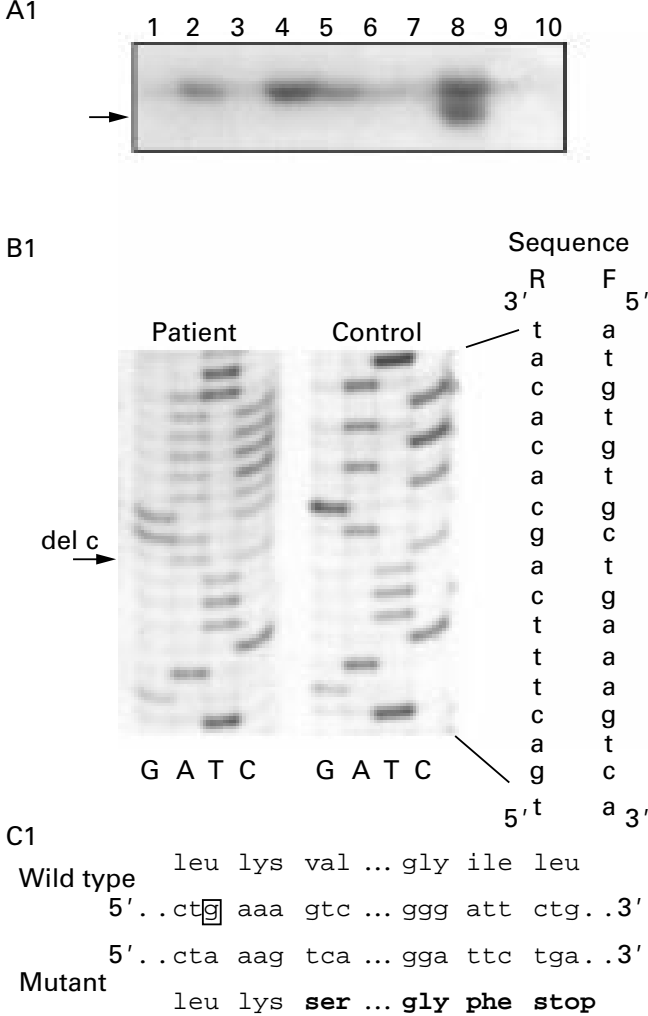

Headache and nausea occasionally developed towards the end of an attack. True vertigo or vomiting was rare. The most consistent precipitating factors were physical and emotional stress. On examination, the patient showed nystagmus on lateral and upward gaze, saccadic pursuit, impaired optokinetic responses, and mild cerebellar limb and gait ataxia.

Exon 19 was shown to contain a number of different conformers that migrate in a very similar pattern (fig 2A2). Exon 19, from patient IV.7 and control samples (fig 2A2, lanes $1,2,5$, and 7 , respectively), each representing a different conformer, was PCR amplified and sequenced. Patient IV.7 was discovered to have a guanine insertion after nucleotide 3091 (codon 939) in one allele, which is shown by the double banding pattern in the sequence starting after base 3091 (fig 2B2). The guanine insertion disrupts the translational reading frame thereby altering downstream amino acids until a premature stop codon is encountered at codon 1067 in the middle of exon 20 (fig 2C2). DNA from 28 family members along with patient IV.7 was subjected to ASOH. All of the affected, and none of the unaffected, subjects carried the guanine insertion after position 3091, showing that the nucleotide insertion cosegregated with the disease phenotype (fig 3A, B). ASOH was also performed using genomic DNA from 50 controls in which none of them hybridised to the mutant allele, indicating that this change was not present in the 100 chromosomes tested (data not shown). DNA sequence

A2
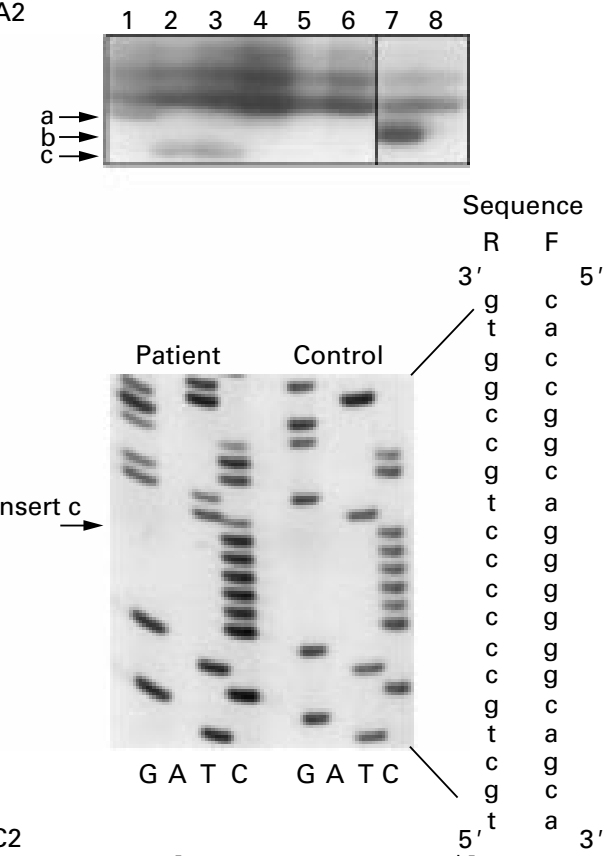

Wild type

gly ser $\arg \ldots$ asp ile asp

$$
5^{\prime} . \text {.ggc agc agg ... gat att gac..3' }
$$$$
\text { Mutant }
$$

Figure 2 Detection of aberrantly migrating conformers (panel $A$ ) and the resultant nucleotide changes (panels $B$ and $C$ ) in the CACNA1A gene. Panel A1: SSCP analysis of exon 30 of the CACNA1A gene showing an aberrantly migrating conformer (arrow) in case 1 with EA-2 (lane 8). Panel A2: a composite of SSCP results of exon 19 of the CACNA1A gene depicting the presence of four different banding patterns. An aberrantly migrating conformer (arrow a) is present in EA-2 patient IV.7 (lane 1). Aberrantly migrating conformers (arrows $b$ and c) in lanes 2, 3, and 7 represent polymorphisms in unrelated subjects. Lanes 4, 5, 6, and 8 represent the wild type banding pattern. Panel B1 and B2: DNA sequence analysis of the reverse strand of exon 30 and exon 19 of the CACNA1A gene displays a cytosine deletion and a cytosine insertion in one allele (arrow) of case 1 and patient IV.7, respectively, which corresponds to a guanine deletion at nucleotide 5123 and a guanine insertion after nucleotide 3091 in the coding strand. DNA sequence from the autoradiograph is given in both the reverse $(R)$ and forward $(F)$ orientations starting at nucleotide 5114 or nucleotide 3078 of the coding strand. Panel C1 and C2: nucleotide and amino acid comparison of wild type and mutant sequences as a result of the guanine deletion at position 5123 and the guanine insertion after position 3091. The guanine deletion and guanine insertion are boxed with the subsequent amino acid changes in bold. 
Table 2 Polymorphisms in exon 19 of the CACNA1A gene

\begin{tabular}{llll}
\hline Location & Sequence change & Consequence & Frequency \\
\hline Exon 19 & 2965 C-G & Pro896Arg & 0.014 \\
Exon 19 & 3029 G-C & Glu917Asp & 0.021 \\
Exon 19 & 3125 G-A & Thr949Thr & 0.146 \\
\hline
\end{tabular}

analysis showed that the other conformers detected in exon 19 were rare polymorphisms in patient DNA samples (table 2).

In the present study, we report the identification of two novel mutations in the $C A C N A 1 A$ gene that are responsible for EA-2, as well as the discovery of three new polymorphisms. These mutations are consistent with those previously published as they alter the translational reading frame of the $\alpha_{1 \mathrm{~A}}$ subunit gene and are predicted to result in the production of truncated proteins (fig 1)..$^{810} 11$

The guanine deletion in exon 30 occurs in domain IV S2 and is predicted to result in the premature truncation of the protein following this transmembrane region. Interestingly, delG5123 represents the most C-terminal mutation published to date. If the mutant allele is translated, we would predict the complete formation of domains I, II, and III.

The guanine insertion in exon 19 is also a unique EA-2 mutation as it represents the first reported mutation to occur in an intracellular loop. The ASOH results for exon 19 showed that the mutation cosegregated with the disease allele in all of the affected family members (7/7). Previous screening of this family failed to detect a mutation in exon 19 , which may have been because of other polymorphic conformers which migrated with similar banding patterns. We were able to decipher the different conformers as three polymorphisms and a mutation by extending the electrophoresis time of the SSCP gels. The need for long migration times for specific exons may partially explain why
SSCP analysis may only detect $85 \%$ of all aberrantly migrating bands. ${ }^{26}$

This single nucleotide insertion in exon 19 occurs at codon 939 between domains II and III and is predicted to change 128 amino acids before forming a truncated protein. The synaptic protein interaction site of the $\alpha_{1 \mathrm{~A}}$ subunit of the $\mathrm{P} / \mathrm{Q}$ type calcium channel encompasses amino acids $722-1036$ within the domain II-III linker. ${ }^{27}$ Thus, the guanine insertion and subsequent shift in the translational reading frame may affect the normal function of the channel, not only through the formation of a truncated protein, but also through the disruption of the direct interaction of the intracellular loop with proteins of the synaptic vesicle docking/fusion machinery as well as altering $G$ protein and protein kinase $C$ dependent modulation. ${ }^{28-30}$ Disruption of these intracellular interactions may contribute to the disease mechanism and could explain subtle differences observed in EA-2 phenotypes. This synaptic protein interaction site is also subject to alternative splicing which may lead to the formation of isoforms with varying functions. ${ }^{19}{ }^{30}$ The guanine insertion mutation will have been translated in some isoforms and spliced out of others, supporting our prediction that a mutation in this region may lead to varying EA-2 phenotypes and as such may explain the very early age of onset in patient IV.7.

To date, all of the known EA-2 mutations are unique and have resulted in premature truncations of CACNA1A beyond domain I. We predict that a truncation mutation in domain I would result in an unstable protein, leading to haploinsufficiency, and not an EA-2 phenotype, whereas a truncation mutation beyond domain I could be expected to produce a stable truncated protein resulting in episodic ataxia. Thus, the severity of the disease is most likely affected by the location of the mutation and the identification of new EA-2 causing mutations is therefore important

A

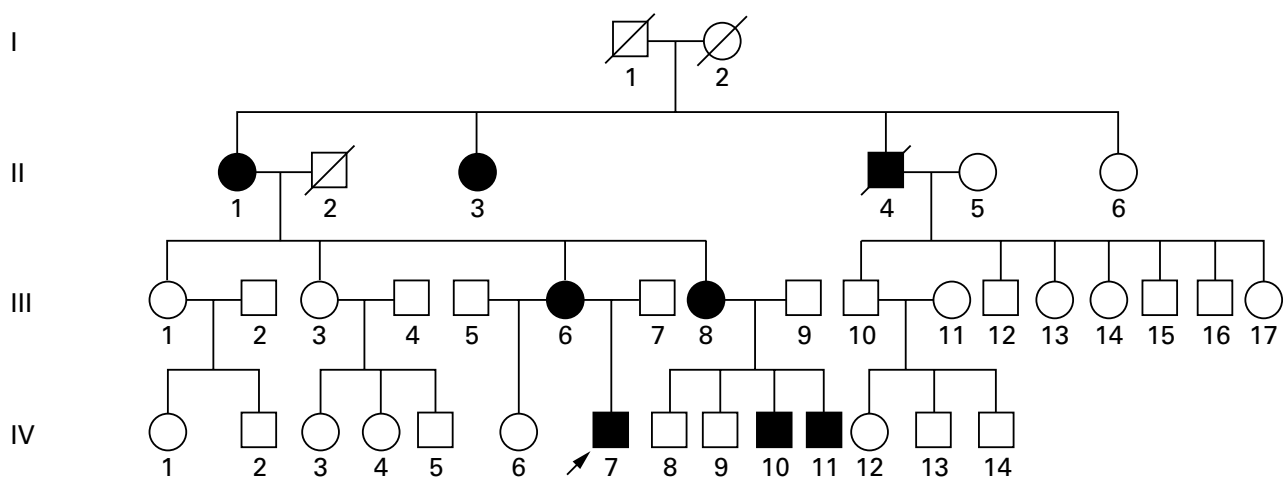

B

Subjects

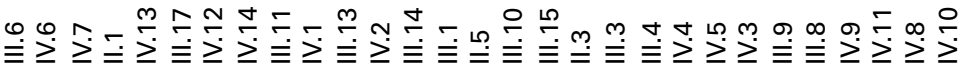

Exon 19 WT probe

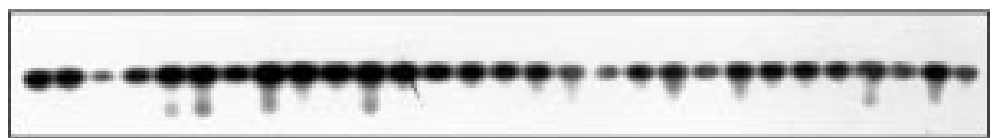

Exon 19 MUT probe

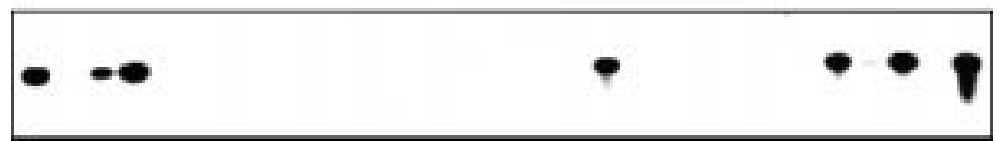

Figure 3 The guanine insertion in exon 19 of the CACNA1A gene cosegregated with all affected family members. Panel A: pedigree of EA-2 segregating kindred where the proband is indicated by an arrow. Panel $B: A S O H$ was performed using a wild type oligonucleotide, which hybridised to DNA from all family members tested, and a mutant oligonucleotide, which only hybridised to DNA from the affected subjects. 
for elucidating the disease mechanism and for providing more accurate disease diagnosis.

The authors would like to thank Sharyll Fyffe and Lemuel Racacho for technical assistance, Dr Jon Stoessl for help with the clinical evaluation of a family cal assistance, Dr Jon Stoess for help with the clinical evaluation of a family member, and Dr R Parks for helpful suggestions. KAS is a recipient of a Medical Research Council of Canada fellowship award. TC is a recipient of a Cana-
dian Genetic Disease Network summer studentship award. DEB is a scholar of dian Genetic Disease Network summer studentship award. DEB is a scholar of
the Medical Research Council of Canada. This research was funded by a grant the Medical Research Council of Canada. This
from the Medical Research Council of Canada.

K A SCOGGAN* T CHANDRA* R NELSON† A F HAHN $\ddagger$

D E BULMAN ${ }^{\star}+$

*Ottawa Hospital Research Institute, 501 Smyth Road, Ottawa Hospital General Campus, Ottawa, Ontario, Canada K1H 8L6

†Division of Neurology, Ottawa Hospital - General Campus, Ottawa, Ontario, Canada K1H 8 L6

$\ddagger$ Department of Clinical Neurological Sciences, London Health Sciences Centre, London, Ontario, Canada N6A 5A5

Correspondence to: Dr Bulman, dbulman@ottawahospital.on.ca

1 Bulman DE. Phenotype variation and newcomers in ion channel disorders. Hum Mol Genet 1997;6:1679-85.

2 Brandt T, Strupp M. Episodic ataxia type 1 and 2 (familial periodic ataxia/ vertigo). Audiol Neurootol 1997;2:373-83.

3 von Brederlow B, Hahn AF, Koopman WJ, Ebers GC, Bulman DE. Mapping the gene for acetazolamide responsive hereditary paroxysmal cerebellar ataxia to chromosome 19p. Hum Mol Genet 1995;4:279-84.

4 Griggs RC, Nutt JG. Episodic ataxias as channelopathies. Ann Neurol 1995; 37:285-7.

5 Teh BT, Silburn P, Lindblad K, Betz R, Boyle R, Schalling M, Larsson C. Familial periodic cerebellar ataxia without myokymia maps to a $19-\mathrm{cM}$ Familial periodic cerebellar ataxia without myokym
region on 19p13. Am ₹ Hum Genet 1995;56:1443-9.

6 Vahedi K, Joutel A, Van Bogaert P, Ducros A, Maciazeck J, Bach JF, Bousser $\mathrm{MG}$, Tournier-Lasserve E. A gene for hereditary paroxysmal cerebellar ataxia maps to chromosome 19p. Ann Neurol 1995;37:289-93.

7 Kramer PL, Yue Q, Gancher ST, Nutt JG, Baloh R, Smith E, Browne D, Bussey K, Lovrien E, Nelson S. A locus for the nystagmus-associated form of episodic ataxia maps to an $11-\mathrm{cM}$ region on chromosome $19 \mathrm{p} . \mathrm{Am} \mathcal{F}$ Hum Genet 1995;57:182-5.

8 Ophoff RA, Terwindt GM, Vergouwe MN, van Eijk R, Oefner PJ, Hoffman SM, Lamerdin JE, Mohrenweiser HW, Bulman DE, Ferrari M, Haan J, Lindhout D, van Ommen GJ, Hofker MH, Ferrari MD, Frants RR. Familial hemiplegic migraine and episodic ataxia type- 2 are caused by mutations in the Ca2+ channel gene CACNL1A4. Cell 1996;87:543-52.

9 Zhuchenko O, Bailey J, Bonnen P, Ashizawa T, Stockton DW, Amos C, Dobyns WB, Subramony SH, Zoghbi HY, Lee CC. Autosomal dominant cerebellar ataxia (SCA6) associated with small polyglutamine expansions in the alpha 1A-voltage-dependent calcium channel. Nat Genet 1997;15:62-9.

0 Yue Q, Jen JC, Thwe MM, Nelson SF, Baloh RW. De novo mutation in CACNA1A caused acetazolamide-responsive episodic ataxia. $\mathrm{Am} \mathcal{F} \mathrm{Med}$ Genet 1998;77:298-301

11 Denier C, Ducros A, Vahedi K, Joutel A, Thierry P, Ritz A, Castelnovo G, Deonna T, Gerard P, Devoize JL, Gayou A, Perrouty B, Soisson T, Autret A, Warter JM, Vighetto A, Van Bogaert P, Alamowitch S, Roullet E, Tournier-Lasserve E. High prevalence of CACNA1A truncations and broader clinical spectrum in episodic ataxia type 2. Neurology 1999;52: 1816-21.
12 Jen J, Yue Q, Nelson SF, Yu H, Litt M, Nutt J, Baloh RW. A novel nonsense mutation in CACNA1A causes episodic ataxia and hemiplegia. Neurology 1999;53:34-7.

13 Ducros A, Denier C, Joutel A, Vahedi K, Michel A, Darcel F, Madigand M, Guerouaou D, Tison F, Julien J, Hirsch E, Chedru F, Bisgard C, Lucotte G, Despres P, Billard C, Barthez MA, Ponsot G, Bousser MG, TournierLasserve E. Recurrence of the T666M calcium channel CACNA1A gene mutation in familial hemiplegic migraine with progressive cerebellar ataxia. Am f Hum Genet 1999;64:89-98.

14 Carrera P, Piatti M, Stenirri S, Grimaldi LM, Marchioni E, Curcio M, Righetti PG, Ferrari M, Gelfi C. Genetic heterogeneity in Italian families with familial hemiplegic migraine. Neurology 1999;53:26-33.

15 Battistini S, Stenirri S, Piatti M, Gelfi C, Righetti PG, Rocchi R, Giannini F, Battistini N, Guazzi GC, Ferrari M, Carrera P. A new CACNA1A gene mutation in acetazolamide-responsive familial hemiplegic migraine and ataxia. Neurology 1999;53:38-43.

16 Yue Q, Jen JC, Nelson SF, Baloh RW. Progressive ataxia due to a missense mutation in a calcium-channel gene. Am f Hum Genet 1997;61:1078-87.

17 Gillard SE, Volsen SG, Smith W, Beattie RE, Bleakman D, Lodge D. Identification of pore-forming subunit of P-type calcium channels: an antisense study on rat cerebellar Purkinje cells in culture. Neuropharmacology 1997;36:405-9.

18 Pinto A, Gillard S, Moss F, Whyte K, Brust P, Williams M, Stauderman K, Harpold M, Lang B, Newsom-Davis J, Bleakman D, Lodge D, Boot J. Human autoantibodies specific for the alpha1A calcium channel subunit reduce both P-type and Q-type calcium currents in cerebellar neurons. Proc Natl Acad Sci USA 1998;95:8328-33.

19 Catterall WA. Structure and function of neuronal $\mathrm{Ca} 2+$ channels and their role in neurotransmitter release. Cell Calcium 1998;24:307-23.

20 Mori Y, Friedrich T, Kim MS, Mikami A, Nakai J, Ruth P, Bosse E, Hofmann F, Flockerzi V, Furuichi T. Primary structure and functional expression from complementary DNA of a brain calcium channel. Nature 1991;350:398-402.

21 Starr TV, Prystay W, Snutch TP. Primary structure of a calcium channel that is highly expressed in the rat cerebellum. Proc Natl Acad Sci USA 1991;88: 5621-5.

22 Westenbroek RE, Sakurai T, Elliott EM, Hell JW, Starr TV, Snutch TP, Catterall WA. Immunochemical identification and subcellular distribution of the alpha 1A subunits of brain calcium channels. 7 Neurosci 1995;15:640318.

23 Catterall WA. Structure and function of voltage-gated ion channels. Annu Rev Biochem 1995;64:493-531.

24 Glavic D, Dean M. Optimization of the single-stranded conformation polymorphism (SSCP) technique for the detection of point mutations. Hum Mutat 1993;2:404-14.

25 Orita M, Suzuki Y, Sekiya T, Hayashi K. Rapid and sensitive detection of point mutations and DNA polymorphisms using the polymerase chain reaction. Genomics 1989;5:874-9.

26 Bassett JH, Forbes SA, Pannett AA, Lloyd SE, Christie PT, Wooding C, Harding B, Besser GM, Edwards CR, Monson JP, Sampson J, Wass JA, Wheeler MH, Thakker RV. Characterization of mutations in patients with multiple endocrine neoplasia type 1. Am f Hum Genet 1998;62:232-44.

27 Rettig J, Sheng ZH, Kim DK, Hodson CD, Snutch TP, Catterall WA. Isoform-specific interaction of the alpha1A subunits of brain $\mathrm{Ca} 2+$ channels with the presynaptic proteins syntaxin and SNAP-25. Proc Natl Acad Sci USA 1996;93:7363-8.

28 Stanley EF, Mirotznik RR. Cleavage of syntaxin prevents G-protein regulation of presynaptic calcium channels. Nature 1997;385:340-3.

29 Yokoyama CT, Sheng ZH, Catterall WA. Phosphorylation of the synaptic protein interaction site on N-type calcium channels inhibits interactions with SNARE proteins. F Neurosci 1997;17:6929-38

30 Zamponi GW, Snutch TP. Modulation of voltage-dependent calcium channels by G proteins. Curr Opin Neurobiol 1998;8:351-6.

\section{Detection of 11 germline inactivating TP53 mutations and absence of TP63 and $H C H K 2$ mutations in 17 French families with Li-Fraumeni or Li-Fraumeni-like syndrome}

EdIToR-The Li-Fraumeni syndrome (LFS) represents one of the most devastating genetic predispositions to cancers. This rare syndrome, affecting children and young adults, is characterised by a wide spectrum of early onset malignancies including bone and soft tissue sarcomas, brain tumours, adrenocortical tumours, and premenopausal breast cancers. ${ }^{1}$ LFS was initially defined using stringent criteria ${ }^{2}$ : (1) a proband with a sarcoma diagnosed before the age of $45,(2)$ a first degree relative with cancer before the age of 45 , and (3) another first or second degree relative with either a sarcoma diagnosed at any age or any cancer diagnosed under the age of 45 . Subsequently, Birch et $a l^{\beta}$ defined Li-Fraumeni-like (LFL) syndrome as a proband with any childhood tumour or sarcoma, brain tumour, or adrenocortical tumour under 45 years, plus a first or second degree relative with a typical LFS tumour at any age and another first or second degree relative with any cancer under the age of 60 . Eeles ${ }^{4}$ proposed more relaxed criteria for LFL: a clustering of two typical LFS tumours in subjects who are first or second degree relatives at any age. Since the original reports of germline mutations of the tumour suppressor gene TP53 in LFS, ${ }^{5}$ numerous studies have shown that germline TP53 mutations can be detected in approximately $70 \%$ of LFS families and $20 \%$ of LFL families, ${ }^{1}$ suggesting the possible involvement of other genes in LFS. This hypothesis was recently confirmed by the detection, in one LFS family and one family suggestive of LFS, of germline mutations of $h C H K 2$, the human homologue of the Saccharomyces cerevisiae RAD53 gene, located on chromosome $22 \mathrm{q} 12 .^{78} h C H K 2$ encodes a kinase, which is able to phosphorylate, in response to DNA 
damage, the Cdc25C phosphatase involved in the G2 checkpoint $^{7}$ and TP53. ${ }^{9-11}$ We considered that the TP53 homologue, TP63/p51/KET $T^{12-14}$ located on 3q27-29, was also a candidate gene for the LFS not associated with the germline TP53 mutation, since the isotype p63 $\gamma$ transactivates reporter constructs containing the TP53 binding sites present within $p 21 / W A F 1 / C I P 1 / C D K N 1 A, B A X, M D M 2,{ }^{15}$ and PIG3 (G Bougeard, T Frebourg, unpublished data) genes.

We therefore analysed in this study the TP53, $h C H K 2$, and TP63 genes in $17 \mathrm{LFS} / \mathrm{LFL}$ families referred to our laboratory. These 17 families (table 1, figs 1 and 2) included four families fulfilling the complete criteria for LFS, five the criteria for LFL, as defined by Birch et $a l^{3}$ and were therefore designated LFLb, and eight the criteria for LFL proposed by Eeles ${ }^{4}$ and were therefore designated LFLe. For 15 index cases, we performed the TP53 functional assay developed in yeast on cDNA derived from lymphocytes. ${ }^{16}{ }^{17}$ Briefly, the reporter yeast strain yIG397RGC was co-transformed with PCR amplified TP53 cDNA (between codons 53 and 364) and the gapped expression vector pSS16 linearised between codons 67 and 346 , and cDNA was cloned in vivo by homologous recombination. The activation by wild type TP53 of the reporter system, containing the ADE2 open reading frame and the TP53 binding site RGC, changes the colour of the yeast colonies (red $\rightarrow$ white) and samples containing wild type TP53 commonly give a background of $5-8 \%$ red colonies owing to PCR induced errors and the presence of an alternatively spliced TP53 mRNA. ${ }^{16}{ }^{17}$ In 10 families, the percentage of red colonies (above 10\%) suggested the presence of a heterozygous mutation, which was confirmed by sequence analysis of cDNA and/or genomic DNA (table 1 , fig 1). Sequencing of exons 2 to 11 confirmed the absence of mutation in the five families with a normal TP53 functional assay and, in one of the two families for which no RNA was available, allowed the detection of an additional mutation.

In the six families without detectable TP53 germline mutation (fig 2), we then analysed the TP63 gene. To screen for inactivating TP63 mutations, we performed a functional assay in yeast. Transformation of the pCI51 plasmid $^{18}$ containing the wild type coding region corresponding to the isoform $\gamma$ of TP63 into the yIG397-RGC yeast reporter strain resulted in white colonies. Transformation of two mutant pCI51 plasmids (with the mutation Leu264Ser or Cys269Ser generated by PCR induced mutagenesis), used as controls, resulted only in red colonies. In four index cases, for whom mRNA was available, the TP63 cDNA was PCR amplified from lymphocytes between codons 18 and 434, cloned by homologous recombination into the gapped expression vector pCI51 linearised between codons 30 and 420, and transformed into yIG397-RGC; the percentage of red colonies (table 1) suggested the absence of heterozygous inactivating mutations. We also sequenced in the six families without detectable TP53 mutation exons 2 to 15 of the TP63 gene from genomic DNA, using primers described by Hagiwara et $a l,{ }^{19}$ and detected no nucleotide change. We then analysed the open reading frame of $h C H K 2$ by RT-PCR in the four index cases for whom mRNA was available. As recently highlighted by Sodha et al, ${ }^{8}$ exons 10 to 14 of $h C H K 2$ have homologous fragments on numerous chromosomes, which limits analysis from genomic DNA, and the mutation screening should therefore be performed by RT-PCR. The entire coding region of $h C H K 2(1662 \mathrm{bp})$ was PCR amplified from cDNA derived from lymphocytes using primers (5'-TGT CTC GGG AGT CGG ATG TTG AGG CTC AGC-3') and (5'-GGA CAT TTC TTT CGT GTT CAA ACC ACG GAG-3'), and the PCR products were then submitted to a second stage PCR amplification generating three overlapping fragments which were sequenced. In all subjects, RT-PCR showed an in frame deletion of $87 \mathrm{bp}$, which was also observed in controls. Alignment, using the BLAST program (National Center for Biotechnology Information), of the $h C H K 2$ cDNA (accession number AF086904) to the genomic clones RP11-44G7 (accession number AL117330) and RP11436C9 (accession number AL121825) derived from chromosome 22 showed that the deleted fragment corresponds to an exon (probably exon 9), indicating the presence of an alternative splicing of $h C H K 2$ in lymphocytes. Sequence analysis detected no germline $h C H K 2$ mutation in the four probands.

Table 1 Functional and sequencing analysis of the TP53, TP63, and hCHK2 genes in 17 LFS or LFL families

\begin{tabular}{|c|c|c|c|c|c|c|c|}
\hline \multirow[b]{2}{*}{ Family } & \multirow[b]{2}{*}{ Presentation } & \multicolumn{3}{|l|}{ TP53 } & \multicolumn{2}{|l|}{ TP63 } & \multirow{2}{*}{$\begin{array}{l}h C H K 2 \\
\text { s } 2 \text { Nequence }\end{array}$} \\
\hline & & $\begin{array}{l}\text { FASAY\% } \\
\text { of red } \\
\text { colonies }\end{array}$ & Nucleotide change & Amino acid change & $\begin{array}{l}\text { FASAY \% } \\
\text { of red } \\
\text { colonies }\end{array}$ & $\begin{array}{l}\text { DNA } \\
\text { sequence }\end{array}$ & \\
\hline $\mathrm{F} 1$ & LFS & 74 & $\mathrm{TGC} \rightarrow \mathrm{TAC}$ & Cys141Tyr* ${ }^{\star}$ & / & / & 1 \\
\hline F2 & LFS & 17 & $\mathrm{CGC} \rightarrow \mathrm{GGC}$ & Arg175Gly^ & 1 & I & l \\
\hline F3 & LFS & 12 & $1 \mathrm{bp}(\mathrm{T})$ Del & 212 FS Del $\dagger$ & 1 & 1 & 1 \\
\hline F4 & LFS & 48 & $\mathrm{GGC} \rightarrow \mathrm{AGC}$ & Gly245Ser $\ddagger$ & I & i & l \\
\hline F5 & LFLb & 17 & Intron $6 \mathrm{SD}$ ag $\rightarrow$ aa $\$$ & 225 FS Ins & 1 & 1 & / \\
\hline F6 & LFLb & $\mathrm{ND}^{\star \star}$ & ATG $\rightarrow$ ATA & Met237Ile* & 1 & 1 & l \\
\hline F7 & LFLb & 53 & $\mathrm{CGT} \rightarrow \mathrm{TGT}$ & Arg273Cys ${ }^{\star} \ddagger$ & I & 1 & l \\
\hline F8 & LFLb & 49 & $\mathrm{CCT} \rightarrow \mathrm{TCT}$ & Pro278Ser $\star^{\top}$ & 1 & 1 & i \\
\hline F9 & LFLb & 6 & WT & I & ND & WT & ND \\
\hline F10 & LFLe & 22 & $\mathrm{CGC} \rightarrow \mathrm{CAC}$ & $\operatorname{Arg} 175 \mathrm{His}^{\star} \ddagger$ & 1 & j & 1 \\
\hline F11 & LFLe & 50 & $\mathrm{CGG} \rightarrow \mathrm{TGG}$ & Arg282Trp ${ }^{\star} \ddagger$ & 1 & 1 & \\
\hline F12 & LFLe & 14 & $\mathrm{CGA} \rightarrow \mathrm{TGA}$ & Arg306Stop $\ddagger$ & 1 & 1 & 1 \\
\hline F13 & LFLe & 6 & WT & j & 8 & WT & WT \\
\hline F14 & LFLe & 4 & WT & 1 & 4 & WT & WT \\
\hline F15 & LFLe & 3 & WT & 1 & 4 & WT & WT \\
\hline F16 & LFLe & 2 & WT & 1 & 5 & WT & WT \\
\hline F17 & LFLe & $\mathrm{ND}$ & WT & 1 & ND & WT & ND \\
\hline
\end{tabular}

*This missense mutation was shown to alter the transactivation of $\mathrm{p} 21$ and bax reporter constructs in yeast. ${ }^{24}$

†Frameshift deletion.

¥Germline mutation previously listed in data base from Christophe Beroud, Karim Debouche, and Thierry Soussi (http://perso.curie.fr/Thierry.Soussi/).

Analysis of the cDNA showed that this mutation of the splicing donor site resulted in a partial retention of intron 6 owing to the activation of a cryptic site.

ๆFrameshift insertion.

$\star \star$ Not done.

WT=wild type. 
F1

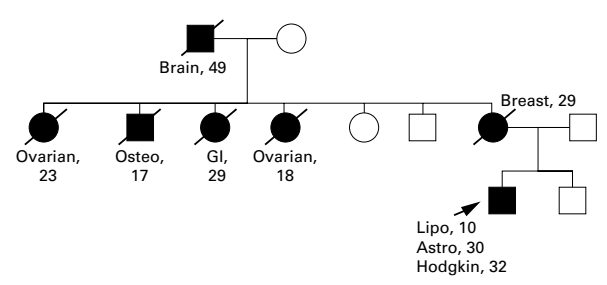

F4

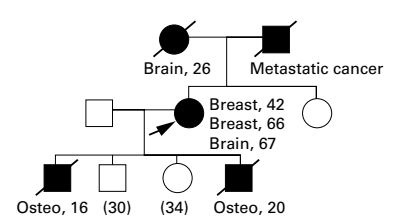

F7

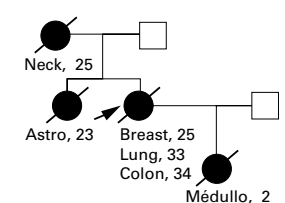

F10

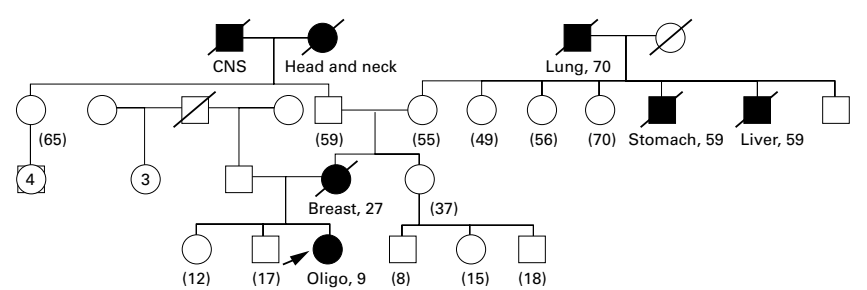

F2

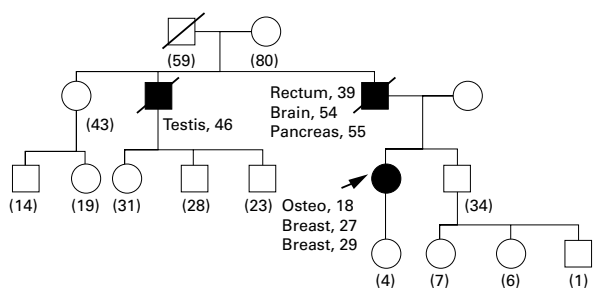

F5

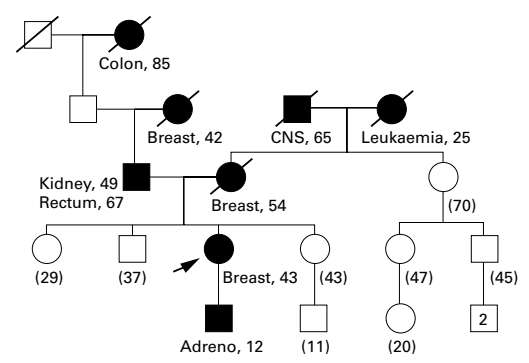

F8

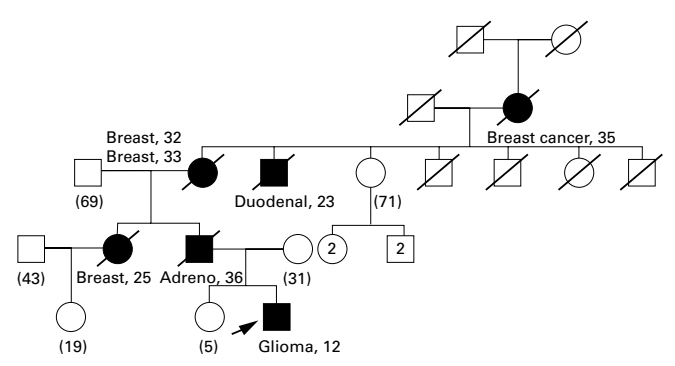

F3

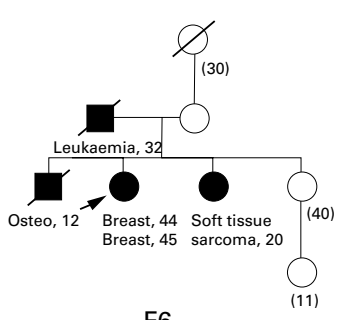

F6

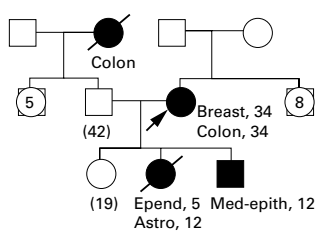

F11

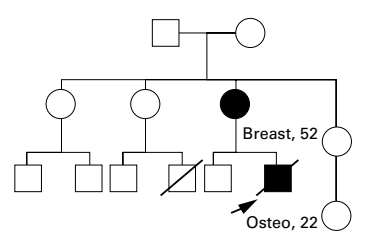

Figure 1 Partial pedigrees of $11 \mathrm{LFS} / \mathrm{LFL}$ families with a germline TP53 mutation. Filled symbols=affected subjects, open symbols=asymptomatic subjects. For each affected subject, the tumour (or site of the tumour) and age of diagnosis are indicated. The age of unaffected subjects is indicated in brackets. Adeno: adenocarcinoma of unknown origin; adreno, adrenocortical carcinoma; astro, astrocytoma; epen, ependymoma; GI, gastrointestinal tumour; histio, histiofibrosarcoma; lipo, liposarcoma; med-epith, medullo-epithelioma; medullo, medulloblastoma; oligo, oligodendroglioma; osteo, osteosarcoma. Germline TP53 mutations are shown in table 1.

We therefore identified in this study 11 germline TP53 mutations, including six previously unreported germline mutations (table 1), in 4/4 LFS, 4/5LFLb, and 3/8 LFLe families (fig 1), confirming that the use of relaxed criteria decreases the probability of identifying a germline mutation. This study shows that the functional assay is an efficient method to detect germline TP53 mutations since, in this series, it detected all the germline mutations. The recent identification in LFS families of germline mutations of $h C H K 2,{ }^{7}$ encoding a kinase whose substrates include Cdc25C ${ }^{20}$ and TP53 $3^{9-11}$ strongly suggests that the critical defect in LFS is the constitutional alteration of the G1 and/or G2 checkpoints in response to DNA damage. In four LFL families, with no detectable germline TP53 mutation, we did not detect any germline mutation of $h C H K 2$. In this study, we also explored the involvement of TP63, one of the TP53 homologues identified over the last two years. Somatic TP63 mutations appear very rare in tumours. ${ }^{18} 19$ Nevertheless, when we performed a functional assay in yeast on a TP63 cDNA submitted to PCR induced mutagenesis, as previously described, ${ }^{21}$ we were able to estimate the number of sites in which mutations could be detected as 528, indicating that TP63 exhibited in vitro the same intrinsic sensitivity to mutations as TP53. Our study provides no evidence for the involvement of TP63 in LFS. In contrast, germline TP63 mutations were recently identified in the EEC (ectrodactyly, ectodermal dysplasia, and cleft lip) syndrome. ${ }^{22}$ It could be argued that, in this study, the six families with no detectable mutation correspond either to other inherited forms of cancers or to the aggregation of sporadic cancers. Nevertheless, the association of early breast cancer with sarcoma or a CNS tumour in first degree relatives, observed in families F13, F14, and F15 (fig 2), is strongly suggestive of LFS. Therefore, our results indicate the involvement of other genes in LFS. If the medical benefit of presymptomatic testing in these families is not obvious considering the wide spectrum of tumours, in contrast identification of the germline alteration in affected subjects confirms on a molecular basis the diagnosis of LFS, which may have important 
F9

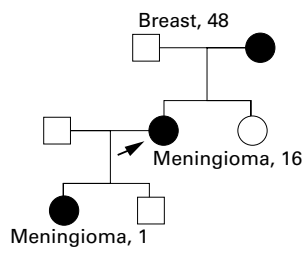

F15

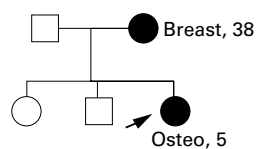

F13

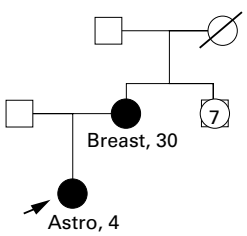

F16

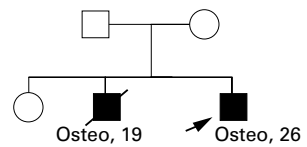

F14

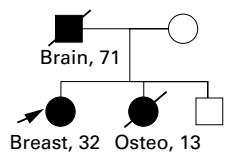

F17

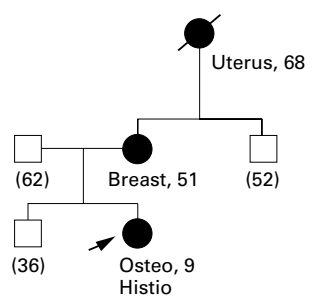

Figure 2 Partial pedigrees of six LFL families with no detectable germline TP53 mutation.

clinical implications. These patients, who have a high risk of developing multiple primary cancers, ${ }^{23}$ may benefit from a regular clinical review. Furthermore, several studies have reported, in mutation carriers, the development of second tumours in the radiotherapy fields, which raises the question of the use of ionising radiation in these patients. ${ }^{23}$ Therefore, the complete characterisation of the molecular basis of LFS will be important for the correct clinical management of these families.

This work was supported by l'Association pour la Recherche sur le Cancer, La Ligue Nationale Contre le Cancer, and le Groupement des Entreprises Françaises dans la Lutte Contre le Cancer. We are grateful to Chikashi Ishioka who provided the pCI51 plasmid.

\section{GAËLLE BOUGEARD* JEAN-MARC LIMACHER† COSETTE MARTIN ${ }^{\star}$ FRANÇOISE CHARBONNIER * AUDREY KILLIAN* OLIVIER DELATTRE $\$$ MICHEL LONGYS PHILIPPE JONVEAUX

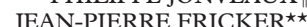 DOMINIQUE STOPPA-LYONNET: JEAN-MICHEL FLAMAN * THIERRY FRÉBOURG*}

*Institut National de la Santé et de la Recherche Médicale (INSERM) EMI 9906, Faculté de Médecine et de Pharmacie, 76183 Rouen, and IFRMP, 76821 Mont-Saint-Aignan Cedex, France

†Hôpitaux Universitaires, 67091 Strasbourg, France

$¥$ Service de Génétique Oncologique, Institut Curie, 75248 Paris, France

\Institut Bergonié, 33076 Bordeaux Cedex, France

-Laboratoire de Génétique, Hôpitaux de Brabois, CHU de Nancy, 54511

Vandoeuvre les Nancy, France

${ }^{\star}$ Centre Paul Strauss, 67085 Strasbourg, France

Correspondence to: Dr Frébourg, frebourg@chu-rouen.fr

1 Varley JM, Evans DGR, Birch JM. Li-Fraumeni syndrome - a molecular and

2 Li FP, Fraumeni JF Jr, Mulvihill JJ, Blattner WA, Dreyfus MG, Tucker MA, Miller RW. A cancer family syndrome in twenty-four kindreds. Cancer Res 1988;48:5358-62.

3 Birch JM, Hartley AL, Tricker KJ, Prosser J, Condie A, Kelsey AM, Harris M, Morris Jones PH, Binchy A, Crowther D, Craft AW, Eden OB, Evans DGR, Thompson E, Mann JR, Martin J, Mitchell ELD, Santibanez-Koref MF. Prevalence and diversity of constitutional mutations in the p53 gene among 21 Li-Fraumeni families. Cancer Res 1994;54:1298-304.

4 Eeles RA. Germline mutations in the TP53 gene. Cancer Surv 1995;25:10124.

5 Malkin D, Li FP, Strong LC, Fraumeni JF Jr, Nelson CE, Kim DH, Kassel J, Gryka MA, Bischoff FZ, Tainsky MA, Friend SH. Germ line p53 mutations in a familial syndrome of breast cancer, sarcomas, and other tions in a familial syndrome of b
neoplasms. Science 1990;250:1233-8.

6 Srivastava S, Zou Z, Pirollo K, Blattner W, Chang EH. Germ-line transmission of a mutated p 53 gene in a cancer-prone family with Li-Fraumeni syndrome. Nature 1990;348:747-9.
7 Bell DW, Varley JM, Szydlo TE, Kang DH, Wahrer DC, Shannon KE, Lubratovich M, Verselis SJ, Isselbacher KJ, Fraumeni JF, Birch JM, Li FP, Garber JE, Haber DA. Heterozygous germ line hCHK2 mutations in Li-Fraumeni syndrome. Science 1999;286:2528-31.

8 Sodha N, Williams R, Mangion J, Bullock SL, Yuille MR, Eeles RA. Screening hCHK2 for mutations. Science 2000;289:359.

9 Shieh SY, Ahn J, Tamai K, Taya Y, Prives C. The human homologs of checkpoint kinases Chk1 and Cds1 (Chk2) phosphorylate p53 at multiple DNA damage-inducible sites. Genes Dev 2000;14:289-300.

10 Chehab NH, Malikzay A, Appel M, Halazonetis TD. Chk $2 /$ hCds 1 functions as a DNA damage checkpoint in $G(1)$ by stabilizing p53. Genes Dev 2000; 14:278-88.

11 Hirao A, Kong YY, Matsuoka S, Wakeham A, Ruland J, Yoshida H, Liu D, Elledge SJ, Mak TW. DNA damage-induced activation of p53 by the checkpoint kinase Chk2. Science 2000;287:1824-7.

12 Yang A, Kaghad M, Wang Y, Gillett E, Fleming MD, Dötsch V, Andrews NC, Caput D, McKeon F. p63, a p53 homolog at 3q27-29, encodes multiple products with transactivating, death-inducing, and dominant-negative ple products with Mol Cell 1998;2:305-16.

13 Osada M, Ohba M, Kawahara C, Ishioka C, Kanamaru R, Katoh I, Ikawa Y, Nimura Y, Nakagawara A, Obinata M, Ikawa S. Cloning and functional analysis of human p 51, which structurally and functionally resembles p53. Nat Med 1998;4:839-43.

14 Augustin M, Bamberger C, Paul D, Schmale H. Cloning and chromosomal mapping of the human p53-related KET gene to chromosome 3q27 and its murine homolog Ket to mouse chromosome 16. Mamm Genome 1998;9:899-902.

15 Shimada A, Kato S, Enjo K, Osada M, Ikawa Y, Kohno K, Obinata M, Kanamaru R, Ikawa S, Ishioka C. The transcriptional activities of p53 and its homologue p51/p63: similarities and differences. Cancer Res 1999;59:27816.

16 Flaman JM, Frebourg T, Moreau V, Charbonnier F, Martin C, Chappuis P, Sappino AP, Limacher JM, Bron L, Benhattar J, Tada M, Van Meir EG, Estreicher A, Iggo RD. A simple p53 functional assay for screening cell lines, blood, and tumors. Proc Natl Acad Sci USA 1995;92:3963-7.

17 Frebourg T, Flaman JM, Estreicher A, Iggo RD. In: Cotton RGH, Edkins E, Forrest SM, eds. Mutation detection: a practical approach. Oxford: Oxford University Press, 1998:211-22.

18 Sunahara M, Shishikura T, Takahashi M, Todo S, Yamamoto N, Kimura H, Kato S, Ishioka C, Ikawa S, Ikawa Y, Nakagawara A. Mutational analysis of p51A/TAp63gamma, a p53 homolog, in non-small cell lung cancer and p51A/TAp63gamma, a p53 homolog,

19 Hagiwara K, McMenamin MG, Miura K, Harris CC. Mutational analysis of the $\mathrm{p} 63 / \mathrm{p} 73 \mathrm{~L} / \mathrm{p} 51 / \mathrm{p} 40 / \mathrm{CUSP} / \mathrm{KET}$ gene in human cancer cell lines using intronic primers. Cancer Res 1999;59:4165-9.

20 Chaturvedi P, Eng WK, Zhu Y, Mattern MR, Mishra R, Hurle MR, Zhang X, Annan RS, Lu Q, Faucette LF, Scott GF, Li X, Carr SA, Johnson RK, Winkler JD, Zhou BB. Mammalian Chk2 is a downstream effector of the ATM-dependent DNA damage checkpoint pathway. Oncogene 1999;18: 4047-54.

21 Flaman JM, Frebourg T, Moreau V, Charbonnier F, Martin C, Ishioka C, Friend SH, Iggo R. A rapid PCR fidelity assay. Nucleic Acids Res 1994;22: 3259-60.

22 Celli J, Duijf P, Hamel BCJ, Bamshad M, Kramer B, Smits AP, Newbury-Ecob R, Hennekam RCM, van Buggenhout G, van Haeringen A, Woods CG, van Essen AJ, de Waal R, Vriend G, Haber DA, Yang A, McKeon F, Brunner HG, van Bokhoven H. Heterozygous germline mutations in the p53 homolog p63 are the cause of EEC syndrome. Cell 1999;99:14353.

23 Hisada M, Garber JE, Fung CY, Fraumeni JF Jr, Li FP. Multiple primary cancers in families with Li-Fraumeni syndrome. I Natl Cancer Inst 1998;90:606-11.

24 Flaman JM, Robert V, Lenglet S, Moreau V, Iggo R, Frebourg T. Identification of human $\mathrm{p} 53$ mutations with differential effects on the bax and $\mathrm{p} 21$ promoters using functional assays in yeast. Oncogene 1998;16:1369-72. 


\section{A distinct splice form of $A P C$ is highly expressed in neurones but not commonly mutated in neuroepithelial} tumours

EDITOR-The APC tumour suppressor gene contains at least 21 exons, including four exons upstream of exon $1 .^{12}$ Alternative splicing involves at least seven exons, including the first five exons, and creates distinct splice forms of $A P C$ RNA. ${ }^{1-4}$ Exon 1 contains an in frame stop codon upstream of its initiating methionine; hence only splice forms of $A P C$ that lack exon 1 allow exons $5^{\prime}$ of exon 1 to be translated. Interestingly, splice forms lacking exon 1 are enriched in terminally differentiated tissues including brain, ${ }^{5}$ intimating that protein isoforms containing domains encoded by the exons 5 ' to exon 1 may be important in cellular differentiation. This study evaluates neurones and glia of the rodent nervous system and asks which cell types express $A P C$ isoforms lacking exon 1.

Medulloblastomas and glioblastomas are neuroepithelial tumours derived from neuronal progenitor cells and glial cells, respectively. ${ }^{6}$ Both tumour types occur at increased frequency in a subset of adenomatous polyposis coli (APC) patients ${ }^{8}$; APC patients developing these tumour types have a variant of APC known as Turbot's syndrome. ${ }^{9}$ APC is an autosomal dominant disorder caused by the inactivation of one copy of the APC gene. ${ }^{10}{ }^{11}$ APC patients develop hundreds to thousands of adenomatous polyps and if the colon is not removed, colon carcinoma develops. ${ }^{8}$ The relative risk of brain tumour formation is 23 times greater for APC patients when compared to the general population between the ages of 0 and $29 .^{12}$ This study also examines the genetic basis of neuroepithelial tumour formation and examines $A P C$ as a mutational target in medulloblastomas and glioblastomas. We assayed 41 sporadic glioblastomas and medulloblastomas, five cell lines derived from neuroepithelial tumour types, and one medulloblastoma from an APC patient to examine the possibility that mutations in the 5' exons of the $A P C$ gene are associated with neuroepithelial tumour formation. The mutation cluster region in exon 15 of the $A P C$ gene was also examined.

Adult rat cerebellum and spinal cord were dissected and stored at $-20^{\circ} \mathrm{C}$. Embryonic rat spinal cord was dissected from embryonic day 16 (E16) rats and stored at $-20^{\circ} \mathrm{C}$. Rat embryonic neurones were purified from E16 dorsal root ganglia as described by Kim et al. ${ }^{13}$ Rat Schwann cells were purified from postnatal day 1 (P1) rats as described by Brockes and Raff. ${ }^{14}$ Rat astrocyte cells were derived from P1 rats as described by McCarthy and de Vellis. ${ }^{15}$

Total RNA was extracted from samples by the guanidinium thiocyanate method. ${ }^{16}$ cDNA was synthesised using random hexamers and Stratascript reverse transcriptase (Stratagene, La Jolla, CA) according to the manufacturer's instructions. The resulting cDNA was used as template in PCR reactions with an upstream primer, UPGGAGAGAGAATGGAGGTGCTGC, derived from exon 0.3 of mouse $A p c$, and the downstream primer, RP-CTCTCTTTCTCAAGTTCTTCTA, in exon 3 of mouse $A p c$. UP and RP represent the universal and reverse primer, respectively, of M13 and were used for sequencing analysis. The upstream primer anneals specifically with nucleotides 154 to 175 of exon 0.3 , nucleotide number 1 marking the $5^{\prime}$ end of mouse $A p c$ exon 0.3 (GenBank Accession No U66412). The downstream primer anneals specifically with nucleotides 401 to 422 of $A p c$ exon 3, f Med Genet 2001;38:257-262 nucleotide number 1 being the beginning of the initiating methionine codon of mouse Apc. RT-PCR products were electrophoresed through a 3\% agarose gel, stained with ethidium bromide, and photographed. Intensities of RT-PCR product bands were analysed by Image Quant software (Molecular Dynamics, Sunnyvale, CA).

All cell lines were obtained from the ATCC in Rockville, MD. The human astrocytoma cell line SW1088 (ATCC HTB12) was cultured in Liebovitz's L-15 medium (Gibco BRL, Grand Island, NY) with $10 \%$ fetal bovine serum (Hyclone, Logan, UT). The human glioblastoma cell line T98G (ATCC CRL1690) and the human medulloblastoma cell line DAOY (ATCC HTB186) were cultured in Minimum Essential Medium (Gibco BRL, Grand Island, NY) supplemented with $10 \%$ fetal bovine serum, $1 \%$ nonessential amino acids (Gibco BRL, Grand Island, NY), and $1 \%$ sodium pyruvate (Gibco BRL, Grand Island, NY). The human medulloblastoma cell lines D341 (ATCC HTB187) and D283 (ATCC HTB185) were cultured in Minimum Essential Medium-alpha formulation (Sigma, St Louis, MO) supplemented with $10 \%$ fetal bovine serum.

All human tissues were obtained with Institutional Review Board (IRB) approvals from the University of Cincinnati College of Medicine and University Hospital, and Instituto Nazionale per la Ricerca sul Cancro in Genova, Italy. Fresh frozen specimens of 17 medulloblastomas were obtained from Italy and the United States, as described by Badiali et al. ${ }^{17}$ Twenty three paraffin embedded glioblastoma samples and five corresponding normal samples were obtained through the Department of Pathology and Laboratory Medicine, University of Cincinnati College of Medicine. Genomic DNA was prepared from paraffin embedded samples as described in Wright and Manow. ${ }^{18}$ A paraffin embedded sample from a medulloblastoma and accompanying normal tissue were obtained from an APC patient treated at The Ohio State University James Cancer Hospital and Research Institute.

Normal genomic DNA was a gift from the laboratory of Anil G Menon, Department of Molecular Genetics, Biochemistry and Microbiology, University of Cincinnati College of Medicine. These samples were obtained with IRB approval from patients followed by the Hypertensive Clinics of the University of Cincinnati and the Veterans Administration Hospital, as well as from the community at large. DNA was extracted from peripheral blood as published in Su et $a l^{19}$ using Puregene DNA Isolation Kit (Gentra Systems Inc, Minneapolis, MN).

PCR-single strand conformational polymorphism (SSCP) analysis of $A P C$ nucleotide positions 1959 to 4904 (exon $15 \mathrm{~A}$ to $15 \mathrm{I}$, according to Groden et $a l^{10}$ ) was performed using two different running conditions as described in Varesco et $a l^{20}$ and Groden et al. ${ }^{21}$ Exons 1-14 and the remainder of exon 15 were not screened owing to limited tumour DNA amounts and the clustering of most sporadic $A P C$ mutations within a small section of exon 15.

PCR-SSCP analysis of exon 0.3 of the $A P C$ gene was performed using primer pairs UP-CGAGGGG TACGGGGCTAGG and RP-ATGGGGAGCG CCCTGGTCC, UP-ATCCGCTGGATGCGGACC and RP-GGCAGCACCTCCATTCTGTCT, and UPCTGTATTGGTGCAGCCCGCCA and RP-AAGA CAGTGCGAGGGAAAACCA. PCR-SSCP analysis of exon BS was performed using primer pairs UP-GGG GAGTCTGCTGAGAAAAG and RP-GCCTTTCAAT GGGGTAGAGC, and UP-GCTCTACCCCATT GAAAGGC and RP-ACCACCACTCACGCTCTCGA. PCR-SSCP analysis of exons 0.1 and 0.2 was performed using primer pairs UP-AGATGGCGGAGGGCAAG 
TAG and RP-CTTCCTCACCAACAGCCAAC, UPGTTGGCTCGATGCTGTTCCC and RP-CCGAGA ACTGAGGGTGGTAC, and UP-CCCCTATGTACG CCTCCCT and RP-CAATGCCTGCAGCCTCACTC. All primers are shown in the $5^{\prime}$ to $3^{\prime}$ direction. PCR was performed for one minute at $94^{\circ} \mathrm{C}$, one minute at $64^{\circ} \mathrm{C}$, and one minute at $72^{\circ} \mathrm{C}$, for 40 cycles. PCR products were labelled by incorporation of $100 \mu \mathrm{Ci}$ of $6000 \mathrm{Ci} / \mathrm{mmol}$ $a^{32}$ P-dCTP (NEN Research Products, Boston, MA). SSCP was performed using MDE gel solution (FMC Bioproducts, Rockland, ME) according to the manufacturer's instructions. Running conditions for SSCP gels were $4{ }^{\circ} \mathrm{C}$ at $40 \mathrm{~W}$ for three hours at room temperature with $10 \%$ glycerol at $40 \mathrm{~W}$ for seven hours.

Gel purified, abnormal SSCP conformers from exon 15 were used as templates in new amplification reactions. These PCR products were sequenced with the dideoxy termination method using Taq polymerase and fluorescently tagged M13 universal or reverse sequencing primers on the Applied Biosystems model 373A DNA sequencer. Gel purified, abnormal SSCP conformers from exons 0.3, BS, 0.1 , and 0.2 were amplified by symmetrical PCR using DNA from each conformer as template. Sequences were obtained by automated sequencing as described and were confirmed by TA cloning (Invitrogen, San Diego, CA) and manual sequencing using a cycle sequencing method (Invitrogen, San Diego, CA).

Exon 15 of $A P C$ was examined in four separate overlapping sections using germline DNA from an APC patient. Forward primers, including the T7 promoter and a Kozak sequence, and reverse primers (as described in Powell et $\left.a l^{2}\right)$ were used to amplify the DNA samples. PCR was performed for 35 cycles as follows: initial denaturation for three minutes, $95^{\circ} \mathrm{C}$ for 30 seconds, at or $2^{\circ} \mathrm{C}$ less than the predicted $\mathrm{T}_{\mathrm{m}}$ of the primers for one minute 30 seconds, and $70^{\circ} \mathrm{C}$ for one minute 30 seconds. PCR products were separated by gel electrophoresis in $1 \%$ agarose (Midwest, St Louis, MO) to screen for any large deletions. The PCR samples were used as templates for in vitro transcription and translation reactions (Protein Truncation Nonradioactive Kit, Roche, Indianapolis, IN). The resulting biotinylated proteins were resolved on a 10\% SDS-PAGE gel, electrotransferred to Immobilon-P membrane (Millipore, Bedford, MA), and visualised by chemiluminescence (Boehringer Mannheim Chemiluminescence Blotting Kit, Roche, Indianapolis, IN). PCR products that generated truncated proteins were TA cloned and sequenced as previously described to identify specific $A P C$ mutations.

To identify the splice forms of $A P C$ in specific cell types of the nervous system, we performed RT-PCR on a mixed population of cells from adult rat cerebellum, adult rat spinal cord, and embryonic day 16 (E16) spinal cord. We also performed RT-PCR on cultures of rat dorsal root ganglion (DRG) neurones derived from E16 embryos from which glia and fibroblasts had been removed by antimitotic treatment, rat astrocytes derived from postnatal day 1 (P1) brain, and rat Schwann cells derived from P1 sciatic nerve. The upstream primer was placed in exon 0.3 and the downstream primer was placed in exon 3. Each sample containing a mixed population of CNS derived cells primarily produced the $321 \mathrm{bp}$ product, indicating that although $0.3 / 1$ and $0.3 / 2$ splice forms of $A p c$ were present, the main $A p c$ splice form was RNA without exon 1 (fig 1). RT-PCR performed on a population enriched for neurones also primarily produced the $321 \mathrm{bp}$ product, similarly indicating an enrichment for the $A p c$ splice form lacking exon 1 (fig 1). Analysis of RT-PCR product bands using Image Quant software showed that the 321 bp band amplified from the splice form lacking exon 1 accounts for $58 \%$ or more of RT-PCR products from mixed CNS cell type

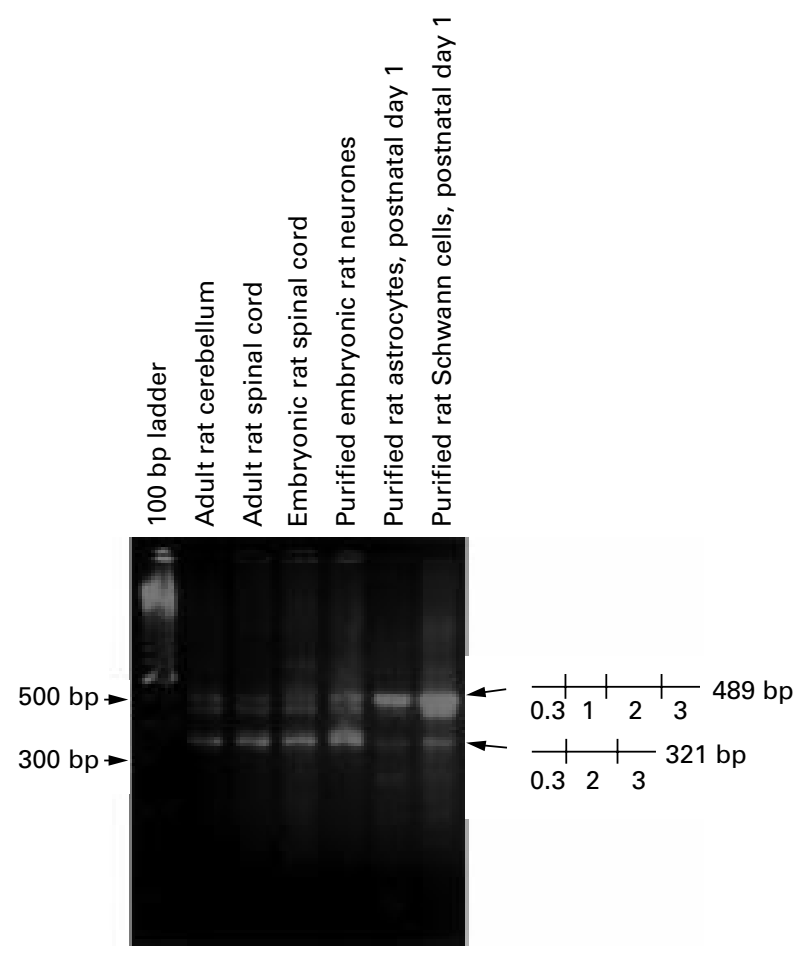

Figure 1 Rat neurones are enriched for the 0.3/2 Apc splice form. An ethidium bromide stained 3\% agarose gel of RT-PCR products is shown. The upstream PCR primer anneals with Apc exon 0.3; the downstream primer anneals with Apc in exon 3. Arrows indicate the 0.3/1 and 0.3/2 $R N A$ splice forms of Apc and the expected sizes of the amplification products. Image analysis shows that the $0.3 / 2$ splice form exists as a higher proportion of RT-PCR products from mixed CNS cell populations and purified neurones as compared to RT-PCR products from purified astrocytes or Schwann cells. Additional bands between the two expected bands are the result of heteroduplex DNA."

populations and in a cell population enriched for neurones. In contrast, preparations of purified astrocytes and purified Schwann cells are greatly enriched for the $0.3 / 1$ splice form of $A p c$ and generally lack abundant expression of the $0.3 / 2$ splice form (fig 1). Analysis of RT-PCR product bands using Image Quant software showed that the $321 \mathrm{bp}$ band amplified from the splice form lacking exon 1 accounts for $24 \%$ or less of RT-PCR products derived from either purified astrocytes or purified Schwann cells. Apc splice forms were verified by direct sequencing of representative samples. Intermediate bands on the gels represent heteroduplex PCR products as previously described. ${ }^{5}$

PCR-SSCP was used to evaluate sequence variations in the $A P C$ gene in our sporadic tumour and cell line sample set. Exons 0.3, BS, 0.1 , and 0.2 were examined, as well as nucleotides 1959-4904 in exon 15. This last region of APC is known as the "mutation cluster region" and was the only part of $A P C$ screened in our samples owing to limited sample sizes and the inability of PCR to generate larger DNA fragments from paraffin sections. Base changes were identified in eight of 22 unaffected individual genomic DNA samples, two of 23 sporadic glioblastomas, eight of 17 sporadic medulloblastomas, and one of five cell lines tested. Table 1 lists all base pair changes observed in these samples.

Base changes affecting amino acid sequence include a heterozygous $\mathrm{G}$ to $\mathrm{A}$ transition at position 148 of exon 0.3 in cell line SW 1088 from a human astrocytoma and a heterozygous $3 \mathrm{bp}$ deletion in exon 15 in a sporadic medulloblastoma (table 1). The resultant amino acid changes are Cys to Tyr and a loss of a single glutamine residue, neither of which disrupts the reading frame. 
Table 1 Nucleotide changes in the APC gene detected in tumours and cell lines. A total of 22 unaffected genomic DNA samples, 23 sporadic glioblastomas, 18 sporadic medulloblastomas, five CNS tumour derived cell lines, and one medulloblastoma from an APC patient (see Materials and methods) were examined

\begin{tabular}{|c|c|c|c|c|}
\hline Position & & Source of DNA & Base change & Amino acid change \\
\hline Exon 0.1 & nt 26 & Unaffected 5 & Heterozygous $\mathrm{C} \rightarrow \mathrm{G}$ & \\
\hline \multirow[t]{2}{*}{ Exon 0.1} & nt 26 & Unaffected 10 & Homozygous $\mathrm{C} \rightarrow \mathrm{G}$ & \\
\hline & nt 90 & & Heterozygous $\mathrm{G} \rightarrow \mathrm{T}$ & \\
\hline Exon 0.1 & nt 26 & Unaffected 11 & Heterozygous $\mathrm{C} \rightarrow \mathrm{G}$ & \\
\hline Exon 0.1 & nt 50 & Unaffected 14 & Heterozygous $\mathrm{C} \rightarrow \mathrm{T}$ & \\
\hline Exon 0.1 & nt 26 & Unaffected 15 & Homozygous $\mathrm{C} \rightarrow \mathrm{G}$ & \\
\hline Exon 0.1 & nt 26 & Unaffected 16 & Homozygous $\mathrm{C} \rightarrow \mathrm{G}$ & \\
\hline Exon 0.1 & nt 26 & Unaffected 17 & Heterozygous $\mathrm{C} \rightarrow \mathrm{G}$ & \\
\hline \multirow[t]{2}{*}{ Exon 0.1} & nt 26 & Unaffected 37 & Homozygous $\mathrm{C} \rightarrow \mathrm{G}$ & \\
\hline & nt 17 & & Heterozygous $\mathrm{G} \rightarrow \mathrm{A}$ & \\
\hline Exon 0.1 & nt 26 & Glioblastoma 93445 & Heterozygous $\mathrm{C} \rightarrow \mathrm{G}$ & \\
\hline Exon 0.1 & nt 26 & Medulloblastoma 1835 & Heterozygous $\mathrm{C} \rightarrow \mathrm{G}$ & \\
\hline Exon 0.1 & nt 26 & Medulloblastoma 1833 & Heterozygous $\mathrm{C} \rightarrow \mathrm{G}$ & \\
\hline Exon 0.1 & nt 26 & SW1088 (astrocytoma) & Heterozygous $\mathrm{C} \rightarrow \mathrm{G}$ & \\
\hline Exon 0.1 & nt 34 & Glioblastoma 93133 & Heterozygous addition of $\mathrm{G}$ & \\
\hline Exon 0.1 & nt 34 & Medulloblastoma 1838 & Heterozygous addition of $\mathrm{G}$ & \\
\hline Exon 0.2 & nt 38 & Medulloblastoma 1833 & Heterozygous $\mathrm{T} \rightarrow \mathrm{G}$ & \\
\hline Exon 0.2 & nt 38 & Medulloblastoma 1837 & Homozygous $T \rightarrow G$ & \\
\hline Exon 0.2 & nt 38 & SW1088 (astrocytoma) & Homozygous $T \rightarrow G$ & \\
\hline Exon 0.3 & nt 148 & SW 1088 (astrocytoma) & Heterozygous $\mathrm{G} \rightarrow \mathrm{A}$ & $\mathrm{Cys} \rightarrow \mathrm{Tyr}$ \\
\hline Exon 15 & nt 4326 & Medulloblastoma 1836 & Heterozygous $\mathrm{T} \rightarrow \mathrm{A}$ & \\
\hline Exon 15 & nt 3460 & Medulloblastoma 1840 & Heterozygous $3 \mathrm{bp}$ deletion & Loss of Glu \\
\hline Exon 15 & nt 4326 & Medulloblastoma 1843 & Heterozygous $\mathrm{T} \rightarrow \mathrm{A}$ & \\
\hline Exon 15 & nt 4326 & Medulloblastoma 1847 & Heterozygous $\mathrm{T} \rightarrow \mathrm{A}$ & \\
\hline \multirow[t]{2}{*}{ Exon 15} & nt 3188 & APC medulloblastoma & Heterozygous GTGA deletion & Stop at nt 3373 \\
\hline & nt 3187 & & Heterozygous A deletion & Stop at nt 3373 \\
\hline
\end{tabular}

Several other sequence variations were observed in unaffected subjects, CNS tumours, and one cell line that did not alter the predicted amino acid sequence of APC; these are most likely silent polymorphisms. A site of common variation exists at position 26 of exon 0.1 , as seven of 22 unaffected subjects, one of 23 sporadic glioblastomas, two of 18 sporadic medulloblastomas, and one of five cell lines contained a $\mathrm{C}$ to $\mathrm{G}$ transversion at this location. DNA from two unaffected subjects contained this transversion as well as additional base changes. One of these unaffected subjects contained a heterozygous $\mathrm{G}$ to $\mathrm{T}$ base change at position 90 and the other contained a heterozygous $\mathrm{G}$ to $\mathrm{A}$ base change at position 17 of exon 0.1. Additionally, DNA from one unaffected subject contained a heterozygous $\mathrm{C}$ to $\mathrm{G}$ base change at position 50 of exon 0.1 .

One of 23 sporadic glioblastomas and one of 17 sporadic medulloblastomas were heterozygous for an additional $\mathrm{G}$ following a string of seven Gs located at position 34 of exon 0.1 . This addition of an eighth $\mathrm{G}$ was confirmed by independent PCR and sequencing reactions and is not the result of PCR or sequencing artefact. Examination of genomic samples from 22 unaffected subjects did not show this single nucleotide addition. Exon 0.1 does not contain a putative translation start, hence the effect of amino acid sequence is difficult to predict.

Three samples contained either a heterozygous or homozygous $\mathrm{T}$ to $\mathrm{G}$ transition in exon 0.2 of $A P C$. For medulloblastoma 1837, it is not possible to distinguish between germline homozygosity for this polymorphism versus a loss of heterozygosity in the tumour because normal tissue was not available. This $T$ to $G$ transition is located upstream from the putative translation start site within exon 0.2 and most likely would not affect APC amino acid sequence. Three medulloblastoma samples contained a heterozygous $\mathrm{T}$ to $\mathrm{A}$ transversion at position 4326 in exon 15 within the "mutation cluster region" of the $A P C$ gene. This transversion does not change the amino acids encoded within this region.

Two heterozygous base changes were observed in a medulloblastoma from an APC patient that would truncate the APC protein (table 1). The germline APC mutation was a heterozygous GTGA deletion at nucleotide 3188, resulting in a premature stop codon at nucleotide 3373. This deletion was identified using the protein truncation test and was verified by direct sequencing. Analysis of
DNA from a paraffin section of the patient's medulloblastoma showed that the second $A P C$ allele carried a deletion of an adenine at nucleotide 3187 , resulting in a premature stop codon at nucleotide 3373 . This somatic mutation was identified by direct sequencing. TA cloning and direct sequencing were performed to verify that the two mutations occurred on separate alleles.

The APC protein is a $310 \mathrm{kDa}$ protein that homodimerises, ${ }^{23}{ }^{24}$ binds $\beta$-catenin, ${ }^{25}{ }^{26}$ axin, ${ }^{27}$ tubulin, ${ }^{28}{ }^{29} \mathrm{~EB} 1,{ }^{30}$ and the human homologue of Drosophila disks large protein. ${ }^{31}$ APC is phosphorylated by GSK $3 \beta^{32}$ and the cyclin dependent kinase CDK $1 / \mathrm{p} 34^{\text {cdc2 }} \cdot{ }^{33}$ The current model of APC function highlights the ability of APC to down regulate $\beta$-catenin, modulate Wnt signalling pathways, and effect gene transcription. ${ }^{34}$

The homodimerisation domain of APC is located at the amino-terminus and is predicted to play a role in APC function. ${ }^{23}{ }^{24}$ Exon 1 encodes the first heptad repeat of APC, which is sufficient for homodimerisation. Four $A P C$ exons have been identified 5' of exon 1 and are alternatively included in different $A P C$ splice forms. Exon 1 contains an in frame stop codon upstream of its start codon, arguing that these $5^{\prime}$ exons, $0.3, \mathrm{BS}, 0.1$, and 0.2 , are translated into APC protein products only if exon 1 is removed from the transcript. Such alternative splicing occurs in human brain frontal lobe tissue; the $0.3 / 2$ splice form is enriched in skeletal muscle, heart muscle, cerebrum, and cerebellum of mouse. ${ }^{5}$ At least some transcripts without exon 1 encode APC isoforms with distinct domains and distinct cellular functions, as an isoform without amino acids encoded by exon 1 does not dimerise with an APC isoform containing amino acids encoded by exon $1 .{ }^{35}$ We report here that rat neurones are enriched for the 0.3/2 splice form of $A p c$ lacking exon 1 , which may have functional significance in the terminal differentiation of neuronal cells. Mixed populations of cells expressed both the $0.3 / 1$ and $0.3 / 2$ splice forms, but purified astrocytes and purified Schwann cells contained primarily the $0.3 / 1$ splice form of $A p c$, suggesting that the cell type contributing to the abundance of the $0.3 / 2$ splice form in the mixed population of CNS derived cells is either neuronal or oligodendroglial. Neurones were confirmed as the predominant cell type contributing to the abundance of the $0.3 / 2$ splice form via the predominance of the $0.3 / 2$ splice form in purified embryonic rat neurones (fig 1). Purified oligodendrocytes 
were not assayed for the expression of $A p c$ splice forms. These findings are particularly interesting given the existence of a brain specific homologue of APC, APCL, reinforcing the possible importance of APC isoforms or homologues in terminal differentiation. ${ }^{36}$ APCL, like the isoforms of APC without amino acids encoded by exon 1, interacts with $\beta$ catenin and may therefore also mediate Wnt signalling pathways. ${ }^{35}{ }^{36}$ APCL contains a novel domain at its C-terminus that interacts with 53BP2, a protein that interacts with both $\mathrm{p} 53$ and $\mathrm{Bcl}-2$, and EB3, an EB1 homologue expressed preferentially in brain. ${ }^{37}{ }^{38} A p c$ splice forms without exon 1 and containing exons $5^{\prime}$ of exon 1 may encode isoforms that also interact with distinct cellular proteins and, without a dimerisation domain, that allow these isoforms to play distinct functional roles in specific cell types.

APC patients are at an increased risk for developing neuroepithelial tumours such as medulloblastoma and glioblastoma. ${ }^{12}$ Hamilton et $a l^{12}$ first reported an APC patient whose medulloblastoma contained a homozygous protein truncating mutation. The increased risk of central nervous system (CNS) tumours in APC patients, the high expression of APC in developing and adult rodent $\mathrm{CNS},{ }^{39-42}$ and scattered mutational reports ${ }^{12} 43$ suggest that a loss of APC function can be a causative factor in the development of neuroepithelial tumours. This also provides a rationale for assaying sporadic neuroepithelial tumours for $A P C$ mutations. Mori et $a l,{ }^{44}$ Yong et al ${ }^{45}$ and Vortmeyer et $a l^{46}$ assayed 91 sporadic neuroepithelial tumours and a cumulative total of 22 sporadic medulloblastomas respectively for mutations in the $A P C$ gene. No alterations were found by the loss of heterozygosity assays used in these studies. The exons 5' of exon 1 were not surveyed by any of these groups. In this study, we report the absence of frameshift mutations or premature stop codons using more sensitive techniques and assaying different exons than in previous reports.

The high frequency of sequence variation identified in exon 0.1 by SSCP and sequence analysis, and the lack of an AUG start codon in this exon, argue that exon 0.1 may not be translated in vivo. Sequence variations were found in genomic DNA from eight of 22 unaffected subjects as well as in two of 23 sporadic glioblastoma samples, three of 18 medulloblastoma samples, and one of five cell lines. One sporadic glioblastoma sample and one sporadic medulloblastoma sample contained a heterozygous addition of a base that was not observed in any of the unaffected genomic DNA samples. While this addition of a nucleotide is specific to CNS tumour samples in our sample set, it is difficult to assign a significance to this addition of a base and CNS tumour formation owing to small sample sizes. The absence of a putative translation start site in exon 0.1 also suggests that this polymorphism may not affect protein sequence.

One sporadic medulloblastoma contained a heterozygous $\mathrm{T}$ to $\mathrm{G}$ transition in exon 0.2 of $A P C$; one sporadic medulloblastoma and the astrocytoma cell line SW1088 contained a homozygous $\mathrm{T}$ to $\mathrm{G}$ transition at the same site. This base change is located upstream from the putative translation start site within exon 0.2 and most likely does not affect amino acid composition. This base change is most likely a silent polymorphism.

A heterozygous, silent $\mathrm{T}$ to A transversion was observed at nucleotide 4326 of $A P C$ in three of 17 medulloblastomas. This variant has been reported by Mandl et $a l^{47}$ in one of 202 polyposis families. DNA obtained from blood from one of the patients with this silent $\mathrm{T}$ to A transversion contained the same nucleotide alteration, indicating a germline alteration. We were unable to obtain sample material for additional DNA extraction to confirm the presence of this rare $A P C$ variant in the other two medulloblastomas containing this $\mathrm{T}$ to A transversion. One of the three subjects carrying this heterozygous base change was treated in Italy and two were treated at the Mayo Clinic; they are unrelated.

We observed two heterozygous sequence changes in this study that subtly alter the amino acid composition of APC. Neither of the base changes results in a truncation or other large scale disruption of APC amino acid sequence. The first is in the astrocytoma cell line SW1088, in which a heterozygous $G$ to A substitution in exon 0.3 results in the single amino acid change of cysteine to tyrosine. It is unknown whether this base change and the resultant amino acid change exist in the primary tumour that gave rise to the cell line, or if the change occurred during or after the creation of the SW 1088 cell line. The amino acid change is not predicted to change the secondary structure, as the region encoded by exon 0.3 is predicted to form a non-helical, non-coiled coil structure classified as an extended or loop structure in both wild type and variant APC $0.3 / 2$ isoforms. ${ }^{48-50}$

The second base change affecting amino acid composition was identified in a sporadic medulloblastoma. A heterozygous $3 \mathrm{bp}$ deletion at nucleotide 3460 results in the loss of a single glutamic acid residue at amino acid 1154. This glutamic acid is located immediately before the third of three 15 amino acid repeat motifs that are involved in $\beta$-catenin binding. ${ }^{25}{ }^{26}$ The loss of a glutamic acid residue at amino acid position 1154 does not affect the sequence of the 15 amino acid motif; however, it is possible that a loss of a residue at this location disrupts the spacing between the second and third 15 amino acid repeat. These amino acid repeats are separated by only four amino acids, the fourth of which is the glutamic acid deleted in this sporadic medulloblastoma. Although this is a slight change in amino acid sequence, it is possible that the integrity of the $\beta$ catenin binding region of APC is disrupted in this medulloblastoma. We were unable to obtain non-tumour tissue from this patient to establish whether this is a germline or sporadic change.

Although we found no evidence for severe disruption of $A P C$ in sporadic medulloblastomas, sporadic glioblastomas, or CNS derived cell lines, we did identify a disruption of both alleles of $A P C$ in a medulloblastoma from an APC patient. The germline $A P C$ mutation was a GTGA deletion at nucleotide 3188 that prematurely terminates APC. Analysis of DNA from a paraffin section of the patient's medulloblastoma showed that the second $A P C$ allele carried a deletion of an adenine at nucleotide 3187 that also terminates APC. Both alleles encode a protein consisting of 1062 normal amino acids followed by 61 novel amino acids and a stop codon. The protein truncation occurs between the first and second 15 amino acid repeats that are involved in $\beta$-catenin binding. ${ }^{26}$ The sporadic mutation in the medulloblastoma is most likely not the result of somatic recombination or isodisomy, as the single base deletion in the second allele of the medulloblastoma is different from the germline deletion.

The possibility exists that additional base changes in $A P C$ could have been identified using more sensitive techniques than SSCP analysis or by more extensive analyses. Indeed, a recent study showed missense mutations in $A P C$ in two of 46 sporadic medulloblastomas. ${ }^{51}$ Additionally, the possibility exists that mutations in sporadic medulloblastomas and glioblastomas occur in different gene targets that affect the same signalling pathway as APC. Examples include Huang et $a T^{1}$ and Zurawel et $a l^{52}$ where oncogenic $\beta$-catenin mutations were found in three of 67 and four of 46 sporadic medulloblastomas respectively. Activated, or oncogenic, $\beta$-catenin is not down regulated by APC and 
results in non-regulated WNT signalling through $\beta$ catenin. $^{53}$ Screening of our DNA set for sequence alterations in exon 3 of $\beta$-catenin by SSCP analysis and direct sequencing did not show any nucleotide changes (data not shown). Therefore, although specific splice forms of $A P C$ are highly enriched in neurones, these splice forms do not appear to be mutational targets in neuroepithelial tumour formation.

This work was supported by NIH Award CA-63507 (JG), the Elsa U Pardee Foundation (JG), the Council for Tobacco Research (JG), the American Gastroenterological Association (JG), Albert J Ryan Foundation (KS and CT), and the American Cancer Society (AML). We thank the University of Cincinnati DNA Core Laboratory for automated sequencing and oligonucleotide synthesis. JG is an Assistant Investigator with the Howard Hughes Medical Institute.

KIRA STEIGERWALD* IRMA M SANTORO*+‡ JENNIFER J KORDICHS VIVIANA GISMONDI CHRIS TRZEPACZ* ${ }^{\star}$ MANUELA BADIALI ${ }^{\star \star}$ F GIANGASPERO+t $M$ GREGORY BALKO JENNIFER S GRAHAMSS 9 ฯ

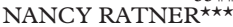
ANDREW M LOWY LILIANA VARESCO JOANNA GRODEN*

${ }^{\star}$ Howard Hughes Medical Institute, University of Cincinnati College of Medicine, Cincinnati, Ohio 45267-0524, USA

†Department of Molecular Genetics, Biochemistry and Microbiology, University of Cincinnati College of Medicine, Cincinnati, Ohio 45267, USA $\$$ Department of Surgery, Division of Surgical Oncology, University of Cincinnati College of Medicine, Cincinnati, Ohio 45267, USA IExperimental Oncology Laboratory, Instituto per la Ricerca sul Cancro, Genova, Italy

${ }^{\star}$ Microcythemic Hospital, Laboratory of Bone Marrow, Transplantation Unit, Calgiari, Italy

$\dagger^{\dagger}$ Azienda Ospedaliera San Camillo-Forlanini, Dip di Neuscienze G M Lancisi, Rome, Italy

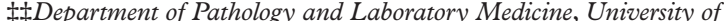
Cincinnati College of Medicine, Cincinnati, Ohio 45267, USA SSOhio State University Comprehensive Cancer Center, Clinical Cancer Genetics Program, Arthur G Fames Cancer Hospital and Richard $\mathcal{F}$ Solove Research Institute, Columbus, Ohio 43210, USA

$\star \star \star$ Department of Cell Biology, Neurobiology and Anatomy, University of Cincinnati College of Medicine, Cincinnati, Ohio 45267, USA

Correspondence to: Dr Groden, JOANNA.GRODEN@UC.EDU

$\ddagger$ Present address: Howard Hughes Medical Institute, Department of Molecular and Human Genetics, Baylor College of Medicine Houston, TX 77030, USA 9qPresent address: Genetic Health Inc, 1720 S Amphlett Blvd, Suite 130, San Mateo, CA 94402, USA

1 Horii A, Nakatsuru S, Ichii S, Nagase H, Nakamura Y. Multiple forms of the $A P C$ gene transcripts and their tissue-specific expression. Hum Mol Genet 1993;2:283-7.

2 Thliveris A, Samowitz W, Matsunami N, Groden J, White R. Demonstration of promoter activity and alternative splicing in the region 5 ' to exon 1 of the $A P C$ gene. Cancer Res 1994;54:2991-5.

3 Samowitz WS, Thliveris A, Spirio LN, White R. Alternatively spliced adenomatous polyposis coli $(A P C)$ gene transcripts that delete exons mutated in attenuated APC. Cancer Res 1995;55:3732-4.

4 Bala S, Kraus C, Wijnen J, Meera Khan P, Ballhausen WG. Multiple products in the protein truncation test due to alternative splicing in the adenoucts in the protein truncation test due to alternative splicing in the
matous polyposis coli (APC) gene. Hum Genet 1996;98:528-33.

5 Santoro IM, Groden J. Alternative splicing of the APC gene and its associSantoro IM, Groden J. Alternative splicing of the $A P C$ gene and
ation with terminal differentiation. Cancer Res 1997;57:488-94.

6 Kadin ME, Rubinstein LJ, Nelson JS. Neonatal cerebellar medulloblastoma originating from the fetal external granular layer. $\mathcal{F}$ Neuropathol Exp Neurol 1970;29:583-600

7 Rorke LB. The cerebellar medulloblastoma and its relationship to primitive neuroectodermal tumors. F Neuropathol Exp Neurol 1983;42:1-15.

8 Burt RW. Polyposis syndromes. In: Yamada T, et al, eds. Textbook of gastroenterology. Philadelphia: J B Lippincott, 1991:1674-96.

9 Turcot J, Despres JP, St Pierre F. Malignant tumors of the central nervous system associated with familial polyposis of the colon: report of two cases. Dis Colon Rectum 1959;2:465-8.

10 Groden J, Thliveris A, Samowitz W, Carlson M, Gelbert L, Albertsen H, Joslyn G, Stevens J, Spirio L, Robertson M, Sargeant L, Krapcho K, Wolff E, Burt R, Hughes JP, Warrington J, McPherson J, Wasmuth J, Le Paslier $\mathrm{D}$, Abderrahim H, Cohen D, Leppert M, White R. Identification and characterization of the familial adenomatous polyposis coli gene. Cell 1991;66: 589-600.

11 Nishisho I, Nakamura Y, Miyoshi Y, Miki Y, Ando H, Horii A, Koyama K, Utsunomiya J, Baba S, Hedge P, Markham A, Krush AJ, Petersen G, HamUtsunomiya J, Baba S, Hedge P, Markham A, Krush AJ, Petersen G, Ham-
ilton SR, Nilbert MC, Levy DB, Bryan TM, Preisinger A, Smith KJ, Su LK, Kinzler KW, Vogelstein B. Mutations of chromosome 5q21 genes in FAP and colorectal cancer patients. Science 1991;253:665-9.
12 Hamilton SR, Liu B, Parsons RE, Papadopoulos N, Jen J, Powell SM, Krush AJ, Berk T, Cohen Z, Tetu B, Burger SV, Petersen GM, Offerhaus GJA, Tersmette AC, Giardiello FM, Vogelstein B, Kinzler KW. The
basis of Turcot's syndrome. N Engl f Med 1995;332:839-47.

13 Kim HA, Rosenbaum T, Marchionni MA, Ratner N, DeClue JE. Schwann cells from neurofibromin deficient mice exhibit activation of p21 ras, inhibition of cell proliferation and morphological changes. Oncogene 1995;11: 325-35.

14 Brockes JP, Raff MC. Studies on cultured rat Schwann cells. II. Comparison with a rat Schwann cell line. In Vitro 1979;15:772-8.

15 McCarthy KD, de Vellis J. Preparation of separate astroglial and oligodendroglial cell cultures from rat cerebral tissue. 7 Cell Biol 1980;85:890-902.

16 Chomczynski P, Sacchi N. Single-step method of RNA isolation by acid guanidinium thiocyanate-phenol-chloroform extraction. Anal Biochem 1987;162:156-9.

17 Badiali M, Iolascon A, Loda M, Scheithauer BW, Basso G, Trentini GP, Giangaspero F. p53 gene mutations in medulloblastoma. Immunohistochemistry, gel shift analysis, and sequencing. Diagn Mol Pathol 1993;2:23-

18 Wright DK, Manow MM. In: Innis MA, et al, ed. PCR protocols: a guide to methods and applications. 1st ed. New York: Academic Press, 1990:153-8.

19 Su YR, Rutkowski MP, Klanke CA, Wu X, Cui Y, Pun RY, Carter V, Reif M, Menon AG. A novel variant of the beta-subunit of the amiloride-sensitive sodium channel in African Americans. F Am Soc Nephrol 1996;7:2543-9.

20 Varesco L, Gismondi V, James R, Robertson M, Grammatico P, Groden J, Casarino L, De Benedetti L, Bafico A, Bertario L, Sala P, Sassatelli R, Ponz de Leon M, Biasco G, Illeni MT, Sciarra A, Del Porto G, White R, Ferrara GB. Identification of APC gene mutations in Italian adenomatous polyposis coli patients by PCR-SSCP analysis. Am F Hum Genet 1993;52:280-5.

21 Groden J, Gelbert L, Thliveris A, Nelson L, Robertson M, Joslyn G, Samowitz W, Spirio L, Carlson M, Burt R, Leppert M, White R. Mutational analysis of patients with adenomatous polyposis: identical inactivating mutations in
unrelated individuals. Am f Hum Genet 1993;52:263-72.

22 Powell SM, Petersen GM, Krush AJ, Booker S, Jen J, Giardiello FM, Hamilton SR, Vogelstein B, Kinzler KW. Molecular diagnosis of familial adenomatous polyposis. N Engl F Med 1993;329:1982-7.

23 Joslyn G, Richardson DS, White R, Alber T. Dimer formation by an N-terminal coiled coil in the APC protein. Proc Natl Acad Sci USA 1993;90:11109-13.

24 Su LK, Johnson KA, Smith KJ, Hill DE, Vogelstein B, Kinzler KW. Association between wild type and mutant APC gene products. Cancer Res 1993; 53:2728-31.

25 Rubinfeld B, Souza B, Albert I, Muller O, Chamberlain SH, Masiarz FR, Munemitsu S, Polakis P. Association of the $A P C$ gene product with beta-catenin. Science 1993;262:1731-4

26 Su LK, Vogelstein B, Kinzler KW. Association of the APC tumor suppressor protein with catenins. Science 1993;262:1734-7.

27 Behrens J, Jerchow BA, Wurtele M, Grimm J, Asbrand C, Wirtz R, Kuhl M, Wedlich D, Birchmeier W. Functional interaction of an axin homolog, conductin, with beta-catenin, APC, and GSK3beta. Science 1998;280:596-9.

28 Munemitsu S, Souza B, Muller O, Albert I, Rubinfeld B, Polakis P. The $A P C$ gene product associates with microtubules in vivo and promotes their assembly in vitro. Cancer Res 1994;54:3676-81.

29 Smith KJ, Levy DB, Maupin P, Pollard TD, Vogelstein B, Kinzler KW. Wild-type but not mutant APC associates with the microtubule cytoskeleton. Cancer Res 1994;54:3672-5.

30 Su LK, Burrell M, Hill DE, Gyuris J, Brent R, Wiltshire R, Trent J, Vogelstein B, Kinzler KW. APC binds to the novel protein EB1. Cancer Res 1995;55:2972-7.

31 Matsumine A, Ogai A, Senda T, Okumura N, Satoh K, Baeg GH, Kawahara T, Kobayashi S, Okada M, Toyoshima K, Akiyama T. Binding of APC to the human homolog of the Drosophila discs large tumor suppressor protein. Science 1996;272:1020-3.

32 Rubinfeld B, Albert I, Porfiri E, Fiol C, Munemitsu S, Polakis P. Binding of GSK3beta to the APC-beta-catenin complex and regulation of complex assembly. Science 1996;272:1023-6.

33 Trzepacz C, Lowy AM, Kordich JJ, Groden J. Phosphorylation of the tumor suppressor adenomatous polyposis coli (APC) by the cyclin-dependent kinase p34. F Biol Chem 1997;272:21681-4.

34 Heppner Goss K, Groden J. Biology of the APC tumor suppressor. $\mathcal{F}$ Clin Oncol 2000;18:1967-79.

35 Pyles RB, Santoro IM, Groden J, Parysek LM. Novel protein isoforms of the APC tumor suppressor in neural tissue. Oncogene 1998;16:77-82.

36 Nakagawa H, Murata Y, Koyama K, Fujiyama A, Miyoshi Y, Monden M, Akiyama T, Nakamura Y. Identification of a brain-specific APC
homologue, APCL, and its interaction with beta-catenin. Cancer Res 1998; 58:5176-81.

37 Nakagawa H, Koyama K, Murata Y, Morito M, Akiyama T, Nakamura Y. APCL, a central nervous system-specific homologue of adenomatous polyposis coli tumor suppressor, binds to p53-binding p
translocates it to the perinucleus. Cancer Res 2000;60:101-5

38 Nakagawa H, Koyama K, Murata Y, Morito M, Akiyama T, Nakamura Y. EB3, a novel member of the EB1 family preferentially expressed in the central nervous system, binds to a CNS-specific APC homologue. Oncogene 2000;19:210-16.

39 Bhat RV, Baraban JM, Johnson RC, Eipper BA, Mains RE. High levels of expression of the tumor suppressor gene APC during development of the rat central nervous system. F Neurosci 1994;14:3059-71.

40 Bhat RV, Axt KJ, Fosnaugh JS, Smith KJ, Johnson KA, Hill DE, Kinzler $\mathrm{KW}$, Baraban JM. Expression of the APC tumor suppressor protein in oligodendroglia. Glia 1996;17:169-74

41 Senda T, Ino S, Matsushita K, Matsumine A, Kobayashi S, Akiyama T. Localization of the adenomatous polyposis coli tumour suppressor protein in the mouse central nervous system. Neuroscience 1998;83:857-66.

42 Brakeman JS, Gu SH, Wang XB, Dolin G, Baraban JM. Neuronal localization of the adenomatous polyposis coli tumor suppressor protein. Neuroscience 1999;91:661-72.

43 Tomaras C, Painter DM, Basha NJ, Koorey DJ. Case report: an inherited APC mutation in the first reported Australian case of Turbot's syndrome. $\mathcal{F}$ Gastroenterol Hepatol 1998;13:401-4.

44 Mori T, Nagase H, Horii A, Miyoshi Y, Shimano T, Nakatsuru S, Aoki T, Arakawa H, Yanagisawa A, Ushio Y, Takano S, Ogawa M, Nakamura M, Shibuya M, Nishikawa R, Matsutani M, Hayashi Y, Takahashi H, Ikuta F, 
Nishishira T, Mori S, Nakamura Y. Germ-line and somatic mutations of the $A P C$ gene in patients with Turbot syndrome and analysis of $A P C$ mutations in brain tumors. Genes Chrom Cancer 1994;9:168-72.

45 Yong WH, Raffel C, von Deimling A, Louis DN. The $A P C$ gene in Turbot's syndrome. N Engl f Med 1995;333:524.

46 Vortmeyer AO, Stavrou T, Selby D, Li G, Weil RJ, Park WS, Moon YW, Chandra R, Goldstein AM, Zhuang Z. Deletion analysis of the adenomatous polyposis coli and PTCH gene loci in patients with sporadic and nevoid basal cell carcinoma syndrome-associated medulloblastoma. Cancer 1999;85:2662-7.

47 Mandl M, Paffenholz R, Friedl W, Caspari R, Sengteller M, Propping P. Frequency of common and novel inactivating $A P C$ mutations in 202 families with familial adenomatous polyposis. Hum Mol Genet 1994;3:181-4.

48 Lupas A. Prediction and analysis of coiled-coil structures. Methods Enzymol 1996;266:513-25
49 Rost B, Sander C. Prediction of protein secondary structure at better than $70 \%$ accuracy. $7 \mathrm{Mol}$ Biol 1993;232:584-99.

50 Rost B, Sander C. Combining evolutionary information and neural networks to predict protein secondary structure. Proteins 1994;19: 55-72.

51 Huang H, Mahler-Araujo BM, Sankila A, Chimelli L, Yonekawa Y, Kleihues P, Ohgaki H. APC mutations in sporadic medulloblastomas. Am f Pathol 2000;156:433-7.

52 Zurawel RH, Chiappa SA, Allen C, Raffel C. Sporadic medulloblastomas contain oncogenic beta-catenin mutations. Cancer Res 1998;58:896-9.

53 Easwaran V, Song V, Polakis P, Byers S. The ubiquitin-proteasome pathway and serine kinase activity modulate adenomatous polyposis coli proteinmediated regulation of beta-catenin-lymphocyte enhancer-binding factor signaling. f Biol Chem 1999;274:16641-5.

\section{Anauxetic dysplasia, a spondylometaepiphyseal dysplasia with extreme dwarfism}

EDITOR-The term spondylometaepiphyseal dysplasia (SMED) embraces a group of skeletal disorders characterised by abnormalities of the metaphyses, epiphyses, and vertebral bodies. The various entities which fall within this spectrum are differentiated on the basis of clinical and radiological anomalies. Following a recent report by Menger et $a l^{1}$ of sibs with an unknown type of SMED, we wish to report the phenotype of two brothers affected with a similar pattern of clinical and skeletal anomalies. The designation anauxetic dysplasia (from the Greek term for not growing, not permitting growth) is proposed.

The patients are the offspring of healthy, nonconsanguineous German parents. The family history was unremarkable. The mother and father were both 22 years of age at the time of the first pregnancy.

Patient 1 , the proband, was born after an uneventful pregnancy at 40 weeks of gestation. His weight was $2400 \mathrm{~g}(-2.0$ SD) and length $43 \mathrm{~cm}(-3.4 \mathrm{SD})$. Short limbs with short hands, short feet, and flexion contractures of the elbows were noted. His early psychomotor development was retarded. He sat without support at 12 months, began to walk at the age of 19 months, and used a few words at 24 months. At 12 months, kyphosis of the thoracic spine was noted.

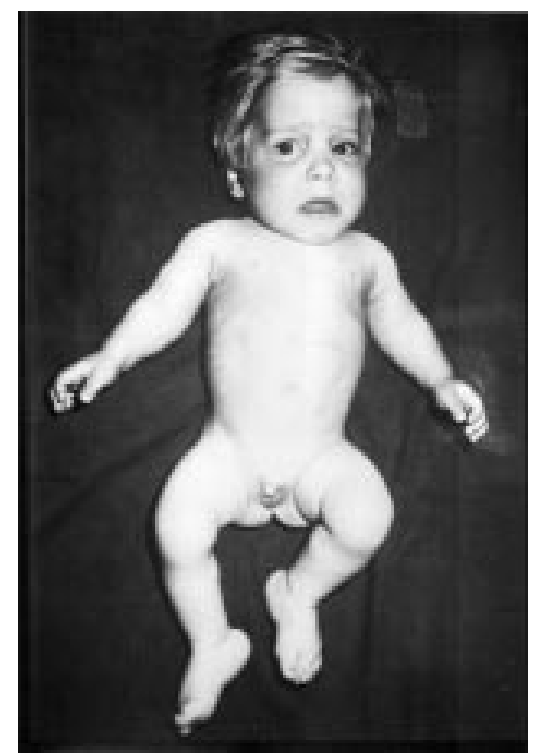

Figure 1 Front view of patient 1 at 23 months showing depressed nasal bridge, short neck, short limbs, and prominent heels.
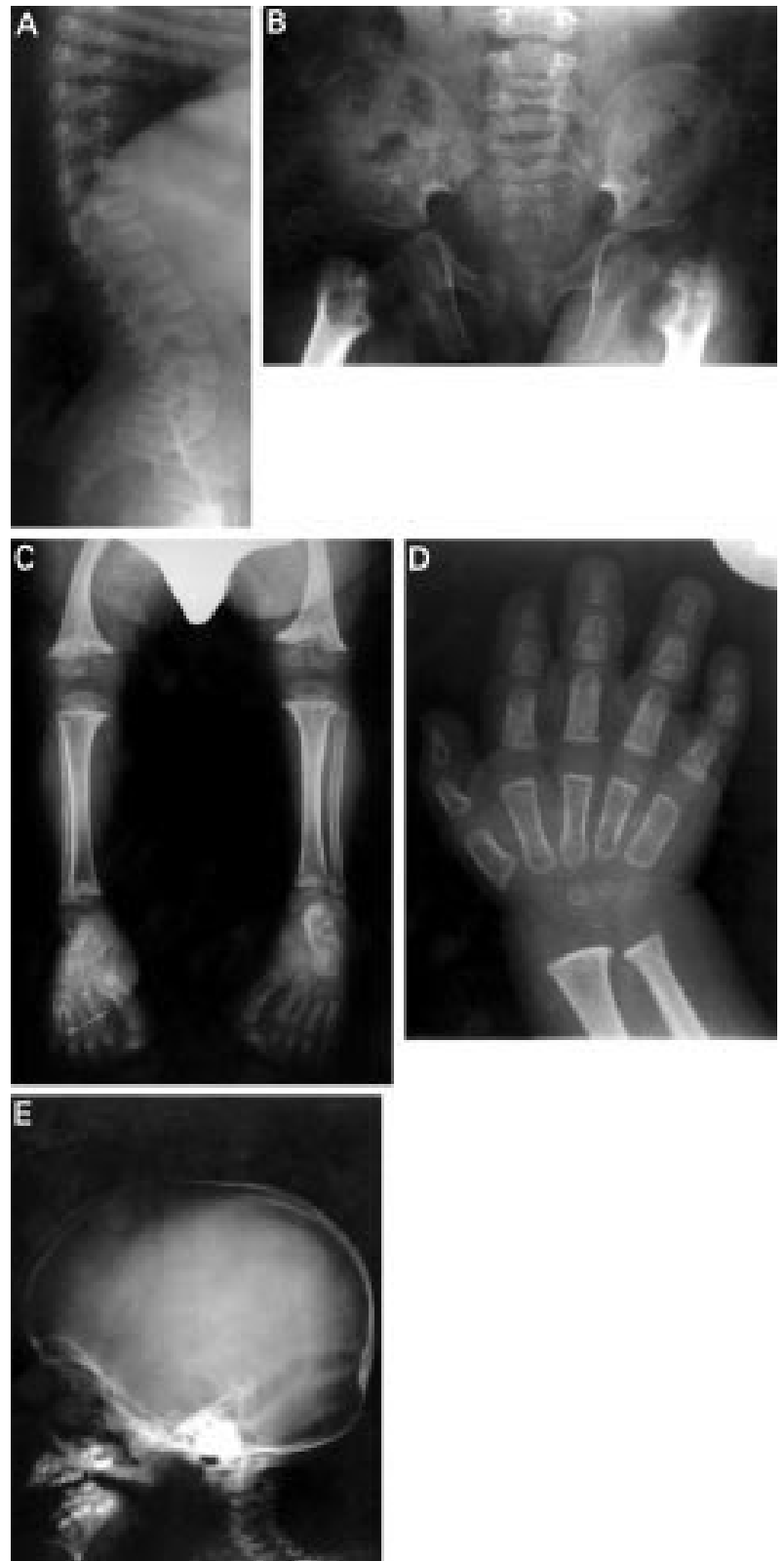

Figure 2 Skeletal changes of patient 1 at 23 months. (A) The vertebral bodies are slightly flattened in the thoracic spine and foreshortened with concave dorsal borders in the lumbar spine. (B) Ossification of the femoral metaphyses is abnormal showing cystic areas reaching into the diaphyses and irregular margins. The femoral heads are small and in varus position. (C) The metaphyseal borders are irregular and delta shaped in the distal femora and distal tibiae. Note forefoot adduction. (D) Carpal and epiphyseal ossification is severely delayed and the middle phalanges are bullet shaped. (E) Radiograph of the skull taken at 23 months showing an enlarged, $\mathfrak{F}$ shaped sella. 

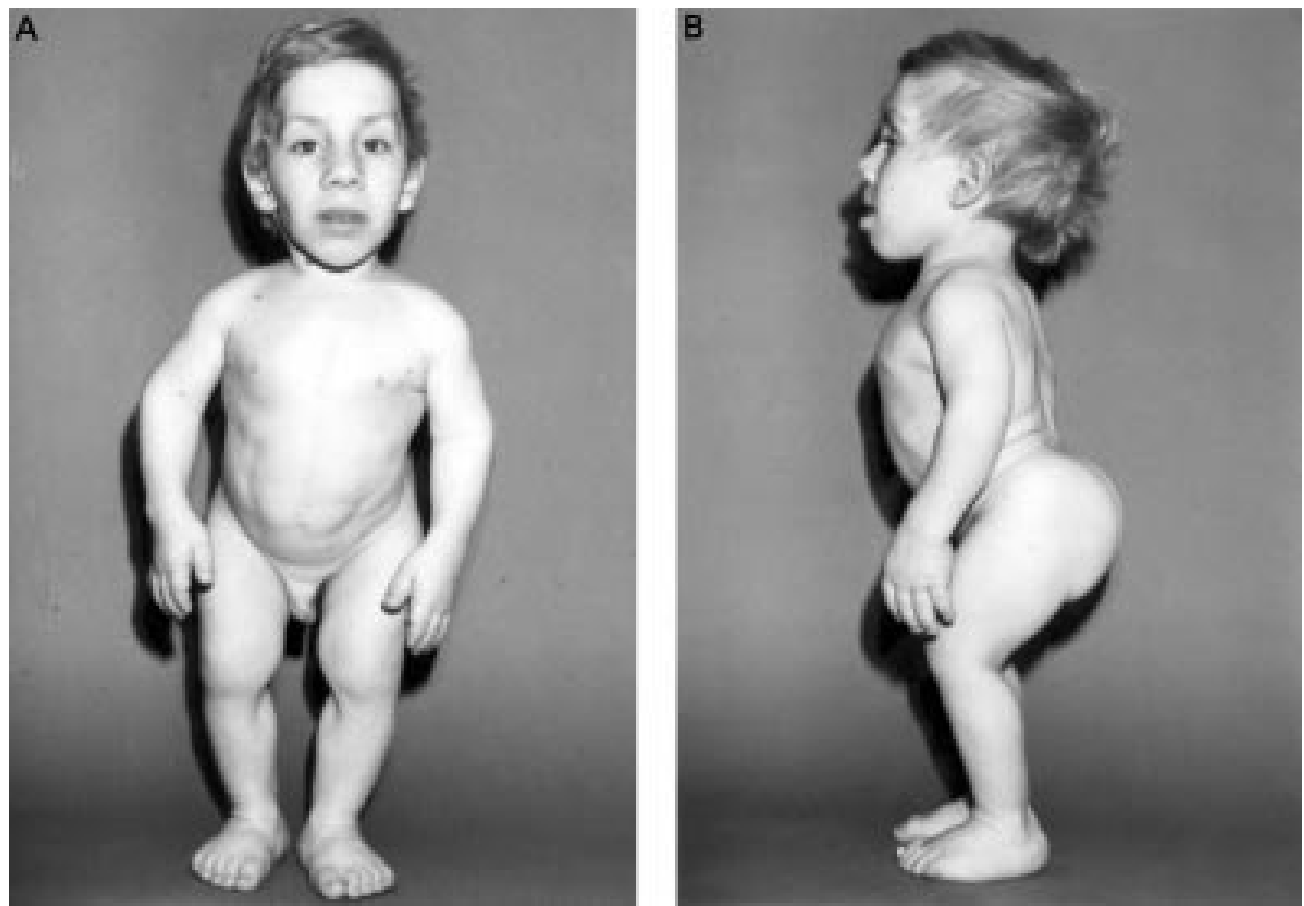

Figure 3 (A) Patient 2 at 11 years. Note depressed nasal bridge, slightly prominent chin, short trunk, and short limbs.

(B) The pithecoid stance and lumbar hyperlordosis point to flexion contractures of the hips.

Examination at 38 months showed a height of $62 \mathrm{~cm}$ (-9.4 SD), weight of $6.5 \mathrm{~kg}$ (-5.2 SD), muscular hypotonia, and short limbs (fig 1). Additional findings included prognathism, small teeth, a large tongue, barrel chest, thoracic kyphosis, lumbar hyperlordosis, and limited extension of the elbows but marked laxity of the other joints. Radiographic findings at the age of 23 months are shown in fig 2 .

At 4 years, respiratory insufficiency and quadriplegia spontaneously occurred, which was attributed to cervical cord compression. After 4 months of ventilation, the patient died of myocardial infarction. Pathological examination showed a height of $63 \mathrm{~cm}(-9.8 \mathrm{SD})$ and weight of $6750 \mathrm{~g}(-5.3 \mathrm{SD})$. Postmortem studies of the cervical spine showed an anterior displacement of C1 on C2 and indentation of the spinal cord at C1. Signs of infection resulting in aortic stenosis were present. Light microscopy of specimens from the iliac crest, vertebral bodies, and femoral and tibial growth plates showed marked hypocellularity of the resting cartilage, somewhat rounded chondrocytes, and a reduced number of proliferating chondrocytes with diminished columnisation of the hypertrophic zone.

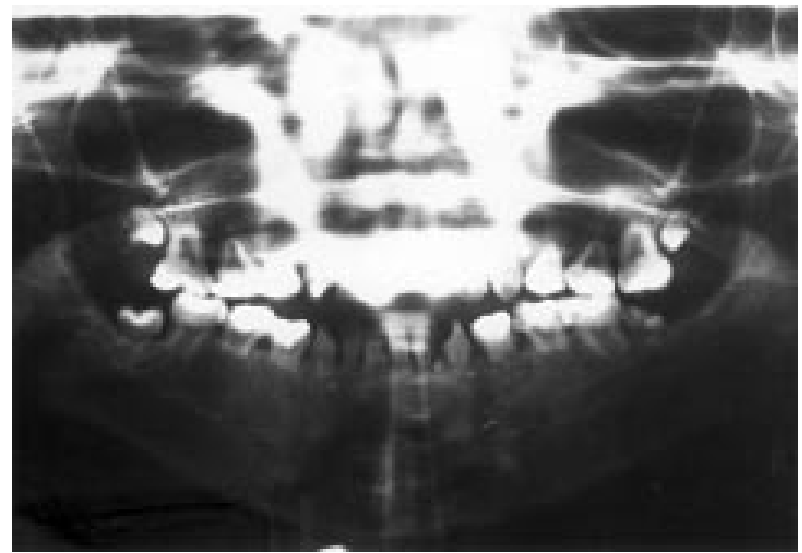

Figure 4 Orthopantomogram of patient 2 at 11 years. Note absence of permanent teeth, generally short dental roots, taurodontism of the premolars, and "pearls" of dental enamel between the roots of the mandibular incisors and canines.
Patient 2, the brother of patient 1 , was born by caesarean section at 42 weeks of gestation with a length of $46 \mathrm{~cm}$ $(-2.1 \mathrm{SD})$ and weight of $2500 \mathrm{~g}(-1.8 \mathrm{SD})$. Growth retardation had been diagnosed by ultrasound at 20 weeks of gestation. His early psychomotor development was unremarkable; he was able to sit without support at 7 months, to walk at 12 months, and to speak his first words at 12 months. He was toilet trained at 3 years. Then retarded speech development was noted. He attended a school for mentally handicapped children.

Examination at 11 years showed a height of $74 \mathrm{~cm}$ (-11.8 SD), weight of $10.3 \mathrm{~kg}$ (weight for length, 75 th centile), and OFC of $49.5 \mathrm{~cm}(-2.7 \mathrm{SD})$, short limbs with short hands and feet, barrel chest, lumbar hyperlordosis, flexion contractures of the elbow and hip, and laxity of the other joints (fig 3 ).

Craniofacial anomalies included a pointed chin, macroglossia, and small teeth. An orthopantomogram showed first permanent maxillary incisors but absence of the remaining permanent dentition (fig 4).

Radiographic examinations at 7 and 11 years showed the bone changes illustrated in fig 5 .

Laboratory studies showed normal values of $\mathrm{Ca}, \mathrm{P}$, alkaline phosphatase, vitamin D3, and urinary mucopolysaccharides. Enzyme studies of blood and skin fibroblasts excluded mucopolysaccharidoses types VI and VII, mucolipidoses types II and III, and $\alpha$-fucosidosis. Chromosome analysis indicated a normal male karyotype. Audiometry showed normal hearing and ophthalmological examination showed no abnormalities. On echocardiographic examination at 11 years, an aortic stenosis was diagnosed. At that time he underwent cervical fusion because of atlantoaxial subluxation documented on CT scans and an MRI of the cervical region.

Judging from the clinical, radiological, and histological appearance, the two sibs in this report and the sibs described by Menger et $a l^{1}$ seem to constitute a distinct bone dysplasia. Clinical characteristics are an extremely severe dwarfism with standard deviation scores of -9 to -13 after the first year of life and an adult height of approximately $85 \mathrm{~cm}$ in females. Other features include a 
pointed chin, oligodontia, mental retardation, congenital contractures of the elbows with hyperlaxity of the remaining large and small joints, and occasional dislocated hips. Atlantoaxial instability, macroglossia, and aortic stenosis were described in two patients. Radiographic signs include a J shaped sella, rounded vertebral bodies with mild platyspondyly, progressive metaphyseal irregularities of the shortened tubular bones, markedly retarded epiphyseal maturation with defective ossification of the femoral head and neck, often slanted acetabula with dislocated hips, and short, bullet shaped middle phalanges. Histological studies of the growth plates show hypocellularity of the resting cartilage and absent columnisation.

The observation of multiple affected children of unaffected parents and the consanguinity of the parents of the sibs described by Menger et $a l^{1}$ are compatible with autosomal recessive inheritance.

We think that mental retardation constitutes part of the condition and is not the consequence of the physical handicap. It is also found in the Dyggve-Melchior-Clausen syndrome. However, that disorder is easily differentiated by the different aspect of the spine, pelvis, and proximal
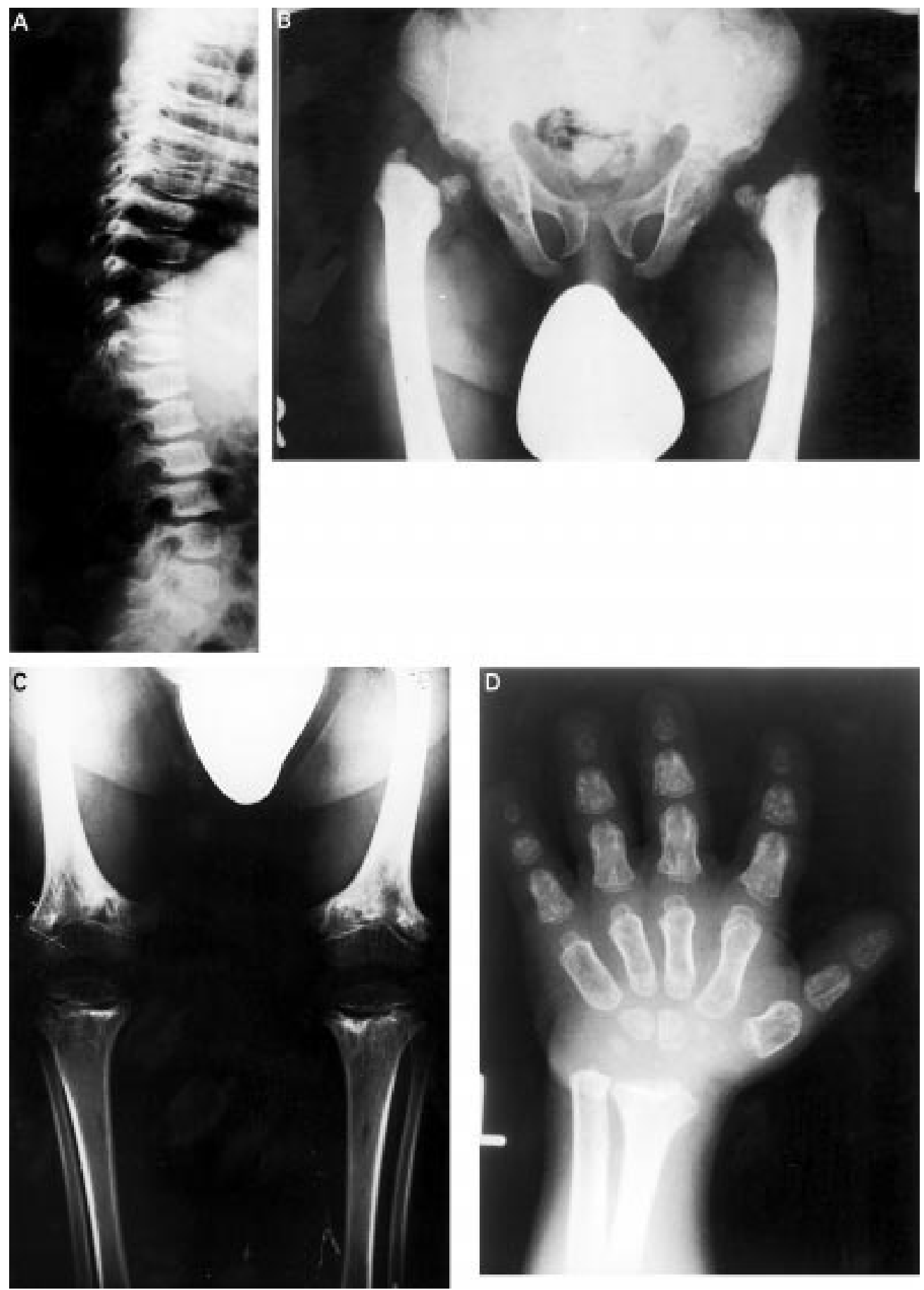

Figure 5 Skeletal changes of patient 2 at 7 years. (A) The vertebral bodies are slightly flattened with convexity of the upper and lower plates and concave anterior and posterior borders. (B) The capital femoral epiphyses are small and in varus position with marked hypoplasia of the femoral necks. The acetabular fossae are shallow and slanted with a wide iliac angle. (C) The metaphyses are mildly flared with abnormal mineralisation and irregular margins. (D) At 11 years the distal metaphysis of the radius is slightly flared. The tubular bones of the hands are short and thick and irregularly mineralised. Note bullet shape of the middle phalanges. Ossification of the carpal bones and epiphyses is grossly retarded. 
femur. An X linked spondyloepimetaphyseal dysplasia with mental retardation was described by Bieganski et al. ${ }^{2}$ In our opinion, our patients do not share the clinical and radiological symptoms of this entity.

The association of a spondyloepimetaphyseal dysplasia and abnormal dentition has been described by Rao et al. ${ }^{3}$ However, the spondylar and epimetaphyseal abnormalities in that condition are much milder and the tubular bones of the hands are slender. Dental anomalies in the Goldblatt syndrome are associated with spondylar and metaphyseal abnormalities but not with such severe epiphyseal changes as seen here. ${ }^{4} 5$

The clinical and radiographic signs of the disorder described here are sufficiently characteristic to differentiate it from other rare spondylometaepiphyseal dysplasias including SMED, short limb-abnormal calcification type, ${ }^{6-8}$ spondyloepimetaphyseal dysplasia (SEMD) with eczema and hypogammaglobulinaemia, ${ }^{9}$ micromelic SMED, ${ }^{10} \mathrm{mi}-$ cromelic dwarfism, humerus, femur, tibia type, ${ }^{11}$ SEMD Irapa type, ${ }^{12}$ SEMD Shohat type,${ }^{13}$ or SEMD caused by ATP sulphurylase kinase 2 deficiency. ${ }^{14}$

In conclusion, the observation of two affected sibs confirms and expands the identity of a bone dysplasia which we propose to name anauxetic dysplasia on the basis of the extreme dwarfism resulting from a severe pre- and postnatal disturbance of skeletal growth and differentiation.

We thank Professor C Opitz for providing the orthopantomogram of patient 2 . DENISE HORN ${ }^{\star} \dagger$ EDGAR RUPPRECHT $\neq$ JÜRGEN KUNZE`S JÜRGEN SPRANGER

*Institute of Human Genetics, Virchow-Klinikum, Humboldt University, Augustenburger Platz 1, D-13353 Berlin Germany

†Department of Tumour Genetics, Max-Delbrueck Centre (MDC) for Molecular Medicine, Berlin, Germany

$\ddagger$ Department of Paediatric Radiology, Technical University of Dresden, Germany
\$Department of Paediatrics, Virchow-Klinikum, Humboldt University, Berlin, Germany

If C Self Research Institute of Human Genetics, Greenwood, USA

Correspondence to: Dr Horn, denise.horn@charite.de

1 Menger H, Mundlos S, Becker K, Spranger J, Zabel B. An unknown spondylo-meta-epiphyseal dysplasia in sibs with extreme short stature. $\mathrm{Am}$ f Med Genet 1996;63:80-3.

2 Bieganski T, Dawydzik B, Kolzlowski K. Spondylo-epimetaphyseal dysplasia: a new X-linked variant with mental retardation. Eur f Pediatr 1999;158:809-14.

3 Rao V, Morton RE, Young ID. Spondyloepimetaphyseal dysplasia and abnormal dentition in siblings: a new autosomal recessive syndrome. Clin Dysmorphol 1997;6:3-12.

4 Goldblatt J, Carman P, Sprague P. Unique dwarfing, spondylometaphyseal skeletal dysplasia, with joint laxity and dentinogenesis imperfecta. $A m \mathcal{F}$ Med Genet 1991;39:170-2.

5 Maroteaux P, Briscioli V, Lalatta F, Bonaventure J. L'odontochondrodysplasie. Arch Pediatr 1996;3:549-54.

6 Borochowitz Z, Langer LO Jr, Gruber HE, Lachman R, Katznelson MBM, Rimoin DL. Spondylo-meta-epiphyseal dysplasia (SMED), short limbhand type: a congenital familial skeletal dysplasia with distinctive features and histopathology. Am f Med Genet 1993;45:320-6.

7 Langer LO Jr, Wolfson BJ, Scott CI Jr, Reid CS, Schidlow DV, Millar EA, Borns PF, Lubicky JP, Carpenter BLM. Further delineation of spondylometa-epiphyseal dysplasia, short limb-abnormal calcification type, with emphasis on diagnostic features. Am f Med Genet 1993;45:488-500.

8 Al-Gazali LI, Bakalinova D, Sztriha, L. Spondylo-meta-epiphyseal dysplasia, short limb, abnormal calcification type. Clin Dysmorphol 1996;5:197206.

9 Slaney SF, Hall CM, Atherton DJ, Winter RM. A new syndrome of spondylometaphyseal dysplasia, eczema and hypogammaglobulinaemia. Clin Dysmorphol 1999:8:79-85.

10 Benz G, Statz A. Mikromele Form der Spondylo-meta-epiphysären Dysplasie. Monatsschr Kinderheilkd 1979;127:690-3.

11 Baxova A, Kozlowski K, Netriova I. Micromelic dwarfism-humerus, femur, tibia type. Pediatr Radiol 1993;23:446-9.

12 Arias S, Mota M, Pinto-Cisternas J. L'osteochonrodysplasie spondylometaphysaire type Irapa: nouveau nanisme avec rachis et metatarsiens courts. Nouv Presse Med 1976;5:319-23.

13 Figuera LE, Ramirez-Duenas ML, Gallegos-Arreola MP, Cantu JM. Spondyloepimetaphyseal dysplasia (SEMD) Shohat type. Am f Med Genet 1994;51:213-15.

14 ul Haque MF, King LM, Krakow D, Cantor RM, Rusiniak ME, Swank RT, Superti-Furga A, Haque S, Abbas H, Ahmad W, Ahmad M, Cohn DH. Mutations in orthologous genes in human spondyloepimetaphyseal dysplasia and the brachymorphic mouse. Nat Genet 1998;20:157-62.

15 Ahmad M, Haque MF, Ahmad W, Abbas H, Haque S, Krakow D, Rimoin DL, Lachman RS, Cohn DH. Distinct, autosomal recessive form of spondyloepimetaphyseal dysplasia segregating in an inbred Pakistani spondyloepimetaphyseal dysplasia segreg
kindred. Am $\mathcal{F}$ Med Genet 1998;78:468-73.
EDITOR-An adducted thumb-club foot syndrome was originally reported by Dundar et $a l^{1}$ in 1997 (MIM 601776). ${ }^{2}$ The patients presented with facial dysmorphism comprising a broad and bossed forehead, widely patent anterior fontanelle, telecanthus, downward slanting palpebral fissures, deep set ears, arachnodactyly, severely adducted thumbs, and club feet. Dundar et al discussed several known conditions featuring adducted thumbs, such as the Freeman-Sheldon syndrome (MIM 193700 and 277720), multiple pterygium syndrome (MIM 265000), congenital contractural arachnodactyly (MIM 121050), the Christian adducted thumb syndrome (201550), and the MASA syndrome/X linked hydrocephalus (MIM 307000). They considered the combination of adducted thumbs, club foot, arachnodactyly, and distinct facial dysmorphism present in their patients to constitute a "new" syndrome. The occurrence of this striking phenotype in male and female cousins, the offspring of consanguineous Turkish parents, indicated autosomal recessive inheritance to them. Very recently, two sibs of healthy Japanese parents with a previously unrecognised combination of distal arthrogryposis with other congenital anomalies were reported by Sonoda and Kouno. ${ }^{3}$ The parents of these patients were first cousins once removed. However, although there are striking similarities between their patients, the authors did not refer to the report of Dundar et al. ${ }^{1}$ We report two male sibs with the same condition, the product of a fourth cousin marriage of an Austrian family. We are tempted to identify the same dysmorphogenetic syndrome in all three families, thereby confirming the existence of a distinguishable syndrome. Autosomal recessive inheritance of the condition is suggested by parental consanguinity in the three kindreds.

Patient 1, a boy, was delivered at 32 weeks of gestation and died shortly after birth from respiratory failure. Birth weight was $1250 \mathrm{~g}$ (10th centile), body length was $40 \mathrm{~cm}$ (25th centile), and head circumference was $28.5 \mathrm{~cm}$ (25th centile). The infant had dysmorphic features including an anteriorly enlarged fontanelle, premature sagittal synostosis, brachycephaly, a low anterior hairline, a broad, bossed forehead, telecanthus, downward slanting palpebral fissures, prominent, deep set ears, and a short neck (fig 1). Clasped fingers, adducted thumbs, and arachnodactyly as well as bilateral talipes equinovarus deformity, scoliosis, hirsutism, cryptorchidism, and a sacral skin tag were noted. There were no additional large joint contractures, dislocations, or skin webs. Postmortem radiographs showed scoliosis, thin ribs, and a thin, high diaphragm (fig 2A) as well as laterally ascending orbital roofs and premature sagittal 
synostosis (fig 2B). Cranial ultrasound examinations showed minor degrees of third and lateral ventricular enlargement. Furthermore, necropsy identified a large secundum type atrial septal defect, mild coarctation of the aorta, a horseshoe kidney, and a common mesentery.

Patient 2 is the brother of patient 1 . He was born at 38 weeks of gestation. Birth weight was $3070 \mathrm{~g}$ (25th centile), body length was $50 \mathrm{~cm}$ (50th centile), and head circumference was $35 \mathrm{~cm}$ (50th centile). He also had a wide open fontanelle, brachycephaly, a deep set anterior hairline, broad, bossed forehead, telecanthus, and downward slanting palpebral fissures. He had bluish sclerae, dysplastic, posteriorly rotated ears, a preauricular tag on the right side, short neck, arachnodactyly, adducted thumbs, bilateral
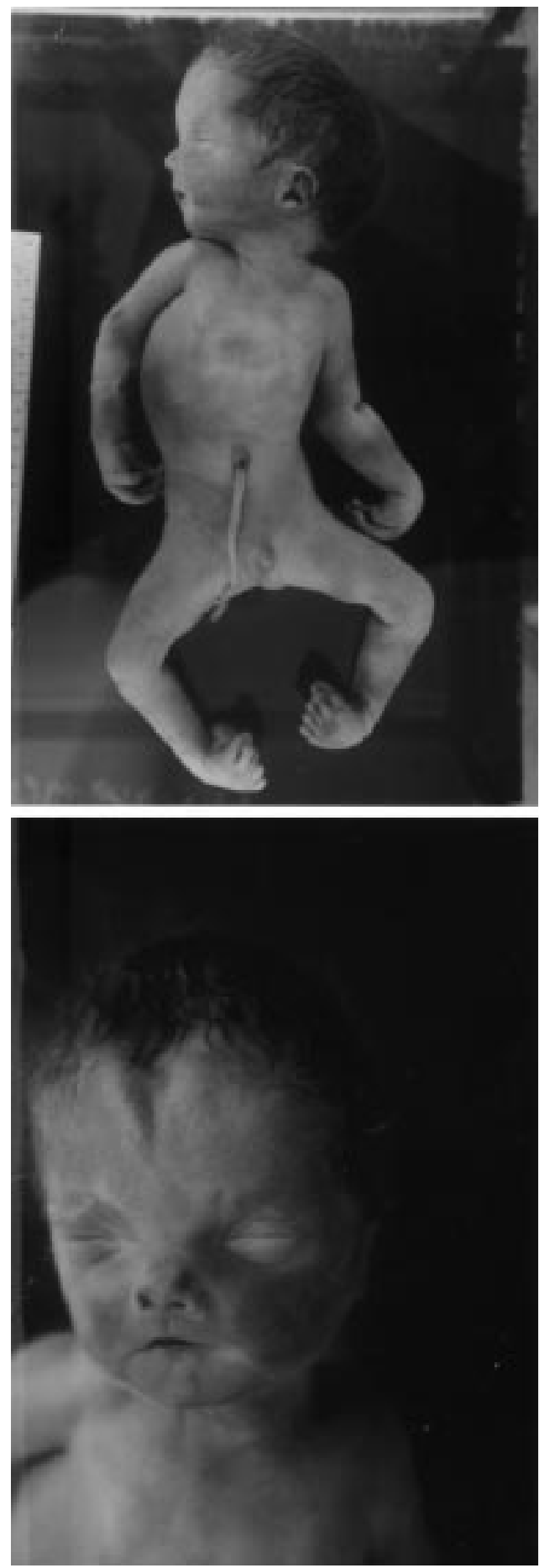

simian creases, narrow chest, umbilical hernia, cryptorchidism, and a bilateral talipes equinovarus deformity (fig 3). Generalised joint laxity was observed. There were no additional large joint contractures, dislocations, or skin webs. $X$ rays of the chest and the skull showed thin ribs (fig $2 \mathrm{E}$ ) and ocular hypertelorism (fig 2C). Ultrasound examinations identified ventricular asymmetry, absence of the left septum pellucidum (fig 2D), and a tethered cord. Ultrasound examinations of the heart and the kidneys were normal. While hearing tests were repeatedly normal, ophthalmological examination identified circumferential corneal pannus when last seen at the age of 12 months. Muscle tone was slightly decreased. Psychomotor development was not retarded. Routine laboratory screening including
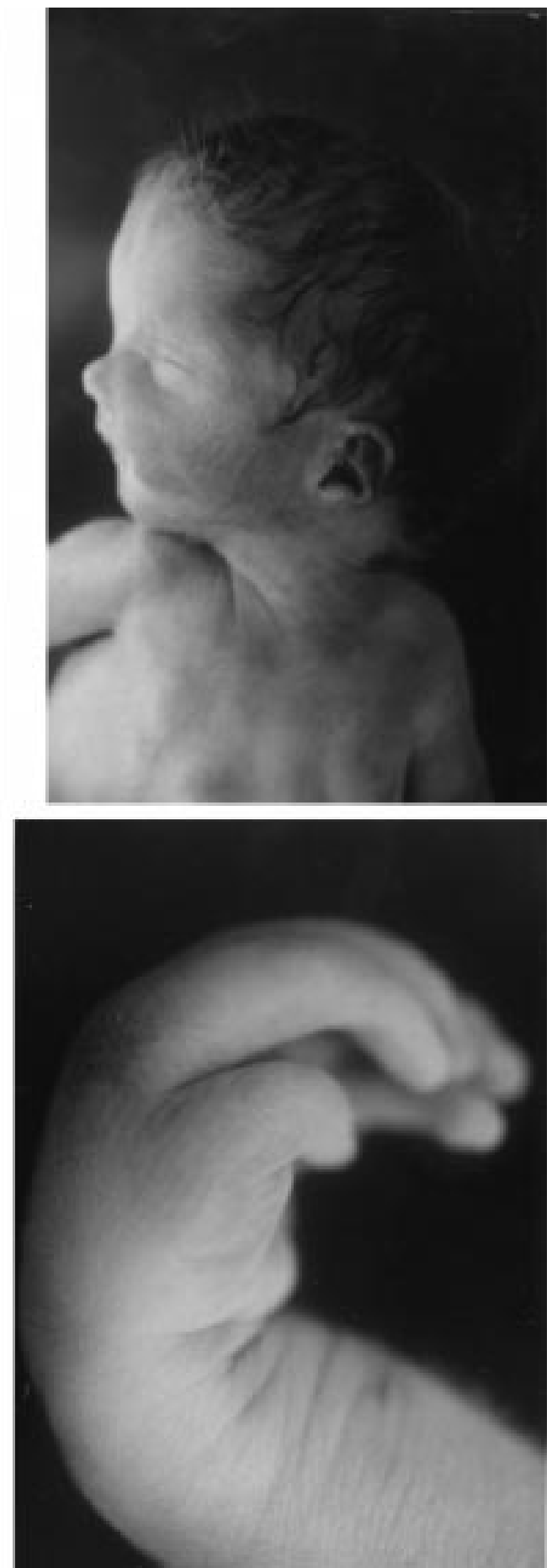

Figure 1 Postmortem appearance of case 1 showing the general aspect, face, and hand of the preterm infant. 

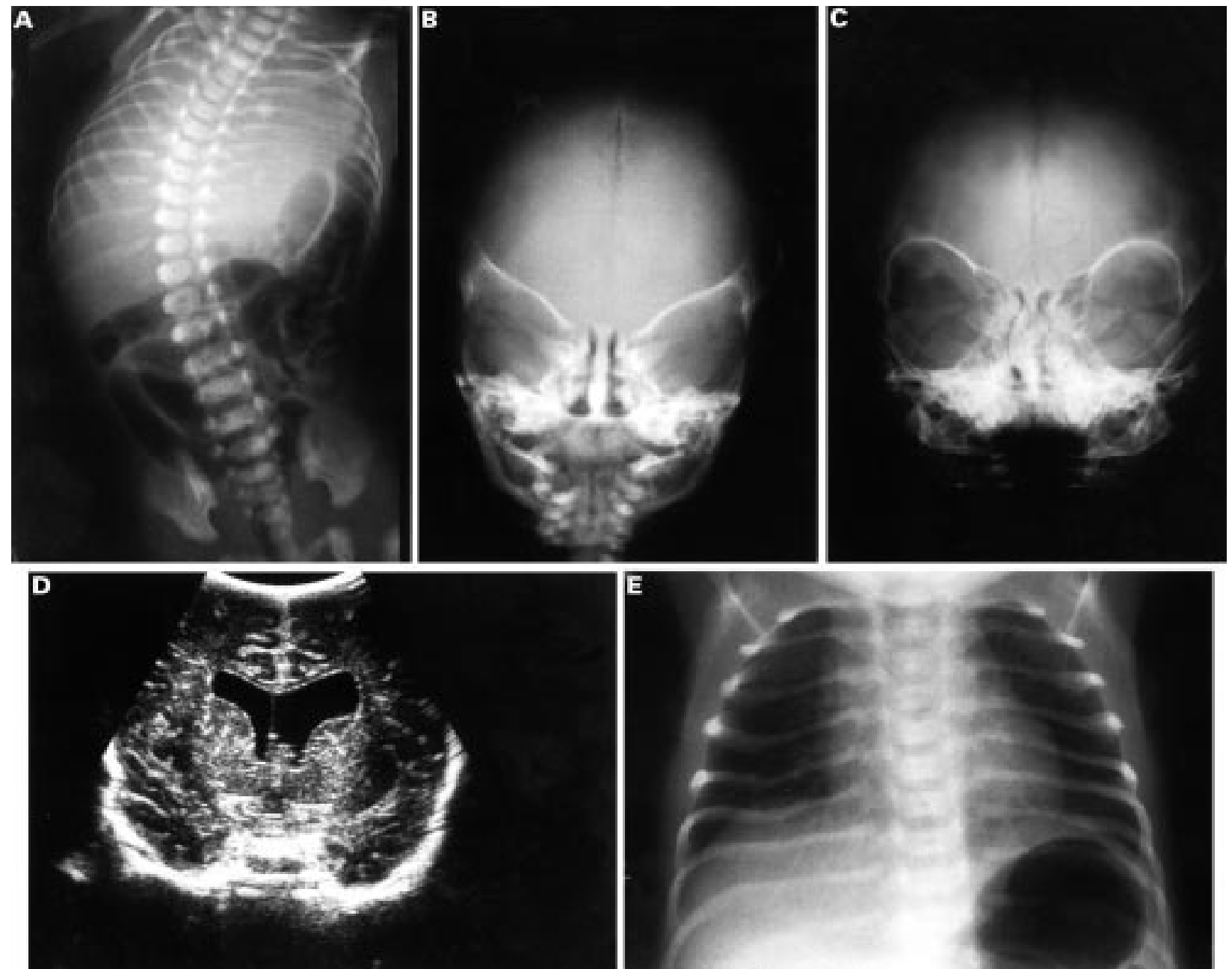

Figure 2 (A) Postpartum thoracoabdominal x ray of case 1. Note severe thoracolumbar scoliosis and thin ribs. (B) Skull x ray of case 1. Note marked sclerosis of the sagittal suture and laterally ascending orbital roofs. (C) Skull x ray of case 2 shows marked hypertelorism. (D) Coronal ultrasound scan showing moderately dilated lateral ventricles and absence of the left leaf of the septum pellucidum in case 2. (E) Chest $x$ ray of case 2 aged 5 days: note thin ribs.

liver function tests and thyroid hormone estimation as well as metabolic screening gave normal results. Chromosome analysis showed a normal male karyotype in both sibs.

The striking similarities between the patients of Dundar et $a l,{ }^{1}$ those reported by Sonoda and Kouno, ${ }^{3}$ and our cases, consisting of dysmorphic facial features, widely patent anterior fontanelle, brachycephaly, shortish neck, arachnodactyly, adducted thumbs, and bilateral talipes equinovarus deformity leads us to conclude that they all have the same syndrome. Moreover, the Turkish and Austrian patients had ventricular abnormalities, such as mild ventricular enlargement, ventricular asymmetry, or absence of the left septum pellucidum in one case. Interestingly, out of the six patients reported three had an atrial septal defect, two had bilateral hydronephrosis not further specified, and one had a horseshoe kidney, whereas the other three patients had no such organ involvement. Undescended testes were a common finding in the male patients in all families.

Some findings are suggestive of an underlying myopathic process in the Austrian and Turkish families. These include the reduced amplitude muscle action potentials with normal distal latency time and nerve conduction velocity in the 18 month old Turkish patient, and the underdeveloped diaphragm, severe scoliosis, and thin ribs in our first case, as well as thin ribs in our second case. Neurological investigation with special regard to tendon reflexes and muscle tone did not show significant abnormalities in our patient examined at the age of 12 months. Generalised joint laxity observed in the Turkish and the Austrian patients indicates a connective tissue disorder in adducted thumb-club foot syndrome. This is emphasised by the presence of bilaterally dislocated hips in both and dislocated elbows in one of the Japanese patients, but no such comment was explicitly made by Sonoda and Kuono. ${ }^{3}$

Importantly, mental development is not significantly impaired in patients with the adducted thumb-club foot syndrome and psychomotor development in our surviving patient was found to be normal at the age of 12 months. This is in line with the findings in both Japanese patients. While global psychomotor developmental delay was evident in both Turkish patients, in the girl at the age of 3.5 and in the boy at the age of 1.5 years, follow up of the boy showed an IQ of 91 and 86 scoring points (Porteus test and Goodenough test, respectively) at 7 years 2 months of age (M Dundar, personal communication). However, further follow up of the patients is indicated since only one of the patients has been examined after the age of 2 years and two affected patients died in infancy, with a connection to the syndrome not conclusively being ruled out.

The differing cardiac and urogenital phenotypes as well as the severe scoliosis in the affected Austrian sibs might be explained by a pleiotropic effect of the disease gene or differences in the genetic and environmental background. This concept might be applied to other phenotypic differences between the Turkish, Japanese, and Austrian patients, notably the more severe degree of the distal arthogryposis, the growth retardation, and the cleft palate 
in the Japanese patients. Another noteworthy difference between the three pairs of patients reported by Dundar et $a l,{ }^{1}$ Sonoda and Kouno, ${ }^{3}$ and us is the presence of anterior synechiae associated with raised intraocular pressure in the Turkish patients and normal ophthalmological findings in the Japanese patients. However, close ophthalmological follow up showed otherwise unexplained circumferential corneal pannus in our patient at the age of 12 months.

To classify the phenotype of their patients, Dundar et al ${ }^{1}$ discussed and excluded several known disease entities including Christian-type adducted thumb syndrome, Escobar syndrome, congenital contractural arachnodactyly (CCA), as well as unclassified published cases, some of which were connective tissue disorders or myopathies. ${ }^{12}$
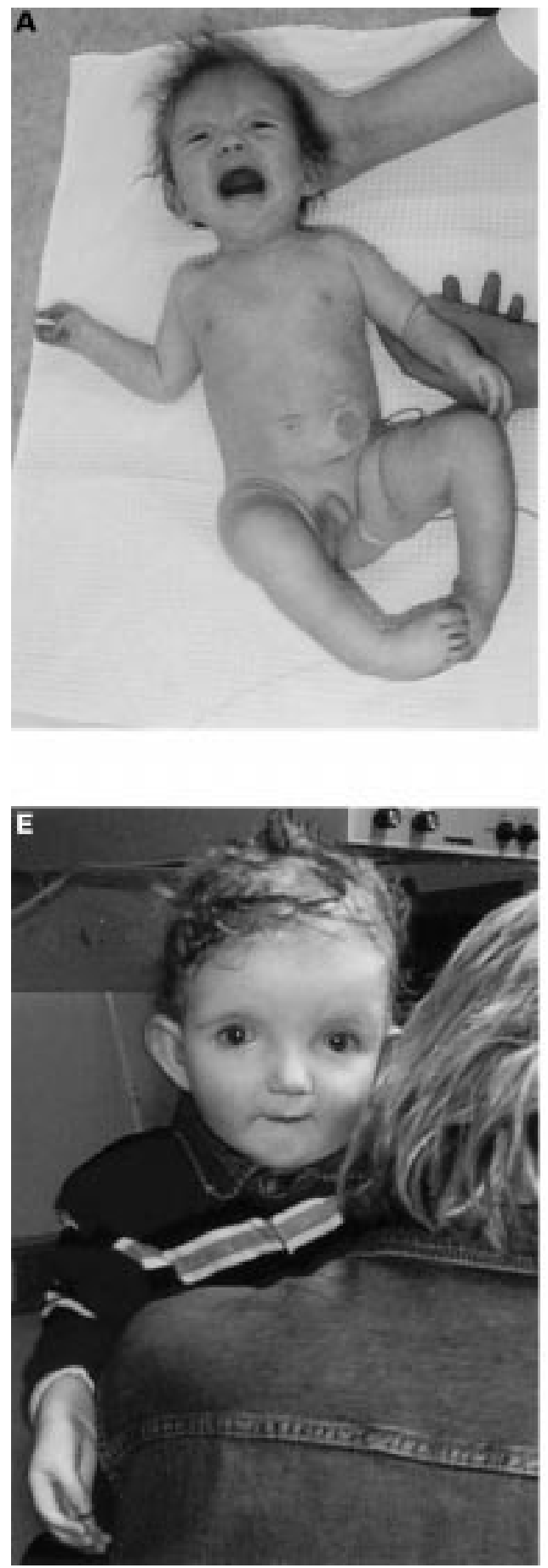

Figure 3 Appearance of case 2. (A-D) General aspect and face of the patient aged 3 months. (E) The patient aged 12 months.
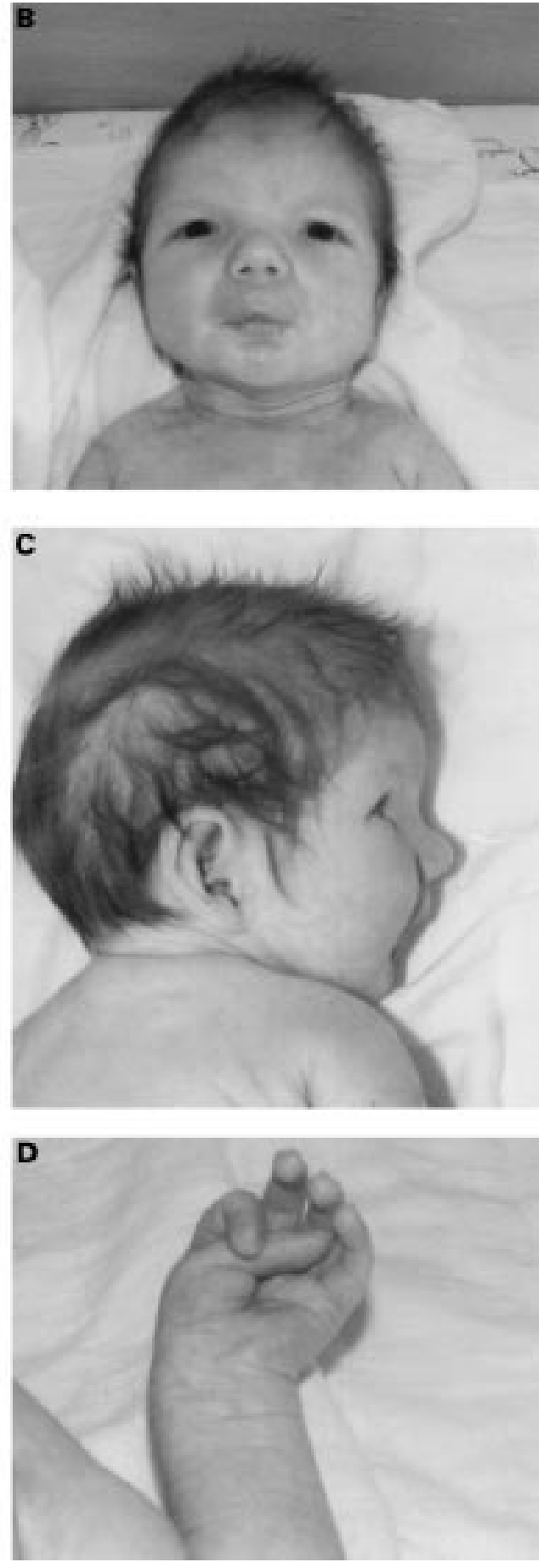

Though some of the facial dysmorphism as well as club foot are found in autosomal recessively inherited Escobar syndrome or the rare type of autosomal recessively inherited Freeman-Sheldon syndrome, these syndromes can be excluded in our case because of absence of major features like pterygia across the large joints or severe microstomia. The same holds true for CCA typically presenting with flexion contractures of all fingers. MASA syndrome/X linked hydrocephalus can be excluded in our case because of the lack of aqueductal stenosis and the presence of distinctive facial dysmorphism. Furthermore, Sonoda and Kouno ${ }^{3}$ reviewed the most important classifications of distal arthrogryposis when discussing their patients. They excluded the known types of distal 
arthrogryposis as well as otopalatodigital syndrome types I and II (MIM 311300 and 304120), Larsen syndrome (MIM 150250), frontometaphyseal dysplasia (MIM 305620), and Freeman-Sheldon syndrome, based either on the probable mode of inheritance in their family, the lack of mental retardation, deafness, or broad distal digits with short nails, and the distinctive facial appearance, finger/toe abnormalities, and radiographic findings in their patients.

Adducted thumbs and club foot as well as downward slanting palpebral fissures, telecanthus, and abnormal ear placement were reported in autosomal recessively inherited Christian-type adducted thumb syndrome. ${ }^{4}$ These features as well as hirsutism, craniosynostosis, and a fatal course of the disease in our first patient are shared in our cases. Therefore, a significant overlap of the adducted thumb syndrome and the adducted thumb-club foot syndrome exists. Most patients classified with this diagnosis, however, presented with additional non-specific findings, such as microcephaly, bifid uvula/cleft or highly arched palate, generalised severe muscular hypotonia, myopathic face, and impaired swallowing. ${ }^{5}$ Myopathic changes in a muscle biopsy were observed in a patient with Christiantype adducted thumb syndrome by Kunze et $a \bar{l}$ and dysmyelination was observed in one of the patients originally reported by Christian et al. ${ }^{4}$ Information as to the aetiology of the disorder is not available in the other cases with that syndrome or in our patients. The existence of a distinctive adducted thumb-club foot syndrome is largely emphasised by the reports of this recognisable dysmorphic condition in three consanguineous families of different ethnic origin. Moreover, the disorder differs significantly from similar established disease entities by the absence of mental retardation and most likely autosomal recessive inheritance. On the other hand, some intra- and interfamilial variability of the syndrome is described.

Finally, our very recent review of published reports, the London Dysmorphology Database, ${ }^{6}$ and the POSSUM Database did not show up any other known syndrome equalling or approximately matching the adducted thumbclub foot syndrome proposed by Dundar et $a l^{1}$ or the syndrome present in the patients reported by Sonoda and Kouno $^{3}$ and considered to represent a new type of distal arthrogryposis. There were some similarities with the patients reported by Moore and Weaver, ${ }^{7}$ who presented with probably autosomal dominant inherited distal arthrogryposis and craniofacial abnormalities and who were considered to have a new subtype of type II arthrogryposis.
We conclude that adducted thumb-club foot syndrome most likely presents a distinct clinical entity. Parental consanguinity observed in our family as well as in the Turkish and Japanese families, strongly supports autosomal recessive inheritance of this syndrome, although we cannot exclude $\mathrm{X}$ linked inheritance or parental germline mosaicism, which has been shown in CCA. ${ }^{8}$ Genome scans in the families with the adducted thumb-club foot syndrome might enable the mapping of the disease causing gene that exerts pleiotropic effects at least in organogenesis and prenatal development.

We wish to thank the family for their cooperation.

ANDREAS R JANECKE* KARIN UNSINN† ALFONS KRECZY IVO BALDISSERAS INGMAR GASSNER $†$ NIKOLAUS NEU† GERD UTERMANN*

THOMAS MÜLLER†

^Institute of Medical Biology and Human Genetics, University of Innsbruck, Schöpfstrasse 41, A-6020 Innsbruck, Austria

†Department of Paediatrics, University of Innsbruck, Austria

¥Institute of Pathology, University of Innsbruck, Austria

\Department of Ophthalmology, University of Innsbruck, Austria

Correspondence to: Dr Janecke, Andreas.Janecke@uibk.ac.at

1 Dundar M, Demiryilmaz F, Demiryilmaz I, Kumandas S, Erkilic K, Kendirci M, Tuncel M, Ozyazgan I, Tolmie JL. An autosomal recessive adducted thumb-clubfoot syndrome observed in Turkish cousins. Clin Genet 1997;51:61-4.

2 Online Mendelian Inheritance in Man, OMIM (TM). Center for Medical Genetics, Johns Hopkins University, Baltimore, MD, and National Center for Biotechnology Information, National Library of Medicine, Bethesda, MD, 1999. World Wide Web URL: http://www.ncbi.nlm.nih.gov/omim/

3 Sonoda T, Kouno K. Two brothers with distal arthrogryposis, peculiar facial appearance, cleft palate, short stature, hydronephrosis, retentio testis, and normal intelligence: a new type of distal arthrogryposis? Am $\mathcal{F}$ Med Genet 2000;91:280-5.

4 Christian JC, Andrews PA, Conneally PM, Muller J. The adducted thumbs syndrome. An autosomal recessive disease with arthrogryposis, dysmyelination, craniostenosis, and cleft palate. Clin Genet 1971;2:95-103.

5 Kunze J, Park W, Hansen KH, Hanefeld F. Adducted thumb syndrome. Kunze J, Park W, Hansen $\mathrm{KH}$, Hanefeld F. Adducted thumb syndrome.
Report of a new case and a diagnostic approach. Eur $\mathcal{f}$ Pediatr

6 Winter RM, Baraitser M. The London Dysmorphology Database. Oxford: Oxford University Press, 1993.

7 Moore CA, Weaver DD. Familial distal arthrogryposis with craniofacial abnormalities: a new subtype of type II? Am F Med Genet 1989;33:231-7.

8 Putnam EA, Park ES, Aalfs CM, Hennekam RC, Milewicz DM. Parental somatic and germ-line mosaicism for a FBN2 mutation and analysis of FBN2 transcript levels in dermal fibroblasts. Am $\mathcal{7}$ Hum Genet 1997;60:818-27.

\section{Diaphragmatic hernia, hydrocephalus, and cardiac malformations in four pregnancies of a non-consanguineous couple}

EDITOR-Diaphragmatic hernia occurs with an incidence of 1/4000-1/5000 newborns. ${ }^{12}$ About half of the cases occur as isolated malformations; anomalies of the central nervous system are well known associated defects, as are midline malformations such as cleft lip and palate and heart defects. ${ }^{12}$ Among syndromic causes of diaphragmatic hernia are numerous chromosomal imbalances ( $4 \mathrm{p}$ deletion, trisomy $18, \mathrm{i}(12 \mathrm{p})$, and some single gene defects such as the autosomal recessive Fryns syndrome ${ }^{3}$ and an $\mathrm{X}$ linked form, the thoracicoabdominal syndrome. ${ }^{45}$ Fryns syndrome is probably the most frequent non-chromosomal malformation syndrome associated with diaphragmatic hernia, ${ }^{3}$ but this disorder presents with typical dysmorphic features, and both heart and CNS malformations are infrequent in Fryns syndrome.

The family reported here, along with several other published reports, combining CNS, heart, and diaphragmatic defects, may help to delineate a distinct syndromic form of diaphragmatic hernia.

Healthy, non-consanguineous parents, of French origin and with unremarkable family histories, had six unsuccessful pregnancies. Two resulted in first trimester spontaneous abortion. The other four led to pregnancy terminations between 15 and 23 weeks' gestation because of malformations detected on ultrasound (table 1). Left diaphragmatic hernia was the earliest observed and most constant feature. Cardiac malformations, present in all cases, were of varying 
Table 1 Summary of malformations in affected fetuses

\begin{tabular}{|c|c|c|c|c|}
\hline & Fetus 1 & Fetus 2 & Fetus 3 & Fetus 4 \\
\hline Gestational age, sex & $23 \mathrm{wk}, \mathrm{M}$ & $24 \mathrm{wk}, \mathrm{M}$ & $18 \mathrm{wk}, \mathrm{F}$ & $16 \mathrm{wk}, \mathrm{F}$ \\
\hline Ultrasound (anomalies) & Brain, diaphragm & Diaphragm, heart & Hydrocephalus, diaphragm & Diaphragm \\
\hline CNS & Hydrocephalus, 3-4 vent & No brain histology done & Tetraventricular hydrocephalus & Tetraventricular hydrocephalus \\
\hline Cardiac & VSD & Hypoplastic left heart & VSD, ASD & Complex heart malformation \\
\hline Gastrointestinal & - & Imperforate anus & - & - \\
\hline Abdominal wall & Diaphragmatic hernia, left & Diaphragmatic hernia, left & Diaphragmatic hernia, left & Diaphragmatic hernia, left \\
\hline
\end{tabular}

types: VSD/ASD was seen twice and hypoplastic left heart and a complex heart malformation once each. Hydrocephalus was also constant on morphological examination of the fetus, although not yet visible on ultrasound in the pregnancy terminated at 15 weeks. In cases 3 and 4, examined by the same neuropathologist, this was a tetraventricular, non-obstructive hydrocephalus. The only inconstant malformation was imperforate anus, described in one male fetus. Muscle histology was normal in the two cases investigated in detail.

We examined the last two fetuses personally. No major dysmorphic features were present (fig 1). Specifically, the craniofacial features and nail/distal digit hypoplasia typical of Fryns syndrome were lacking.

Genetic analyses included karyotyping of fetuses 2-4 on amniocentesis (one) or fibroblasts post-termination (one), or both (one). Cytogenetic studies using RHG, RTBG, and GTBG banding were normal at the 550-600 band resolution level. Standard karyotypes of both parents were also normal, 46,XX and 46,XY. A 22q11 microdeletion was also excluded in the parents and one fetus by fluorescence in situ hybridisation using a critical region probe (Oncor). The parents were investigated with a probe set covering 41 subtelomeric regions (Cytocell Telomeric Multiprobe), which confirmed the presence of all telomeres. Analysis of fetus number 4 with the MultiFish Spectra Vision set (Vysis) was also normal.
We present here a couple whose six pregnancies resulted in two spontaneous abortions and four pregnancy terminations for multiple malformations. The malformed fetuses, two male and two female, presented with a remarkably similar malformation syndrome comprising left diaphragmatic hernia, heart malformation, and nonobstructive hydrocephalus of early onset. The diaphragmatic hernia was suspected as early as 12 weeks on ultrasound and confirmed by $15-16$ weeks; the hydrocephalus developed somewhat later but was clearly present on echographic examination at 19-20 weeks' gestation.

A chromosomal anomaly could have explained the combination of first trimester miscarriage and malformed fetuses in the same family, but cytogenetic and molecular cytogenetic studies, including the use of telomeric probes for detection of a cryptic translocation, were repeatedly normal. We considered a mitochondrial disorder, given that all six pregnancies were abnormal. However, we know of no precedent for such an aetiology in malformation syndromes and fetal muscle histology was normal.

An autosomal recessive aetiology seems the most likely, given four affected fetuses of both sexes born to normal parents. The constancy of the phenotype is anecdotal evidence for a recessive disorder, as is the resemblance to Fryns syndrome, which follows this hereditary transmission. Among syndromic causes of diaphragmatic hernia,
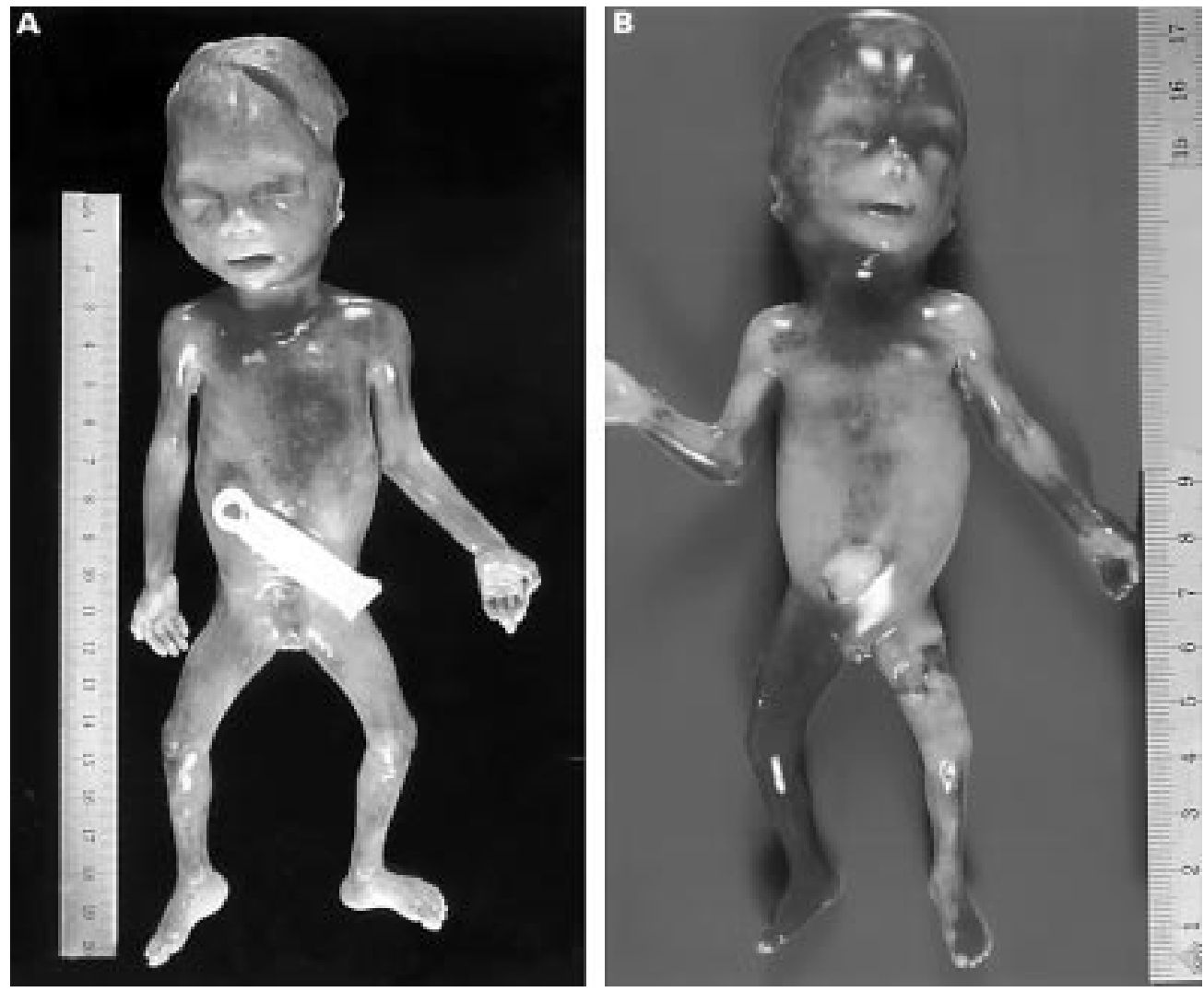

Figure 1 Fetuses $3(A)$ and 4 (B) after pregnancy termination (18 and 16 weeks' gestation). Note lack of distinct dysmorphic features. 
Table 2 Differential diagnosis

\begin{tabular}{lllll}
\hline & Fryns & "Fryns-like” cases & Thoraco-abdominal & Current cases \\
\hline Diaphragmatic hernia & ++ & ++ & ++ & ++ \\
Hydrocephalus & + & ++ & ++ & ++ \\
Heart malformation & + & + & ++ & ++ \\
Anal anomaly (imperforate) & - & - & - & + \\
\hline
\end{tabular}

${ }^{\star}$ See text for discussion of cases reported in references 2,10 , and 11 .

Fryns syndrome is the closest clinically. However, the typical dysmorphic features of facies and limbs were lacking in the fetuses and CNS pathology is not frequent in this disorder. Heart malformations are known but are rarely severe and imperforate anus is rarely, if ever, described. ${ }^{367}$

The thoracicoabdominal syndrome ${ }^{45}$ combines diaphragmatic defects with CNS anomalies, including hydrocephalus in some cases, but there are other midline defects (omphalocele, clefts of lip and palate) and inheritance is X linked recessive. ${ }^{5}$ The family reported here had similarly affected fetuses of both sexes. We also considered the CHARGE association and the hydrolethalus syndrome ${ }^{78}$ in the differential diagnosis, but excluded them given inadequate clinical fit (table 2 ).

Several other families, some of which are described within the Fryns syndrome entry (MIM 229850) in the catalogue of Mendelian inheritance in man, ${ }^{9}$ have been reported with a malformation complex similar to that of our patients. Fitch et $a l^{10}$ reported a child with absent left hemidiaphragm, arhinencephaly, and cardiac malformations born to consanguineous parents; as distal digital hypoplasia was described, it is possible that their case represents Fryns syndrome, which was not delineated nominally until the following year. However, other publications also report the association of diaphragmatic hernia and CNS anomalies, sometimes in association with heart defects. ${ }^{11}$ Bieber $e t ~ a l^{2}$ presented a family in which two sibs, of different sexes, had a right diaphragmatic hernia, pulmonary hypoplasia/agenesis, and hydrocephalus. Their family differs from the one we report in that the hernias were right sided (the rarer form), there was no cardiac defect, and the hydrocephalus was obstructive.

Therefore, although we are not aware of another reported family with exactly the same combination of anomalies, there is some precedent for the combination of heart, CNS, and diaphragmatic defects outside Fryns syndrome. We strongly suggest, based on the family reported here, the existence of a monogenic, probably autosomal recessive aetiology for this combination. Whether this disorder will prove to be the result of a distinct mutated gene, or might perhaps be allelic with that for Fryns syndrome, will await identification of the gene or genes responsible. In the meantime, descriptions of additional families would greatly aid genetic counselling and prenatal diagnosis in severe cases such as the family presented here.

\section{Note added in proof}

The couple's seventh pregnancy resulted in the term birth of a normal boy.

We would like to thank the couple for their cooperation in the face of a devastating situation. We appreciate the collaboration of Drs Jean Ouziel and Gianpaolo ing situation. We appreciate the collaboration of Drs Jean Ouziel and Gianpaolo Pizzolato, as well as that of colleagues in obstetrics, ultrasound, and cytc
ics. Mr Tom Warren's help with graphics is gratefully acknowledged.

C D DELOZIER-BLANCHET* J LESPINASSE + M A BRUNDLER $\ddagger$ P EXTERMANNS

${ }^{\star}$ Division of Medical Genetics, Geneva University Hospital, 1 rue

Michel-Servet, $\mathrm{CH}-1211$ Geneva 4, Switzerland

†Cytogenetics Laboratory, Central Hospital, Chambery, France

$\ddagger$ Department of Pathology, Geneva University Hospital, Switzerland

SFetal Medicine Unit, Department of Obstetrics and Gynecology, Geneva

University Hospital, Switzerland

Correspondence to: Dr DeLozier-Blanchet, delozier@cmu.unige.ch

1 David TJ, Illingsworth CA. Diaphragmatic hernia in the south west of England. F Med Genet 1976;13:253-62.

2 Bieber FR, Dawson AE, Holmes LB. Etiologic complexities of diagphragmatic defects: right diaphragmatic hernia, pulmonary hypoplasia/agenesis and hydrocephalus in sibs. Am $\mathcal{F}$ Med Genet 1991;41:164-8.

3 Fryns JP, Moerman F, Goddeeris P, Bossuyt C, Van den Berghe H . A new lethal syndrome with cloudy corneae, diaphragmatic defects and distal limb deformities. Hum Genet 1979;50:65-70.

4 Parmi R, Meizner I, Katz M. Familial congenital diagphragmatic defect and associated midline anomalies: further evidence for an X-linked midline gene? Am f Med Genet 1990;36:313-15.

5 Parvari R, Carmi, Weissenbach J, Pilia G, Mumm W, Weinstein Y. Refined genetic mapping of X-linked thoracicoabdominal syndrome. Am $\mathcal{F} \mathrm{Med}$ Genet 1996;61:401-2

6 Cunniff C, Jones KL, Saal HM, Stern HJ. Fryns syndrome: an autosomal recessive disorder associated with craniofacial anomalies, diaphragmatic hernias and distal digital hypoplasia. Pediatrics 1990;85:499-504.

7 Jones KL. Smith's recognizable patterns of human malformation, London: Saunders, 1997:857.

8 Winter RM, Baraitser M. London dysmorphology database. Oxford Medical Databases. Oxford: Oxford University Press, 1996.

McKusick VA. Mendelian inheritance in man. On-line edition. Baltimore: The Johns Hopkins University Press, 2000.

10 Fitch N, Srolovitz H, Robitaille Y, Guttman R. Absent left hemidiaphragm, arhinencephaly, and cardiac malformations. F Med Genet 1978;15:399-401. 11 Landau J W, Barry JM, Koch R. Arhinencephaly. F Pediatr 1963;62:895-900.

\section{Deletion 22q11 syndrome: acknowledging a lost eponym as we say farewell to an acronym}

EDITOR-Time may be closing on use of the acronym "CATCH22" for "deletion 22q11 syndrome", ${ }^{1}$ but it is likely to be a good while before it has finally run out. Many will prefer to retain their personal preference and "deletion $22 \mathrm{q} 11$ syndrome" does not easily roll off the tongue (and it really needs to be stated in full to distinguish it from the separate and emerging "deletion 22q13 syndrome" ${ }^{3}$ ). Besides this, any consensus accepted by geneticists will take time to filter through to colleagues in other disciplines who, carrying most of the clinical burden for managing the patients' medical problems, may reasonably question the value of so much discussion about a name. Before (if ever) the relatively unambiguous "deletion 22q11 syndrome" achieves universal acclaim, and/or "velocardiofacial syndrome" (VCFS), the history of medical genetics should record that a little known otolaryngologist from Prague, Dr Eva Sedláčková, almost certainly described the syndrome in $1955,{ }^{4}$ and subsequently in $1967,{ }^{5}$ as a result of good clinical observation on a cohort of patients with congenital shortening of the soft palate. The findings are further referred to in a paper on soft palate innervation. ${ }^{6}$ The first paper, of course, appeared some 10, 13, 23, and 25 years before publications by DiGeorge, ${ }^{7}$ Shprintzen et $a l^{8}$ 
Strong, ${ }^{9}$ and Takao et al, ${ }^{10}$ respectively. With medical and scientific publications dominated by the English language, the publication of Sedláčková's work in her native Czechoslovakian was always likely to pass unnoticed, a problem compounded by the consequences of cold war politics. However, the similarity of Sedláčková's cases to VCFS has previously been noted by one of us (RWP) ${ }^{11}$ and also acknowledged in a major text. ${ }^{12}$ Sedláčková herself, who died in 1976 aged 62, attempted to achieve some recognition for describing the condition that subsequently became known as VCFS (R J Gorlin, personal communication).

In the first and most important description of a syndrome with congenitally short velum, ${ }^{4}$ Sedláčková highlighted many of the features characterising deletion 22q11 syndrome. Between 1950 and 1954, 26 children, 11 boys and 15 girls, were identified with a shortened soft palate and a sufficiently long hard palate but no clefting. They ranged in age from 2 to 16 years and their appearance was so distinctive that it was known the child would "snuffle" even before it spoke. Nine of the children were poor feeders because of a weak suck and motor development was delayed in all but two. Only seven began speaking at the normal age, while the others typically began to speak in their third or fourth years. The facial features were described as striking, with narrow, slanting eye slits, a degree of telecanthus, an open mouth, a wide base to the nose, and a fairly flat nose with small nostrils. The upper lip was described as being short and drawn up, the philtrum somewhat smooth, and there was a degree of micrognathia. In addition, ear lobes were described as small, the entrance to the auditory meatus narrow, and otitis media was common. In 22 of the 26 children the hands were described as small and slender, the fingers being short and slim with pointed ends. Terminal phalanges, in particular, were short. Growth was generally satisfactory, with the exception of three cases who were noticeably shorter and weaker than their sibs. Occasional abnormalities included mild contraction of the fingers $(n=1)$, overlapping toes $(n=2)$, unilateral oligosyndactyly of the right hand $(n=1)$, congenital subluxation of the hip $(\mathrm{n}=2)$, Sprengel deformity $(n=1)$, and undescended testes $(n=3)$. Mental retardation to some degree was noted in nine of the 26 . By the time of her second paper, ${ }^{5}$ Sedláčková had gathered 48 cases, noted an imperfect closure of the eyelids in some, and added congenital heart disease to the list of associated anomalies. Her syndrome became known as velofacial hypoplasia. ${ }^{13}$

Most significantly, Sedláčková provided illustrations of typical cases with a congenitally shortened velum in her first paper, ${ }^{4}$ including two examples with frontal portrait view. In her second paper a further portrait of a typical case is provided. $^{5}$ Clinicians who know deletion 22q11 syndrome could surely not dispute the patients having facies well within the spectrum with which we are now familiar. It seems likely she described children across the DiGeorge-VCFS spectrum, as a short philtrum with tented upper lip tends to be part of DiGeorge syndrome, while slender, tapering fingers tend to be associated with VCFS. However, she made no mention of long fingers, which is generally the pattern in VCFS, and herein lies the only obvious discrepancy. Nevertheless, the illustrations of hands from typical cases ${ }^{4}$ is acceptably within the spectrum for deletion 22q11 syndrome. She has not included children with overt clefting but this probably reflects her ascertainment of cases, perhaps not wanting to potentially "contaminate" the cohort by including those operated on for cleft palate. She does, however, refer to 10 cases with congenitally short palate, operated on for cleft palate, from the huge series of more than 2600 cases operated on by the late Professor Burian. ${ }^{4}$ One cannot, of course, exclude the possibility that she described some non-deletion $22 \mathrm{q} 11$ cases because today, with the benefit of a reliable test, phenocopies are sometimes observed in genetic clinics.

Overall, the close overlap of Sedláčkovás description, together with the illustrative material, is convincing, but expert readers must decide for themselves whether she has reported what we now know as deletion $22 \mathrm{q} 11$ syndrome. If the subjects could be revisited and FISH tested, the controversy would be resolved but the passage of time perhaps makes this unlikely. There has been work showing a common aetiology of velofacial hypoplasia and VCFS, ${ }^{14}$ but no suggestion that any of Sedláčková original cases were included. Given the prevalence of deletion $22 \mathrm{q} 11$ syndrome, any clinician with a substantial case load of velopharyngeal insufficiency is bound to have a cohort with the condition; it is then a matter of distinguishing these from other cases. We suggest that Sedlácková successfully achieved this, provided a good clinical description, and should be acknowledged for the accomplishment.

PETER D TURNPENNY* RON W PIGOTT†

${ }^{\star}$ Clinical Genetics, Royal Devon E Exeter Hospital, Barrack Road, Exeter, Devon EX2 5DW, UK

†Honorary Consultant Plastic Surgeon, Frenchay Hospital NHS Trust, Bristol, UK

1 Burn J. Closing time for CATCH22. F Med Genet 1999;36:737-8.

2 Wong ACC, Ning Y, Flint J, Clark K, Dumanski JP, Ledbetter DH, McDermid HE. Molecular characterisation of a $130-\mathrm{kb}$ terminal microdeletion at $22 \mathrm{q}$ in a child with mild mental retardation. Am f Med Genet 1997;60:11320

3 Precht KS, Lese CM, Spiro RP, Huttenlocher PR, Johnston KM, Baker JC, Christian SL, Kittikamron K, Ledbetter DH. Two 22q telomere deletions serendipitously detected by FISH. F Med Genet 1998;35:939-42.

4 Sedláčková E. Insuficience patrohltanového záveru jako vyvojová porucha. Cas Lék Cesk 1955;94:1304-7.

5 Sedláčková E. The syndrome of the congenitally shortened velum. The dual innervation of the soft palate. Folia Phoniatr 1967;19:441-50.

6 Sedláčková E, Laštovka M, Sram F. Contribution to knowledge of soft palate innervation. Folia Phoniatr 1973;25:434-41.

7 DiGeorge AM. Discussions on a new concept of the cellular basis of immunology. F Pediatr 1965;69:907.

8 Shprintzen RJ, Goldberg RB, Lewin ML, Sidoti EJ, Berkman MD, Argomosa RV, Young D. A new syndrome involving cleft palate, cardiac Argomosa RV, Young D. A new syndrome involving cleft palate, cardiac
anomalies, typical facies and learning disabilities: velo-cardio-facial anomalies, typical facies and learning

syndrome. Cleft Palate 7 1978;15:56-62

Strong WB. Familial syndrome of right-sided aortic arch, mental deficiency, and facial dysmorphism. F Pediatr 1968;73:882-8

10 Takao A, Ando M, Cho K, Kinouchi A, Murukami Y. Etiologic categorization of common congenital heart disease. In: Van Praagh R, Takao A, eds. Etiology and morphogenesis of congenital heart disease. New York: Futura, 1980:253-69.

11 Pigott RW. Velopharyngeal (speech) disorder (VP(S)D) without overt cleft palate. Br 7 Plast Surg 1994;47:223-9.

12 Gorlin RJ, Cohen MM, Levin LS. Syndromes of the head and neck. 3rd ed. New York: Oxford University Press, 1990.

13 Vrticka K, Fokstuen S, Schinzel A, Da Silva, V. Genetic findings in the velofacial (Sedláčková) syndrome. Genet Couns 1999;10:105. 


\section{Do patients with maternal uniparental disomy for chromosome 7 have a distinct mild Silver-Russell phenotype?}

EDITOR-Silver-Russell syndrome (SRS) is characterised by severe intrauterine growth retardation (IUGR), postnatal short stature, asymmetry of the face, body, and limbs, short and incurved fifth fingers, and a characteristic triangular face with a prominent and bossed forehead, a small lower jaw, and downturned corners of the mouth. ${ }^{12}$ Many other slightly dysmorphic features are seen in SRS patients (table 1) and these have been regarded mostly as confirmatory, not obligatory, for the diagnosis. ${ }^{3-5}$ Any one feature is not consistently observed in all SRS patients and the expression of features tends to vary greatly among subjects leading to considerable heterogeneity. ${ }^{3}$ Straightforward criteria for the evaluation of the severity of SRS characteristics have not been set and it has been proposed that SRS might in fact comprise different subgroups. ${ }^{4}{ }^{6}$ Most SRS cases are sporadic, but different monogenic modes of inheritance have been proposed..$^{7-9}$ Abnormalities of chromosomes 8, 15, 17, and 18 have also been associated with SRS. ${ }^{10-15}$

Maternal uniparental disomy of chromosome 7 (mat$\mathrm{UPD}(7)$ ), the inheritance of both copies of chromosome 7 exclusively from the mother, occurs in approximately $10 \%$ of Silver-Russell syndrome (SRS) patients. ${ }^{16-19}$ Altogether, 21 cases of matUPD(7) have been reported ${ }^{6-24}$ and at least 14 of these have been diagnosed with SRS. ${ }^{6}{ }^{16-19}$ All matUPD(7) patients have pre- and postnatal growth retardation, except one case who had short stature only postnatally. ${ }^{23}$ Paternal uniparental disomy of chromosome 7 has no effect on growth and development. ${ }^{25}$ It has been suggested that there is at least one imprinted gene influencing growth and development on chromosome 7. MatUPD(7) patients presumably end up with two copies of the maternally imprinted gene and thus lack the effects of a growth promoting gene. To date, three imprinted genes, PEG1/MEST, $\gamma 2-C O P$, and GRB10, are known on chromosome 7 , but their role in SRS remains undecided. ${ }^{26-29}$

In a systematic screening for cases of matUPD(7) among patients with SRS, we have identified four matUPD(7) cases out of 32 SRS patients studied, consistent with a frequency of approximately $10 \%$. These four matUPD(7) patients present with many common characteristics and seem to form a phenotypically homogeneous group. They consistently lack some classical features of SRS, such as a significantly triangular face, micrognathia, and downturned mouth corners. However, all present with additional specific features such as speech delay, severe feeding difficulties, and excessive sweating. We sought to evaluate which typical SRS features are most predominant in matUPD(7) patients and if these features differentiate a matUPD $(7)$ phenotype from non-matUPD(7) SRS patients.

Patients were recruited from the outpatient clinic for growth disorders at the Hospital for Children and Adolescents, University of Helsinki, Finland. The diagnosis of SRS was confirmed in all patients either by a paediatric endocrinologist or by a medical geneticist. Patients were included in this study using the following criteria: (1) intrauterine growth retardation and/or born small for gestational age, (2) postnatal growth retardation exceeding $-2.5 \mathrm{SD}$, and (3) at least three of the following facial characteristics: triangular face, micrognathia, frontal bossing, craniofacial disproportion in early infancy, and relative macrocephaly, and (4) at least one of the following relative criteria: asymmetry, hemihypertrophy, clinodactyly/brachydactyly of the fifth digits, low set ears, and hypospadias/ cryptorchidism. All patients were also required to have normal karyotype, growth hormone excretion, and thyroid function. Patients and their parents provided written informed consent and blood samples were obtained from the patients and parents. The study was approved by the ethical review board of the Hospital for Children and Adolescents, University of Helsinki, Finland.

We genotyped all SRS patients on blood DNA with 14 chromosome 7 specific fluorescent tetra- and dinucleotide repeat microsatellite markers by PCR and an automated sequencer (ABI). Maternal only inheritance of chromosome 7 was detected in four SRS patients out of 32 studied $(12.5 \%)$. Complete isodisomy was observed in case I and mixed hetero- and isodisomy in the other three cases (fig 1). Correct paternity was verified for all matUPD(7) patients by genotyping 12 chromosome 18 microsatellite markers in a similar way.

We evaluated the patients by reviewing medical data and growth charts. Nine patients were further evaluated by

Table 1 Occurrence of SRS features. Categorisation is based on multiple published reports of SRS features, on the general emphasis stated in these reports for inclusion criteria in SRS studies, and on our own observations

\begin{tabular}{|c|c|c|c|}
\hline & $\begin{array}{l}\text { Diagnostic characteristics (generally } \\
\text { observed) }\end{array}$ & $\begin{array}{l}\text { Confirmatory characteristics (frequently } \\
\text { observed) }\end{array}$ & $\begin{array}{l}\text { Miscellaneous characteristics (rarely observed } \\
\text { in single cases) }\end{array}$ \\
\hline Growth & $\begin{array}{l}\text { Small for gestational age } \\
\text { Short stature postnatally }>-2 \mathrm{SD}\end{array}$ & Delayed bone age & Delayed fontanelle closure \\
\hline Craniofacial appearance & $\begin{array}{l}\text { Triangular face } \\
\text { Frontal bossing } \\
\text { Micrognathia } \\
\text { Downturned mouth } \\
\text { Craniofacial disproportion } \\
\text { Relative macrocephaly }\end{array}$ & $\begin{array}{l}\text { Low set ears/ear anomalies } \\
\text { Irregular teeth } \\
\text { High arched/cleft palate }\end{array}$ & $\begin{array}{l}\text { Anteverted nares } \\
\text { Blue sclerae } \\
\text { Epicanthic folds } \\
\text { Congenital ptosis } \\
\text { Eyebrows meeting in midline }\end{array}$ \\
\hline Limbs \& body & $\begin{array}{l}\text { Clinodactyly of fifth digits } \\
\text { Brachydactyly of fifth digits } \\
\text { Asymmetry of limbs } \\
\text { Hemihypertrophy trunk/limbs }\end{array}$ & $\begin{array}{l}\text { Syndactyly of toes II/III } \\
\text { Muscular hypotrophy/tonia } \\
\text { Hypospadias } \\
\text { Cryptorchidism } \\
\text { Scoliosis-lordosis } \\
\text { Absent sacrum } \\
\text { Absent coccyx } \\
\text { Vertebral abnormalities }\end{array}$ & $\begin{array}{l}\text { Café au lait spots } \\
\text { Short neck } \\
\text { Simian crease } \\
\text { Calcaneovalgus deformities } \\
\text { Ambigious genitalia } \\
\text { Second metacarpal pseudoepiphysis } \\
\text { Hepatomegaly } \\
\text { Splenomegaly }\end{array}$ \\
\hline Development $\&$ behaviour & & $\begin{array}{l}\text { Delayed psychomotor development } \\
\text { High pitched/squeaky voice } \\
\text { Excessive sweating } \\
\text { Feeding difficulties }\end{array}$ & $\begin{array}{l}\text { Raised urinary gonadotrophins } \\
\text { Precocious puberty }\end{array}$ \\
\hline
\end{tabular}


structured interviews and physical examinations. At the last evaluation, the matUPD(7) patients I, II, III, and IV were $19.0,3.0,2.8$, and 4.4 years old, respectively (average 7.3 years), and the average age of non-matUPD(7) SRS patients was 9.9 years (range $0.8-19.0$ years). The clinical parameters evaluated are listed in table 2. Dental age and craniofacial structures of matUPD(7) patients I-III were examined clinically and from photographs, lateral cephalograms, and orthopantomograms by an experienced orthodontist (SP) in comparison to a cohort of 19 SRS patients. ${ }^{30}$ All the SRS patients were sporadic cases and their sibs had normal growth and development. No significantly short relatives were known in any of the families. Maternal and paternal ages at the time of birth were exceptionally high in

A
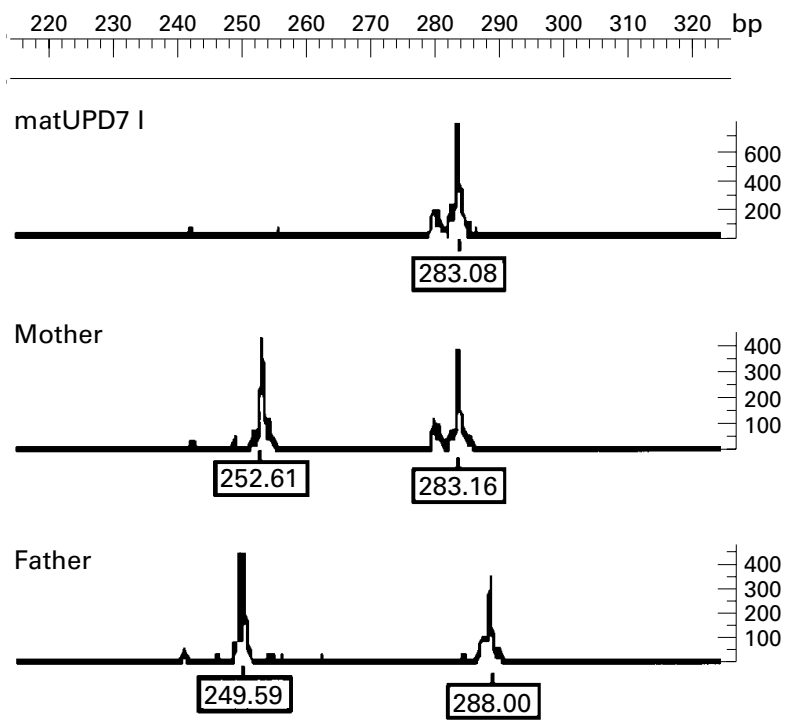

C
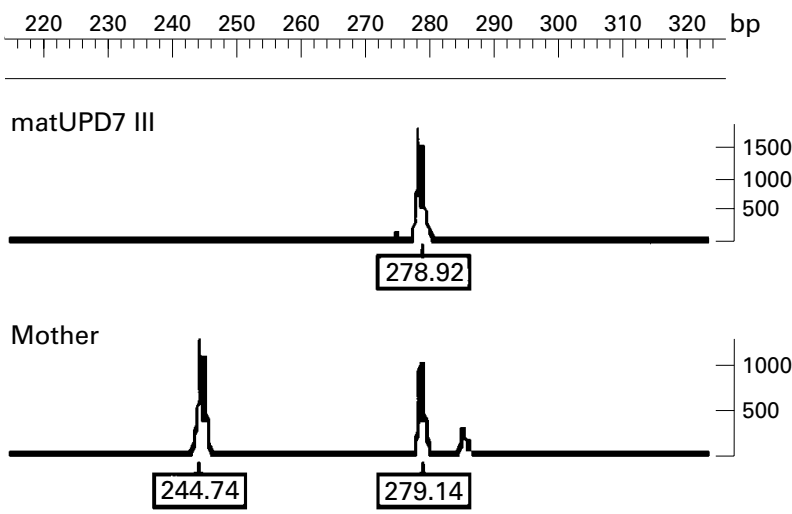

Father

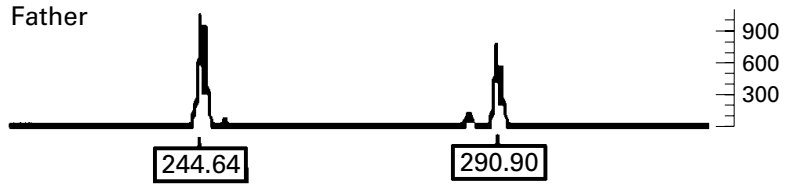

matUPD(7) cases (average maternal age 41 years and average paternal age 44 years) compared to non-matUPD(7) SRS patients (average maternal age 29 years and average paternal age 31 years).

All matUPD(7) patients were born SGA and had significant postnatal growth retardation (average $-4.3 \mathrm{SD}$ at 2 years of age) (table 3 ). The matUPD(7) patients were diagnosed with SRS in early childhood based on typical SRS features: a broad and high forehead, low set and posteriorly rotated ears, relative macrocephaly, craniofacial disproportion (observed both visually as a small face in relation to the head and also radiologically by a discrepancy of skull size to facial bone structure) in early infancy, and the left leg is shorter $(0.5-1 \mathrm{~cm})$ than the right.

B

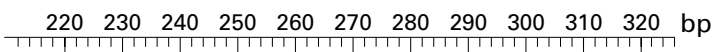
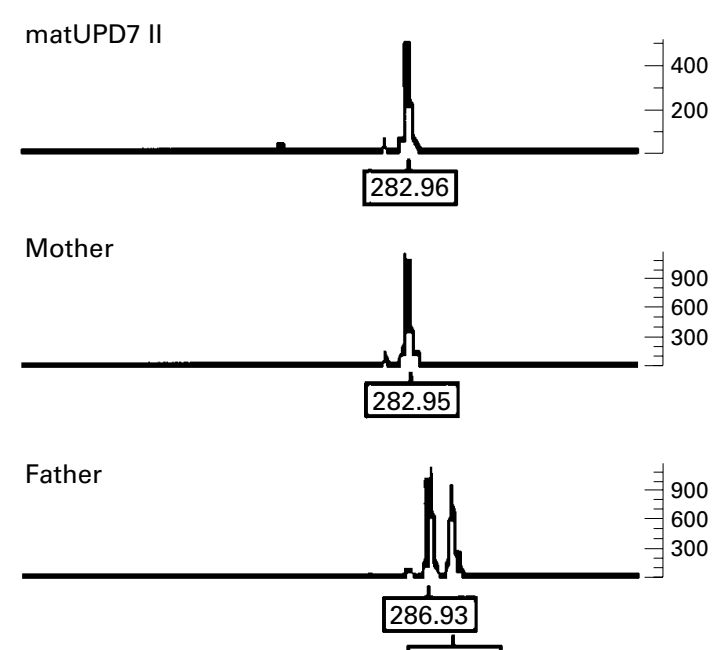

290.86

D
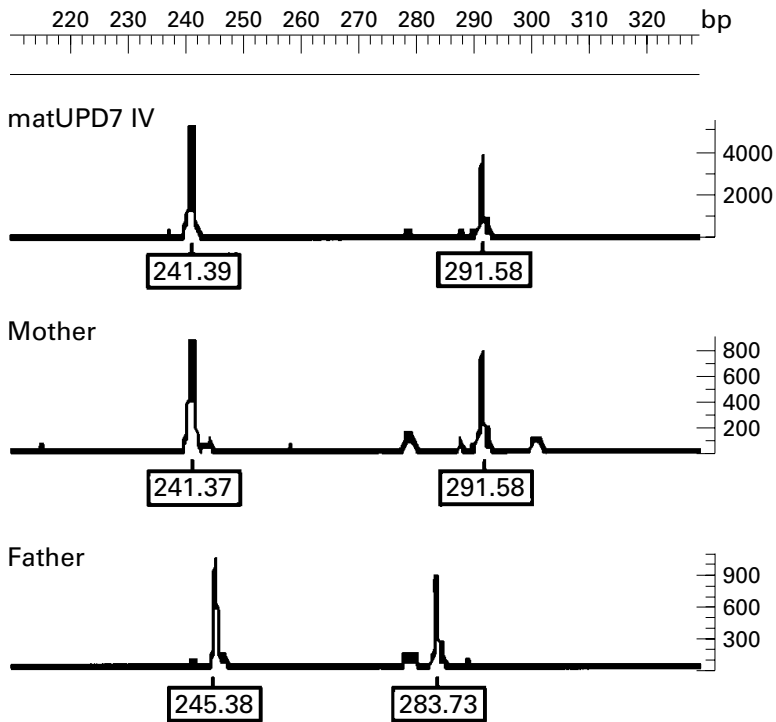

Figure 1 Microsatellite marker D7S2195 (7q35) indicating matUPD(7). Microsatellite markers spanning chromosome 7 showed complete maternal isodisomy in matUPD (7) I and mixed iso- and heterodisomy in matUPD (7) II, III, and IV. (A, C) the probands are homozygous for the larger maternal alleles and have inherited two copies of one maternal chromosome 7 (isodisomy). (B) The proband and the mother are both homozygous for the same allele. Isodisomy and heterodisomy are both possible and it is impossible to discern if the proband has inherited two copies of one maternal chromosome 7 (isodisomy) or both maternal chromosomes (heterodisomy). (D) The proband is heterozygous and shares both alleles with her mother and therefore has inherited both maternal chromosomes 7 (heterodisomy). Marker D7S2195 was fluorescently labelled and analysed by automated detection systems (ABI and Genotyper). 
Table 2 Percentage of typical SRS features observed in our matUPD(7) patients and non-matUPD(7) SRS cases, previously reported matUPD(7) cases, ${ }^{16-24}$ and generally in SRS (three reports). Only findings that were clearly mentioned in each report have been included in these figures. Features not clearly mentioned in patient records or in reports of SRS patients were regarded as not present. However, it is uncertain whether these characteristics were truly missing or if they had not been evaluated. For one SRS patient with matUPD(7) no clinical findings were reported, ${ }^{17}$ so the numbers of previously reported matUPD(7) patients in this table is 20

\begin{tabular}{|c|c|c|c|c|c|c|}
\hline \multirow[b]{2}{*}{ Characteristic } & \multicolumn{2}{|l|}{ Present study } & \multirow[b]{2}{*}{$\begin{array}{l}\text { Previously reported } \\
\text { matUPD (7) cases }\end{array}$} & \multicolumn{3}{|c|}{ General SRS reports } \\
\hline & mat $U P D(7)$ cases & $\begin{array}{l}\text { Non-matUPD(7) } \\
\text { cases }\end{array}$ & & $\begin{array}{l}\text { Price et al } \\
(n=50)\end{array}$ & $\begin{array}{l}\text { Wollman et } a l^{5} \\
(n=143)\end{array}$ & $\begin{array}{l}\text { Escobar et } a l^{3} \\
(n=90)\end{array}$ \\
\hline Speech delay/difficulties & $100 \%(4 / 4)$ & $21 \%(6 / 28)$ & $10 \%(2 / 20)$ & $20 \%$ & & \\
\hline Excessive sweating & $100 \%(4 / 4)$ & $36 \%(10 / 28)$ & $10 \%(2 / 20)$ & & & \\
\hline Feeding difficulties & $100 \%(4 / 4)$ & $36 \%(10 / 28)$ & $20 \%(4 / 20)$ & $56 \%$ & & \\
\hline Low set ears/ear anomalies & $100 \%(4 / 4)$ & $71 \%(20 / 28)$ & $5 \%(1 / 20)$ & & $53 \%$ & $20 \%$ \\
\hline Asymmetry/disproportion of limbs & $100 \%(4 / 4)$ & $75 \%(21 / 28)$ & $25 \%(5 / 20)$ & $34 \%$ & $51 \%$ & $74 \%$ \\
\hline Craniofacial disproportion & $100 \%(4 / 4)$ & $86 \%(24 / 28)$ & & & & \\
\hline Relative macrocephaly & $100 \%(4 / 4)$ & $89 \%(25 / 28)$ & $65 \%(13 / 20)$ & & $64 \%$ & \\
\hline Frontal bossing & $100 \%(4 / 4)$ & $89 \%(25 / 28)$ & $30 \%(6 / 20)$ & & & $65 \%$ \\
\hline Intrauterine growth retaradation & $100 \%(4 / 4)$ & $100 \%(28 / 28)$ & $50 \%(10 / 20)$ & $58 \%$ & & \\
\hline Small for gestational age & $100 \%(4 / 4)$ & $100 \%(28 / 28)$ & $85 \%(17 / 20)$ & & $94 \%$ & \\
\hline Growth retardation $>-2.5 \mathrm{SD}$ & $100 \%(4 / 4)$ & $100 \%(28 / 28)$ & $100 \%(20 / 20)$ & & $99 \%$ & $100 \%$ \\
\hline Short arms & $75 \%(3 / 4)$ & $21 \%(6 / 28)$ & & & & $22 \%$ \\
\hline Hemihypertrophy & $75 \%(3 / 4)$ & $54 \%(15 / 28)$ & & & & \\
\hline Delayed bone age & $75 \%(3 / 4)$ & $61 \%(17 / 28)$ & $15 \%(3 / 20)$ & & & $51 \%$ \\
\hline Neuropsychological delay & $50 \%(2 / 4)$ & $11 \%(3 / 28)$ & $5 \%(1 / 20)$ & $38 \%$ & $37 \%$ * & $18 \%$ \\
\hline Short neck & $50 \%(2 / 4)$ & $14 \%(4 / 28)$ & & & & \\
\hline Motor developmental delay & $50 \%(2 / 4)$ & $29 \%(8 / 28)$ & $15 \%(3 / 20)$ & & $37 \% \star \star$ & \\
\hline Cryptorchidism & $50 \%(1 / 2)$ & $67 \%(10 / 15)$ & & $32 \%$ & & $32 \% \star$ \\
\hline Brachydactyly V & $50 \%(2 / 4)$ & $71 \%(20 / 28)$ & $20 \%(4 / 20)$ & & $48 \%$ & $80 \%+$ \\
\hline Clinodactyly of $\mathrm{V}$ digits & $50 \%(2 / 4)$ & $82 \%(23 / 28)$ & $35 \%(7 / 20)$ & $56 \%$ & $68 \%$ & $80 \% \dagger$ \\
\hline Sacral abnormalities & $25 \%(1 / 4)$ & $7 \%(2 / 28)$ & & & & \\
\hline Vertebral abnormalities & $25 \%(1 / 4)$ & $7 \%(2 / 28)$ & & & & \\
\hline Muscular hypoplasia & $25 \%(1 / 4)$ & $54 \%(15 / 28)$ & $10 \%(2 / 20)$ & & $45 \%$ & \\
\hline Triangular face & $0 \%(0 / 4)$ & $96 \%(27 / 28)$ & $35 \%(7 / 20)$ & & $79 \%$ & $83 \%$ \\
\hline Micrognathia & $0 \%(0 / 4)$ & $86 \%(24 / 28)$ & & & & $33 \%$ \\
\hline Irregular/crowded teeth & $0 \%(0 / 4)$ & $64 \%(18 / 28)$ & $5 \%(1 / 20)$ & & $28 \%$ & $1.3 \%$ \\
\hline Downturned mouth & $0 \%(0 / 4)$ & $61 \%(17 / 28)$ & & & $46 \%$ & $74 \%$ \\
\hline Syndactyly of toes II/III & $0 \%(0 / 4)$ & $36 \%(10 / 28)$ & & & $19 \%$ & $19 \%$ \\
\hline Cleft/high arched palate & $0 \%(0 / 4)$ & $32 \%(9 / 28)$ & $5 \%(1 / 20)$ & $2 \%$ & & $16 \%$ \\
\hline Scoliosis & $0 \%(0 / 4)$ & $32 \%(9 / 28)$ & & & & $17 \%$ \\
\hline High pitched voice & $0 \%(0 / 4)$ & $25 \%(7 / 28)$ & $5 \%(1 / 20)$ & & $22 \%$ & \\
\hline Hypospadias & $0 \%(0 / 2)$ & $13 \%(2 / 15)$ & & $4 \%$ & & $32 \%$ * \\
\hline Early puberty & $0 \%(0 / 1)$ & $7 \%(2 / 2)$ & & & $8 \%$ & \\
\hline Hip/elbow dislocations & $0 \%(0 / 4)$ & $7 \%(2 / 28)$ & & & & $1.3 \%$ \\
\hline Congenital ptosis & $0 \%(0 / 4)$ & $7 \%(2 / 28)$ & & & & \\
\hline Simian crease & $0 \%(0 / 4)$ & $7 \%(2 / 28)$ & & & $25 \%$ & \\
\hline Café au lait spots & $0 \%(0 / 4)$ & $4 \%(1 / 28)$ & $5 \%(1 / 20)$ & $4 \%$ & $19 \%$ & $28 \%$ \\
\hline Blue sclerae & $0 \%(0 / 4)$ & $4 \%(1 / 28)$ & $5 \%(1 / 20)$ & & & \\
\hline Pes cavus & $0 \%(0 / 4)$ & $4 \%(1 / 28)$ & & & & $7 \%$ \\
\hline Hepatomegaly & $0 \%(0 / 4)$ & $4 \%(1 / 28)$ & & & & \\
\hline Delayed closure of anterior fontanelle & $0 \%(0 / 0)$ & $0 \%(0 / 27)$ & & & & $18 \%$ \\
\hline Metacarpal pseudoepiphysis & $0 \%(0 / 4)$ & $0 \%(0 / 27)$ & & & & $1.3 \%$ \\
\hline Maternal age at birth (average) & $41(n=4)$ & $29(\mathrm{n}=28)$ & $32(n=16)$ & & & 28 \\
\hline Paternal age at birth (average) & $44(\mathrm{n}=4)$ & $31(\mathrm{n}=23)$ & $31(\mathrm{n}=13)$ & & & 31 \\
\hline Maternal height (average) & $+0.1 \mathrm{SD}(\mathrm{n}=4)$ & $-0.6 \mathrm{SD}(\mathrm{n}=25)$ & & -0.4 SDS & & \\
\hline Paternal height (average) & $0.0 \mathrm{SD}(\mathrm{n}=4)$ & $0.0 \mathrm{SD}(\mathrm{n}=22)$ & & $-0.3 \mathrm{SDS}$ & & \\
\hline
\end{tabular}

$\star, \dagger=\%$ includes both characteristics.

They all suffered from severe feeding difficulties and excessive sweating. All had speech delay particularly with problems in articulation.

Patient I (fig 2A, B, M) was born at 36 weeks' gestation. He had slight motor and neuropsychological developmental delay and speech delay with marked problems in articulation. At the age of 13.5, WISC-R showed an IQ of 94 with a discrepancy between verbal (IQ 88) and non-verbal skills (IQ 102). Additional neuropsychological evaluation showed dysphasia-like problems caused by difficulties in articulation, mostly because of dyspraxia in the vocal muscles, and significant problems in finding the appropriate words. Dyspraxia in hand movements and clumsiness in motor skills was also noted. At the age of 19 he has trouble finding the correct words and his speech is slightly incoherent. He has concluded a primary education and is currently enrolled in an adjusted school in health care. He had bilateral undescended testes, which were successfully treated. $X$ rays showed slender long bones, a hypoplastic sacrum, an absent coccyx, and only four lumbar vertebrae. He has clino- and brachydactyly of the fifth digits, a short neck, short upper arms, slight facial asymmetry with left side hypertrophy, and slight right sided trunk and limb hemihypertrophy. At 10.9 years he had a delayed dental age

Table 3 Auxological data of matUPD(7) and non-matUPD(7) SRS patients

\begin{tabular}{|c|c|c|c|c|c|c|c|c|c|c|c|}
\hline \multirow[b]{2}{*}{ mat $U P D(7)$ patient } & \multicolumn{3}{|l|}{ Birth } & \multicolumn{2}{|l|}{2 years } & \multicolumn{4}{|c|}{ Last evaluation/before GH treatment } & \multirow[b]{2}{*}{$\begin{array}{l}\text { Expected } \\
\text { height }\end{array}$} & \multirow[b]{2}{*}{$\begin{array}{l}\text { Years bone age delayed } \\
\text { (chronological age) }\end{array}$} \\
\hline & $\begin{array}{l}\text { Length } \\
(S D)\end{array}$ & $\begin{array}{l}\text { Weight } \\
(S D)\end{array}$ & $\begin{array}{l}O F C \\
(S D)\end{array}$ & $\begin{array}{l}\text { Height } \\
(S D)\end{array}$ & $\begin{array}{l}\text { Weight } \\
(\%)\end{array}$ & $\begin{array}{l}\text { Height } \\
(S D)\end{array}$ & $\begin{array}{l}\text { Weight } \\
(\%)\end{array}$ & $\begin{array}{l}\text { OFC } \\
(S D)\end{array}$ & Age & & \\
\hline I & -4.0 & -3.6 & -1.5 & -4.3 & -20 & -3.1 & +46 & +2 & $8.5 \mathrm{y}$ & +0.6 & $2.3 \mathrm{y}(4.8 \mathrm{y})$ \\
\hline II & -3.4 & -2.2 & -2.0 & -3.0 & -28 & -3.1 & -22 & -1.5 & $3.2 \mathrm{y}$ & +0.9 & $1.3 \mathrm{y}(3.2 \mathrm{y})$ \\
\hline III & -3.5 & -2.6 & 0 & -3.8 & -20 & -3.6 & -20 & +1 & $2.8 \mathrm{y}$ & -0.4 & $0 \mathrm{y}(2.0 \mathrm{y})$ \\
\hline IV & -4.6 & -3.4 & -2.0 & -6.0 & -28 & -4.8 & -28 & -0.5 & $4.4 \mathrm{y}$ & -0.4 & $2.6 \mathrm{y}(3.8 \mathrm{y})$ \\
\hline $\begin{array}{l}\text { Non-matUPD }(7) \text { SRS } \\
\text { patients average } \\
(\mathrm{n}=28)\end{array}$ & -4.5 & -3.6 & -0.7 & -4.0 & -23 & -3.7 & -20 & $\mathrm{NE}$ & $5.6 \mathrm{y}$ & 0.0 & $1.6 \mathrm{y}(6.9 \mathrm{y})$ \\
\hline
\end{tabular}

$\mathrm{GH}=$ growth hormone, $\mathrm{OFC}=$ occipitofrontal circumference, $\mathrm{SD}=$ standard deviation from the mean, $\%=$ relative weight for height, $\mathrm{NE}=$ not evaluated. 
A
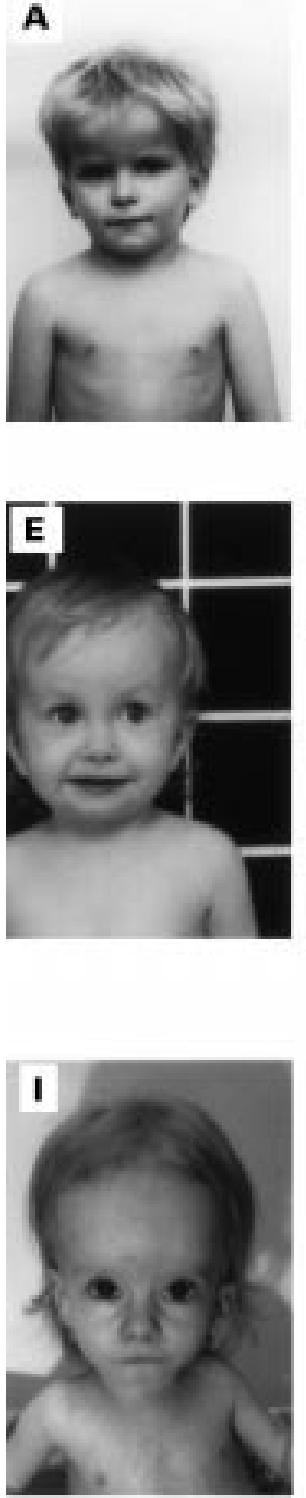

M

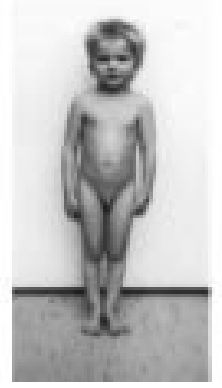

B
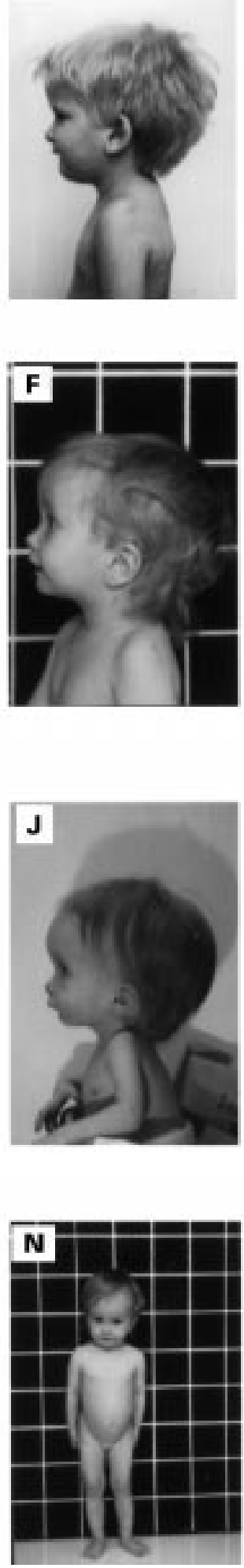
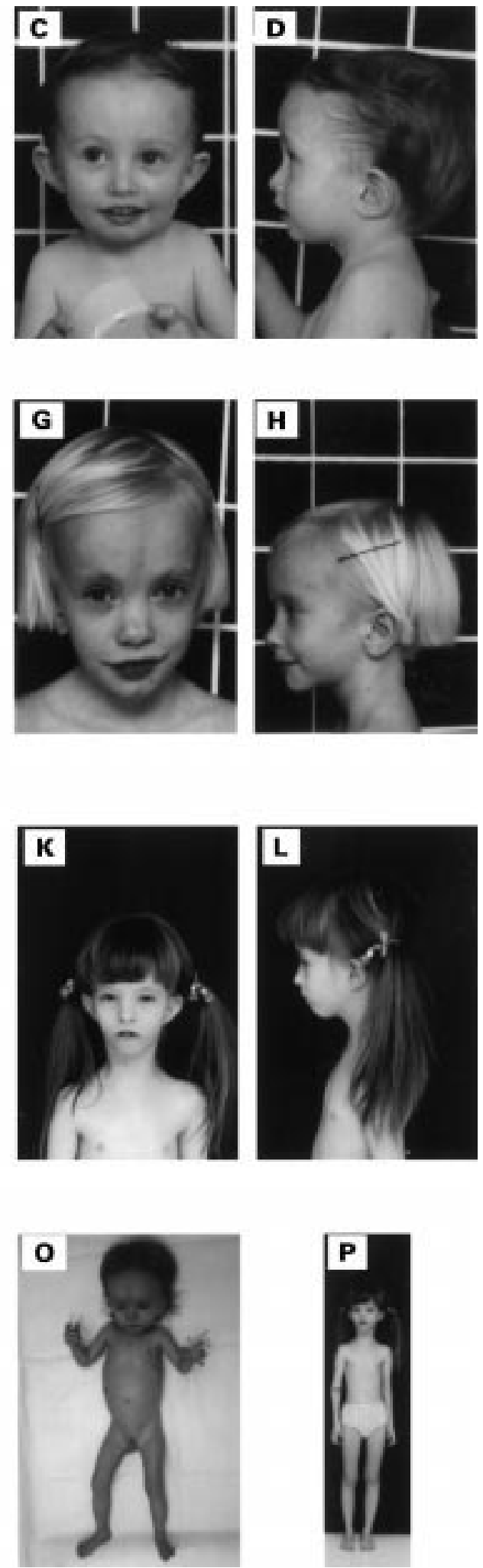

Figure 2 MatUPD(7) patients (A-H) share a similar facial appearance and lack the classical SRS features of micrognathia, downturned mouth corners, and a triangular face seen in non-matUPD (7) SRS patients (I-L). All matUPD (7) patients have low set and posteriorly rotated ears $(B, D, F, H)$. MatUPD (7) patients $(M, N)$ have a sturdy appearance and lack the leanness typical of SRS which is observed in non-matUPD $(7)$ patients $(O, P)$. ( $A$, B) MatUPD (7) I aged 5.5 years, (C, D) matUPD (7) II aged 2.3 years, (E, F) matUPD (7) III aged 1.7 years, (G, H) matUPD (7) IV aged 4.4 years, (I, 7) SRS case 1 aged 1.4 years, $(K, L)$ SRS case 2 aged 6.2 years, (M) matUPD(7) I aged 5.5 years, (N) matUPD(7) III aged 1.7 years, (O) SRS case 1 aged 1.4 years, (P) SRS case 2 aged 6.2 years. Written consent for publishing the photographs was received from all families.

of 9.1 years $(-2.2 \mathrm{SD})$. He received growth hormone $(\mathrm{GH})$ therapy from the ages of 8.6 to 12.8 .

Patient II (fig 2C, D) was born at 35+3 weeks' gestation. His psychomotor development is normal but he has speech delay, with mainly multiple articulation problems. He has brachy- and clinodactyly of the fifth digits, a short neck, short upper arms, and slight right side facial and limb hemihypertrophy. His first tooth erupted at the age of one 
year (-1.5 SD) and at 4.2 years his dental age was 3.6 $(-0.8 \mathrm{SD})$. Slender long bones, round and short hand bones, and exceptionally short fifth metacarpals and phalanges were seen on $x$ ray.

Patient III (fig 2E, F, N) was born at 39+3 weeks' gestation and her neonatal period was marked by excessive vomiting and regurgitation. She had gross feeding difficulties up to the age of 4.5 months, mainly because of deficient sucking, and feeding times reached up to 1.5 hours. Her psychomotor development is otherwise normal but she has marked speech delay, mainly in producing speech. She understands speech well, but produces only rare one or two word sentences, and communicates mostly by gestures and sign language. She has short upper arms and narrow shoulders and hips. A conspicuous delay in the eruption of the first deciduous teeth was seen. Her first teeth erupted at the age of 1.7 years ( $-6.2 \mathrm{SD}$ ) and at the age of 3.0 years her dental delay was $-5.5 \mathrm{SD}$. She had slightly short ulnae and dysmorphic facial structures on $x$ ray.

Patient IV (fig $2 \mathrm{G}, \mathrm{H}$ ) was born at $38+1$ weeks' gestation and neonatally she had hypoglycaemia. She has suffered from gross feeding difficulties since birth and did not learn to suck properly until the age of 6 months. To this day she eats extremely small portions and her meals may take up to two hours. Her oral motor functions are normal. Her psychomotor development is somewhat delayed and she has a speech delay with articulation problems. At 2.6 years she spoke only in two to three word sentences with a soft voice. She has slight facial asymmetry with left side hypertrophy, small muscles including hypoplasia of the buttocks, a narrow pelvis, and her nails are weak and tend to chip on both hands and feet. She also has bilateral pes planovalgus, more severe on the right, and the long bones are slender on $x$ ray. She has received growth hormone therapy from the age of 2.4 years onwards.

Comparison of the four matUPD(7) phenotypes with 28 non-matUPD(7) SRS patients suggests that matUPD(7) patients have a mild SRS phenotype and they may form a distinct clinical entity among SRS patients (fig 2, table 2). Facial triangularity was slight in the matUPD(7) patients in infancy and early childhood, whereas non-matUPD(7) patients showed distinctly triangular faces. MatUPD(7) patients had a broad and high forehead, low set and posteriorly rotated ears, relative macrocephaly, and craniofacial disproportion, which were equally seen in non-matUPD(7) patients. Micrognathia, a high arched or cleft palate, and downturned mouth corners are other classical SRS features that were seen in the vast majority of non-matUPD(7) patients, but those with matUPD(7) consistently lacked these features. Slight asymmetry of the lower limbs with concordant slight lower limb hemihypertrophy and facial asymmetry was seen in matUPD(7) patients I, II, and IV. Asymmetry and hemihypertrophy were also common, but both were more conspicuous in non-matUPD(7) SRS patients. Only two matUPD(7) patients had clinodactyly and brachydactyly of the fifth fingers but both were commonly seen in non-matUPD(7) SRS patients. Syndactyly of the second and third toes was also quite frequently observed in non-matUPD(7) SRS patients but was not present in the matUPD(7) patients. The matUPD(7) patients had a more sturdy appearance than the marked leanness typical of SRS patients (fig 2) and muscular hypoplasia was more frequently observed in non-matUPD(7) SRS patients (table 2). The growth patterns of matUPD(7) patients did not differ from non-matUPD(7) SRS patients (table 3). Both matUPD(7) and non-matUPD(7) SRS patients had an average delay in bone age of 1.6 years from their chronological ages. Growth hormone therapy has been administered to half of the matUPD(7) and SRS patients, and similar effects on growth were seen in both groups.
A varying degree of delayed development of the dentition was noted in matUPD(7) patients I-III (range -6.2 to -0.8 $\mathrm{SD}$; dental examination was insufficient in patient IV) compared to SRS patients in general. ${ }^{30}$ Delayed emergence of the deciduous teeth was seen in all three and delayed development of the permanent teeth in patient I. Dental occlusion was of the class II type in all three, while in SRS patients class II was observed in only $14 \%(2 / 14)$ and class I type in the remaining $12 / 14 .^{30}$ Cephalometric craniofacial measurements showed overall small dimensions, especially in patients II and III, with a very short posterior cranial base (<-3 SD) and total mandibular length (<-2 SD), as with SRS patients in general. ${ }^{30}$ The lower mandible of ma$\operatorname{tUPD}(7)$ patients was broader than generally observed in SRS patients and crowding of the lower incisors was only mild, distinguishing matUPD(7) from other SRS cases. In all three matUPD(7) patients the "hanging" posterior cranial fossa and the short cranial base were present with an abnormally anteriorly tilted foramen magnum and abnormal position of the first cervical vertebra. A short posterior cranial base, small mandible, and an abnormally tilted foramen magnum are commonly also seen in children with SRS, born SGA, and with growth hormone deficiency. ${ }^{31}$

All matUPD(7) patients suffered from excessive sweating and gross feeding difficulties, resulting from difficulties in sucking and swallowing and a lack of sense of hunger from birth onwards. Almost half of non-matUPD(7) SRS patients suffered from poor feeding in the first weeks of life, but matUPD(7) SRS patients still had extremely poor feeding at an average age of 3.4 years. Feeding difficulties have also been noted in four other matUPD(7) cases. $^{6} 1923$ Excessive sweating occurs in matUPD(7) patients shortly after falling asleep and after eating, but it was less frequently recorded in non-matUPD(7) SRS patients. Hypoglycaemic symptoms, such as fatigue and irritability, were not observed in any of our matUPD(7) patients. A history of feeding difficulties and excessive sweating is easily missed if the parents are not specifically asked about them. Therefore, the actual number of SRS patients with these symptoms might be much higher than reported.

MatUPD(7) patients tend to have more problems in development than non-matUPD(7) SRS patients. Neuropsychological developmental delay, predominantly in speech development, was recorded in all the matUPD(7) patients. All had problems in articulation and production of speech. The oldest patient I has difficulties in verbal skills and has received special education. Speech difficulties were only seldom observed in non-matUPD(7) SRS patients. Early motor developmental delay was also somewhat more prominent in matUPD(7) patients than in nonmatUPD(7) SRS patients.

We thoroughly studied the phenotypes of four SRS matUPD(7) patients and found that they have a distinctly milder phenotype and share many common characteristics that distinguish them from the 28 non-matUPD(7) SRS patients. These matUPD(7) patients consistently lack the typical facial features of SRS and the dysmorphic facial features noted in matUPD(7) patients are in fact so minor, and progressively decrease with age, that their appearance might as well be regarded as normal. Previously reported matUPD(7) patients have also been noted to have a mild or incomplete SRS phenotype ${ }^{61617}$ and even when SRS features were noted, they were described as only slight (triangular face, asymmetry of the limbs, and clinodactyly of the fifth digits) and typical features like micrognathia and downward slanting mouth corners were not noted in any matUPD(7) cases (table 2). The absence of a typical SRS facies in many of these previous matUPD(7) patients supports our finding that matUPD(7) patients do not present with a typical SRS face. Only 14/21 (67\%) 
reported matUPD(7) cases have been diagnosed with SRS and it is possible that the dysmorphic findings in the very first reports of matUPD(7) cases were so mild that they were not observed or that they might be absent altogether. ${ }^{20-24}$ However, Spence et $a l^{20}$ suspected that their patient might have SRS because of the observed body asymmetry. SRS features fade as children grow older and thus the diagnosis of SRS is easily missed in older children. In a recent study of 50 SRS patients attempting to set clinical criteria for SRS, a subgroup was observed presenting with homogeneous characteristics, including (1) classical dysmorphic facial features, (2) a higher frequency of asymmetry, (3) hand anomalies, (4) birth length below or equal to $-2 \mathrm{SD}$ from the mean, (5) poor postnatal growth below or equal to $-2 \mathrm{SD}$ from the mean, and (6) preservation of OFC. ${ }^{6}$ Patients included in this group generally had four of these criteria. No matUPD(7) cases fulfilled these criteria but they were noted to have a generally milder phenotype. Screening of matUPD(7) should therefore be focused on SRS patients with a mild phenotype and also on patients with severe intrauterine and postnatal growth retardation who do not clearly fulfil SRS criteria.

Interestingly, mild phenotypes have also been observed in UPD(15) patients compared to deletion patients. Angelman syndrome (AS) patients with patUPD(15) have consistently been observed to have a milder phenotype than AS cases with a deletion. ${ }^{32}{ }^{33}$ Prader-Willi syndrome (PWS) patients with matUPD(15) were found to have a face atypical of PWS more frequently than patients with a paternal deletion of chromosome 15q11-q13. ${ }^{34}$

We conclude that the uniformity of characteristics noted in four SRS patients with matUPD(7) raises the possibility that matUPD(7) patients might comprise a distinct phenotypic entity among SRS patients with a mild SRS phenotype. The characteristics distinctive of this subgroup include (1) pre- and postnatal growth retardation, (2) mild or absent SRS craniofacial dysmorphology consisting of slight or absent facial triangularity, no micrognathia, and no downturned mouth corners, (3) speech delay, (4) strikingly poor feeding throughout childhood, (5) excessive sweating without evidence of hypoglycaemic episodes, and (6) increased parental age at birth. The recent clinical findings of two matUPD (7) patients ${ }^{19}$ are consistent with the phenotypes of the four matUPD(7) cases described here, but thorough characterisation of other matUPD(7) cases is needed to verify these criteria. The delineation of possible subgroups among SRS cases would help in the clinical evaluation of SRS patients and also greatly facilitate the studies of the molecular aetiology of SRS, since genetic heterogeneity is widely postulated in SRS.

We would like to thank all of the families who participated in this study. Drs Ilkka Kaitila, Kalle Simola, and Hanna-Liisa Lenko are thanked for referring SRS patients. This study was supported by the P and S Sohlberg Foundation, Finnish Medical Foundation, Sigrid Juselius Foundation, Foundation for Paediatric Research, Ulla Hjelt Fund, Research and Science Foundation of Farmos, and the Academy of Finland.

KATARIINA HANNULA* JUHA KERE ${ }^{\star}+$ SINIKKA PIRINEN CHRISTER HOLMBERG MARITA LIPSANEN-NYMANS

${ }^{\star}$ Department of Medical Genetics, Haartman Institute, PO Box 21 (Haartmaninkatu 3), FIN-00014 University of Helsinki, Helsinki, Finland †Finnish Genome Centre, PO Box 21 (Tukholmankatu 2), FIN-00014 University of Helsinki, Helsinki, Finland

$\ddagger$ Department of Oral and Maxillofacial Surgery, FIN-00014 University of Helsinki, Helsinki, Finland

$§$ Hospital for Children and Adolescents, Stenbäckinkatu 11, FIN-00029 University of Helsinki, Helsinki, Finland

Correspondence to: Dr Hannula, katariina.hannula@helsinki.fi

1 Silver HK, Kiyasu W, George J, Dreamer WC. Syndrome of congenital hemihypertrophy, shortness of stature, and elevated urinary gonadotropins. Pediatrics 1953;12:368-75.
2 Russell A. A syndrome of "intra-uterine" dwarfism recognizable at birth with cranio-facial dysostosis, disproportionately short arms, and other with cranio-facial dysostosis, disproportionately short
anomalies (5 examples). Proc R Soc Med 1954;47:1040-4.

3 Escobar V, Gleiser S, Weaver DD. Phenotypic and genetic analysis of the Silver-Russell syndrome. Clin Genet 1978;13:278-88.

4 Saal HM, Pagon RA, Pepin MG. Reevaluation of Russell-Silver syndrome. $\mathcal{F}$ Pediatr 1985;107:733-7.

5 Wollmann HA, Kirchner T, Enders H, Preece MA, Ranke MB. Growth and symptoms in Silver-Russell syndrome: review on the basis of 386 patients. Eur F Pediatr 1995;154:958-68.

6 Price SM, Stanhope R, Garrett C, Preece MA, Trembath RC. The spectrum of Silver-Russell syndrome: a clinical and molecular genetic study and new diagnostic criteria. $\mathcal{F}$ Med Genet 1999;36:837-42.

7 Teebi AS. Autosomal recessive Silver-Russell syndrome. Clin Dysmorphol 1992;1:151-6

8 Duncan PA, Hall JG, Shapiro LR, Vibert BK. Three generation dominant transmission of the Silver-Russell syndrome. Am f Med Genet 1990;35:24550

Partington MW. X-linked short stature with skin pigmentation: evidence for heterogeneity of the Russell-Silver syndrome. Clin Genet 1986;29:151-6.

10 Schinzel AA, Robinson WP, Binkert F, Fanconi A. An interstitial deletion of proximal 8q (q11-q13) in a girl with Silver-Russell syndrome-like features. Clin Dysmorphol 1994;3:63-9.

11 Tamura T, Tohma T, Ohta T, Soejima H, Harada N, Abe K, Niikawa N. Ring chromosome 15 involving deletion of the insulin-like growth factor 1 receptor gene in a patient with features of Silver-Russell syndrome. Clin Dysmorphol 1993;2:106-13.

12 Ramirez-Duenas ML, Medina C, Ocampo-Campos R, Rivera H. Severe Silver-Russell syndrome and translocation $(17 ; 20)(\mathrm{q} 25 ; \mathrm{q} 31)$. Clin Genet 1992;41:51-3

13 Midro AT, Debek K, Sawicka A, Marcinkiewicz D, Rogowska M. Second observation of Silver-Russell syndrome in a carrier of a reciprocal translocation with one breakpoint at site 17q25. Clin Genet 1993;44:53-5.

14 Eggermann T, Eggermann K, Mergenthaler S, Kuner R, Kaiser P, Ranke $\mathrm{MB}$, Wollmann HA. Paternally inherited deletion of CSH1 in a patient with Silver-Russell syndrome. 7 Med Genet 1998;35:784-6.

15 Chauvel PJ, Moore CM, Haslam RHA. Trisomy-18 mosaicism with features of Russell-Silver syndrome. Dev Med Child Neurol 1975;17:220-4

16 Kotzot D, Schmitt S, Bernasconi F, Robinson WP, Lurie IW, Ilyina H, Mehes K, Hamel BCJ, Otten BJ, Hegersberg M, Werder E, Schoenle E, Schinzel A. Uniparental disomy 7 in Silver-Russell syndrome and primordial growth retardation. Hum Mol Genet 1995;4:583-7.

17 Preece MA, Price SM, Davies V, Clough L, Stanier P, Trembath RC, Moore GE. Maternal uniparental disomy in Silver-Russell syndrome. $f$ Med Genet 1997;34:6-9.

18 Eggermann T, Wollmann HA, Kuner R, Eggermann K, Enders H, Kaiser P, Ranke MB. Molecular studies in 37 Silver-Russell syndrome patients: frequency and etiology of uniparental disomy. Hum Genet 1997;100:415-19.

19 Bernard LE, Penaherrera MS, Van Ellen MI, Wang MS, Tong SL, Gareis F, Langlois S, Robinson WP. Clinical and molecular findings in two patients with Russell-Silver syndrome and UPD7: comparison with non-UPD7 cases. Am f Med Genet 1999;87:230-6.

20 Spence JE, Perciaccante RG, Greig GM, Willard HF, Ledbetter DH, Hejtmancik JF, Pollack MS, O'Brien WE, Beaudet AL. Uniparental disomy as a mechanism for human genetic disease. Am f Hum Genet 1988;42:217-26.

21 Voss R, Ben-Simon E, Avital A, Godfrey S, Zlotogora J, Dagan J, Tikochinski Y. Hillel J. Isodisomy of chromosome 7 in a patient with cystic fibrosis: could uniparental disomy be common in humans? Am f Hum Genet 1989; 45:373-80.

22 Spotila LD, Sereda L, Prockop DJ. Partial isodisomy for maternal chromosome 7 and short stature in an individual with a mutation at the COLIA2 locus. Am 7 Hum Genet 1992;51:1396-405.

23 Eggerding FA, Schonberg SA, Chehab FF, Norton ME, Cox VA, Epstein CJ. Uniparental disomy for paternal $7 \mathrm{p}$ and maternal $7 \mathrm{q}$ in a child with growth retardation. Am f Hum Genet 1994;55:253-65.

24 Langlois S, Yong SL, Wilson RD, Kwong LC, Kalousek DK. Prenatal and postnatal growth failure associated with maternal heterodisomy for chromosome 7. F Med Genet 1995;32:871-5.

25 Höglund P, Holmberg C, de la Chapelle A, Kere J. Paternal isodisomy for chromosome 7 is compatible with normal growth and development in a patient with congenital chloride diarrhea. Am F Hum Genet 1994;55:747-52.

26 Riesewijk AM, Blagitko N, Schinzel AA, Hu L, Schulz U, Hamel BCJ, Ropers H, Kalscheuer V. Evidence against a major role of PEG1/MEST in ers H, Kalscheuer V. Evidence against a major role of PEC

27 Blagitko N, Schultz U, Schinzel AA, Ropers HH, Kalscheuer VM. $\gamma 2$-COP, a novel imprinted gene on chromosome $7 \mathrm{q} 32$, defines a new imprinting cluster in the human genome. Hum Mol Genet 1999;8:2387-96.

28 Blagitko N, Mergenthaler S, Schultz U, Wollmann HA, Craigen W, Eggermann T, Ropers HH, Kalscheuer VM. Human GRB10 is imprinted and expressed from the paternal and maternal allele in a highly tissue- and isoform-specific fashion. Hum Mol Genet 2000;9:1587-95.

29 Yoshihashi H, Maeyama K, Kosaki R, Ogata T, Tsukahara M, Goto Y, Hata J, Matsuo N, Smith R, Kosaki K. Imprinting of human GRB10 and its mutations in two patients with Russell-Silver syndrome. Am f Hum Genet 2000;67:476-83.

30 Kotilainen J, Hölttä P, Mikkonen T, Arte S, Sipilä I, Pirinen S. Craniofacial and dental characteristics of Silver-Russell syndrome. Am 7 Med Genet 1995;56:229-36

31 Van Ehrum R, Mulier M, Carels C, Verbeke G, De Zegher F. Craniofacial growth in short children born small for gestational age: effect of growth hormone treatment. F Dent Res 1997;76:1579-86.

32 Bottani A, Robinson WP, DeLozier-Blanchet CD, Engel E, Morris MA, Schmitt B, Thun-Hohenstein L, Schinzel A. Angelman syndrome due to paternal uniparental disomy of chromosome 15: a milder phenotype? Am f Med Genet 1994;51:35-40.

33 Moncla A, Malzac P, Voelckel MA, Auquier P, Girardot L, Mattei MG, Philip N, Mattei JF, Lalande M, Livet MO. Phenotype-genotype correlation in 20 deletion and 20 non-deletion Angelman syndrome patients. Eur 7 Hum Genet 1999;7:131-9.

34 Allanson JE, Clericuzio C, Cassidy SB. Prader-Willi syndrome: phenotypic differences observed in an objective study of deletion and disomy. Am $\mathcal{F}$ Hum Genet Suppl 1999;65:180. 